University of Rhode Island

DigitalCommons@URI

Open Access Master's Theses

1970

\title{
Two Unequal Inclusions in Infinite Plate
}

Vijay G. Ukadgaonker

University of Rhode Island

Follow this and additional works at: https://digitalcommons.uri.edu/theses

\section{Recommended Citation}

Ukadgaonker, Vijay G., "Two Unequal Inclusions in Infinite Plate" (1970). Open Access Master's Theses.

Paper 969.

https://digitalcommons.uri.edu/theses/969

This Thesis is brought to you for free and open access by DigitalCommons@URI. It has been accepted for inclusion in Open Access Master's Theses by an authorized administrator of DigitalCommons@URI. For more information, please contact digitalcommons-group@uri.edu. 
PLANE STRESS ANALYSIS OF AN INFINITE PLATE

WITH TWO RIGID CIRCULAR INCLUSIONS

OF DIFFERENT DIAMETERS

BY

VIJAY G. UKADGAONKER

A THESIS SUBMITTED IN PARTIAL FULFILLMENT OF THE REQUIREMENTS FOR THE DEGREE OF

MASTER OF SCIENCE

IN

MECHANICAL ENGINEERING

AND

APPLIED MECHANICS

UNIVEBSITY OF RHODE ISLAND

1970 


\section{MASTER OF SCIENCE THESIS}

OF

VIJAY G. UKADGAONKER

Approved:

Thesis Committee

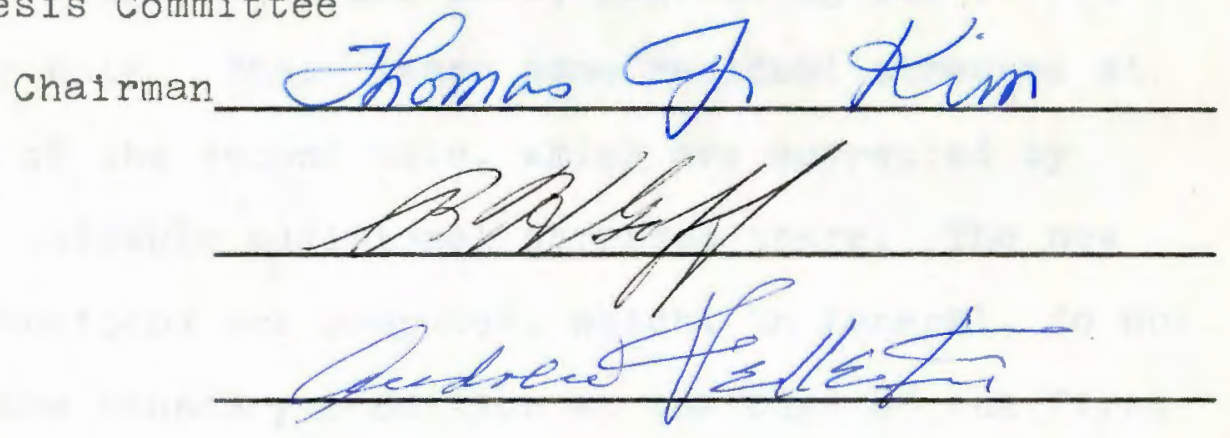

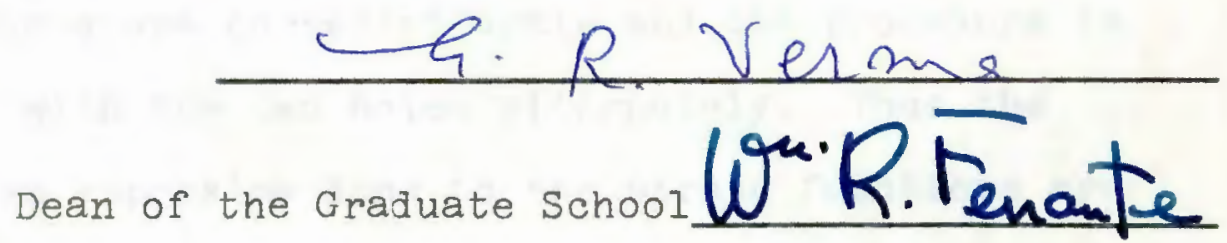

UNIVERSITY OF RHODE ISLAND 


\section{ABSTRACT}

An analytical solution is presented for the stress distribution in an infinite plate which is pierced by two inclusions of rigid circular discs of different diameters. The inclusions are assumed to produce uniform normal pressure along the circular boundaries.

The first fundamental boundary value problem is formulated in complex plane in terms of complex stress functions and then the Schwarz's alternating method is used for obtaining the solution.

The complex stress functions are determined for the case of a single circular hole, neglecting the effect of the other hole. These leave some residual stresses at the edge of the second hole, which are corrected by assuming suitable additional stresses there. The new stress functions are computed, which, in general, do not satisfy the boundary condition at the edge of the first hole. These are corrected again and the procedure is repeated with the two holes alternately. Thus the successive approximations to the stress functions are obtained.

Numerical results of the stress field are computed upto the second approximation by the use of computer. The stress concentration factors for the tangential stresses at the boundaries of the holes are obtained by 
varying distances, internal pressures and hole diameter ratios. The variation of stress distribution along the radial direction are plotted for different angular coordinates. It is found that the maximum stress concentration occurs at a point on the edge of the smaller hole nearest to the larger one. 


\section{ACKNOWLEDGEMENTS}

The auther considers it a distinct privilege to have had Dr. Thomas J. Kim as the chairman of his thesis committee. His deep interest and immense help in the preparation of the thesis are greatly appreciated.

The auther wishes to express his appreciation to Prof. Robert H. Goff, Prof. Andrew Velletri and Dr. Ghasi R. Verma for their helpful suggestions. Thanks are also due to the staff of the University of Rhode Island computer laboratory for the use of their facilities. 
TABLE OF CONTENTS

CHAPTER

PAGE

I. INTRODUCTION $\ldots \ldots \ldots \ldots \ldots \ldots \ldots \ldots \ldots$ I

1. HISTORICAL REVEIW ................ 2

(a) Single Hole $\ldots \ldots \ldots \ldots \ldots \ldots . . .2$

(b) Two Holes .................. 2

(c) Schwarz's Alternating Method .... 4

2. Statement OF THE PROBLEM ........... 5

(a) Problem $\ldots \ldots \ldots \ldots \ldots \ldots \ldots \ldots$

(b) Assumptions $\ldots \ldots \ldots \ldots \ldots \ldots 6$

(c) Method of Solution ...........6 6

(d) Scope and Limitations ........? ?

3. NOMENCLATURE $\ldots \ldots \ldots \ldots \ldots \ldots \ldots . \ldots . \ldots$

II. SOLUTION APPROACH VIA COMPLEX VARIABLES .... II

1. GENERAL THEORY ................... II

2. SCHWARZ'S ALTERNATING METHOD ........ 12

3. THE COMPLEX FUNCTIONS IN THE FORM OF COMPLEX INTEGRALS ............. 15

4. CAUCHY INTEGRAL THEORMS $\ldots \ldots \ldots \ldots \ldots$ I?

III. METHOD OF SOLUTION ................... 19

1. COMMENCING WITH THE STRESS FIELD AROUND

A HOLE OF RADIUS a .............. 19

(a) Determination of $\phi_{1}\left(\boldsymbol{z}_{1}\right)$ and $\boldsymbol{x}_{1}^{\prime}\left(\boldsymbol{z}_{1}\right) \ldots 20$

(b) The Effect of Other Hole of

Radius $b \ldots \ldots \ldots \ldots \ldots . \ldots 22$ 
i) Transformation of Co-ordinates ............. 22

ii) Boundary Value at Radius b .................23

iii) Corrected Stress

Functions ...............24

(c) Boundary Condition Check at

Radius b ............... 25

2. COMMENCING WITH THE STRESS FIELD AROUND

A HOLE OF RADIUS b ........... 26

(a) The Effect of Other Hole of

Radius a ................ 2?

(b) Boundary Condition Check at

Radius a ................ 29

3. FIRST AND SECOND APPROXIMATIONS ...... 30

4. THIRD APPROXIMATION ................. 31

(a) Transformation ...............31

(b) Effect of the Other Hole of

Radius b .................31

(c) Boundary Condition Check at

Radius b ................. 34

IV RESULTS AND DISCUSSION $\ldots \ldots \ldots \ldots \ldots \ldots \ldots$

1. STRESS FIELD DUE TO THE RIGID INCLUSION

IN SINGLE HOLE $\ldots \ldots \ldots \ldots \ldots \ldots . \ldots 36$

2. SINGLE HOLE SOLUTION ............... 3 ? 
CHAPTER

PAGE

3. FIRST APPROXIMATION ................. 38

(a) Special Case .................. 38

(b) General Solution ............ 42

4. SECOND APPROXIMATION .............. 43

(a) Special Case ................ 43

(b) General Case ................ 4 ?

5. DISCUSSION AND CONCLUSIONS ......... 70

(a) Single Hole ................ 70

(b) First Approximation ...........70

(c) Second Approximation .......... 71

BIBLIOGRAPHY ........................... APPENDICES

A. THE GROUPS OF STRESS FUNCTIONS .......... ?6

B. EVALUATION OF THE COMPLEX INTEGRALS ...... 79

C. COMPUTER FORTRAN PROGRAM FOR TANGENTIAL

STRESSES $\ldots \ldots \ldots \ldots \ldots \ldots \ldots \ldots \ldots \ldots$ 


\section{LIST OF TABLES}

TABLE

1. Single Hole Solution .................... 38

2. First Approximation

$$
\text { for } \frac{b}{a}=2 \text { and } \frac{c}{a}=3.1 \ldots \ldots \ldots \ldots \ldots \ldots \ldots
$$

3. First Approximation

$$
\text { for } \frac{b}{a}=2 \text { and } \frac{c}{a} \text { varying } \ldots \ldots \ldots \ldots \ldots \ldots . \ldots 1
$$

4. Second Approximation

$$
\text { for } \frac{c}{a}=4.0, p=q, \frac{b}{a}=2 \ldots \ldots \ldots \ldots \ldots \ldots \ldots . \ldots 4
$$

5. Second Approximation

$$
\text { for } \frac{b}{a}=2 \text { and } \frac{c}{a}=\operatorname{varying} \ldots \ldots \ldots \ldots \ldots \ldots
$$

6. Second Approximation

Maximum Tangential Stress for $\frac{b}{a}$ varying ....4 46 


\section{LIST OF FIGURES}

FIGURE

PAGE

1. Infinite Plate With Two Inclusions .......... 5

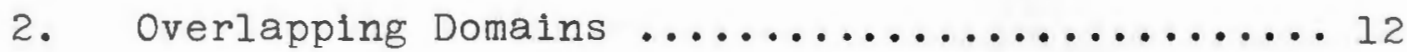

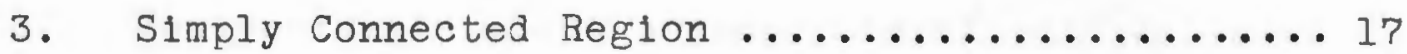

4. Single Hole of Radius a ................. 20

5. Transformation of Co-ordinates ............ 23

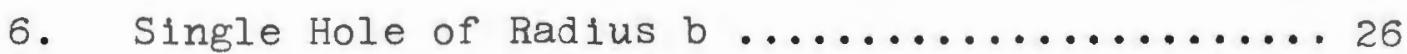

7. Transformation from $\mathrm{o}_{2}$ to $\mathrm{O}_{1} \ldots \ldots \ldots \ldots \ldots \ldots$

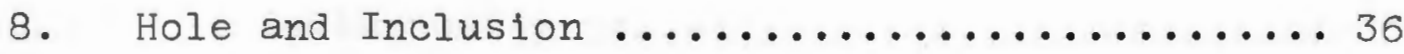

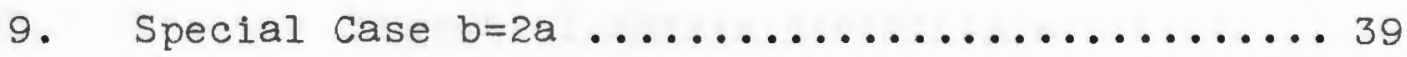

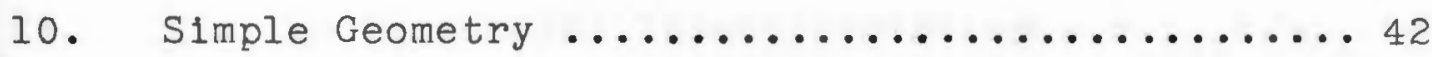

11. Tangential Stresses Along Line FG

$\mathrm{ANG}=0$ or $\pi, \mathrm{b}=\mathrm{a}, \mathrm{c}=3 a \ldots \ldots \ldots \ldots \ldots \ldots \ldots \ldots \ldots \ldots$

12. Tangential Stresses Along Line FG

$A N G=0$ or $\pi, b=a, c$ varying ............ 53

13. Tangential Stresses Along the Line of Symmetry $p=q, b=2 a \ldots \ldots \ldots \ldots \ldots \ldots \ldots \ldots \ldots \ldots$

14. Tangential Stresses Along Line FG

$$
\mathrm{b}=2 \mathrm{a}, \mathrm{p}=\mathrm{q}, \mathrm{c} \text { varying } \ldots \ldots \ldots \ldots \ldots \ldots \ldots \ldots
$$

15. Tangential Stresses Along $\theta_{2}=0$ for $b=2 a, p=q \ldots 56$

16. Tangential Stresses Along $\theta_{1}=0$ for $b=2 a, p=q \ldots 5$ ?

17. Tangential Stresses Around Hole of

Radius a for $p=2 q \ldots \ldots . . \ldots \ldots$ 
18. Tangential Stresses Around Hole of Badius $b$ for $p=2 q \ldots \ldots \ldots \ldots \ldots \ldots$

19. Tangential Stresses Around Hole of

Radius a for $p=q \ldots \ldots \ldots \ldots \ldots \ldots \ldots$

20. Tangential Stresses Around Hole of

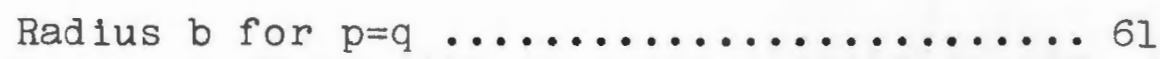

21. Tangential Stresses Around Hole of

Radius a for $p=0.5 q \ldots \ldots \ldots \ldots \ldots \ldots \ldots$

22. Tangential Stresses Around Hole of

Radius b for $p=0.5 q \ldots \ldots \ldots \ldots \ldots \ldots 63$

23. Maximum Tangential Stress Variation w.r.t. d ... 64

24. Maximum Tangential Stress Variation w.r.t. b/a.. 65

25. Radial Stresses for $p=q, b=2 a, c=4 a \ldots \ldots \ldots 66$

26. Shearing Stresses for $p=q, b=2 a, c=4 a \ldots \ldots . .6$ ?

27. Radial Stress Around the Hole Boundaries ......68

28. Shearing Stress Around Hole of Radius b ......69 
INTRODUCTION

The boundary-value problem in plane elasticity can, in general, be solved by the familiar methods such as semiinverse method, polynomial expansion method and separation of variables method[1]*. But for certain classes of problems these approaches are very difficult or lengthy to apply.

Another way of approach is the reduction of the boundary value problems in plane elasticity to solutions of certain functional equations in a complex domain. The systematic use of the complex variable theory in plane elasticity was proposed by Kolossott[2] as early as 1909 and was accomplished by Muskhelishvili[3] in 1949. Many problems which are difficult to handle by the conventional methods can easily be tackled by complex variable approach.

A simply connected region or a doubly connected region can be conformally mapped into a unit circle one-to-one and the first and the second boundary-value problems can be easily solved from a functional equation in complex plane. For example, an infinite plate weakened by a single hole of any arbitrary shape and having uniaxial tensile stresses at * The number in square bracket designates reference number in the Bibliography. 
infinity, can be transformed into a unit circle by the Schwartz-Christoffel's theoremand then can be solved without any mathematical difficulty. However, this procedure becomes cumbersome in case of multi-connected regions because the one-to-one transformation is difficult to obtain. I-l. HISTORICAL REVIEW:

(a) Single Hole: The theoretical analysis of the elastic stresses distribution around holes of various shapes in infinite and semi-infinite plates with uniaxial tension, has provided a fruitful field of investigation.

For obvious practical reasons, the stresses around a circular hole have been the subject of detailed examination by Kirch[4], Sternberg and Sadowsky[5], Timoshenko[1], Durelli and Murry[6], Howland[7], Jeffery[8], Mindlin[9], Wang[10] and Sjostrorm[11].

The stress analysis for elliptical holes, has been carried out by Kolosoff[2], Inglis[12], Poschl[13], Coker[14], Donell[15], Stevenson[16], Savin[17] and Muskhelishvili[3].

Holes of polygonal shapes such as triangular, square and rectangular have been analysed by Stevenson[16], Sen[18], Cox [19], Savin[17], who extended the work of Muskhelishvili[3]. A general solution for square holes with rounded corners is due to Heller, Brock and Bart[20] which is an improvement on an earlier solution by Greenspan[21].

(b) Two Holes: The solution in terms of a biharmonic function for two equal circular holes in an infinite plate under biaxial and uniaxial stresses was first discussed by 
Chih Bing Ling[22] in 1948. He took advantage of the double symmetry and used bipolar coordinates, a method used earlier by Jeffery[8] and latter corrected by Mindlin[9] for the case of single circular hole near the stralght edge of a sem1infinite plate. These cases have also been considered by Ustinov[23].

Bipolar coordinates were also used by Podstrigach[24] to study the stress concentration in an infinite elastic plate weakened by two unequal circular holes. He has studied two cases:(1) with the boundary of each hole subjected to uniform pressures of different magnitude, (ii) with the plate uniformly stretched and the boundary of the holes being free.

With the help of conformal mapping, stress distribution in a plate with two circular holes of different diameters was first analyzed by Davies and Hoddinott[25] in 1963, but this method is rather restricted. Their paper examines the accuracy of a simple theory which superimposes the solution for a small hole in the field of stress generated by a larger hole.

Other research work in this field has been by Hodden[26] who obtained the solution in a closed form for unequal holes under uniaxial external force, with the same approach (1967). In 1968, Salerno and Mahoney[27] published a paper discussing the solution to the problem of two unequal holes under biaxial stresses of equal magnitude at infinity. The complex variables and the Schwarz's alternating method are used. First solution for a single circular hole was obtained 
which gives residual stresses on the edge of second hole. This is corrected by assuming additional stresses. The procedure is repeated with the two holes alternately. The method of obtaining successive approximations has been clearly described,*

The integral equations involved in the above calculations have been throughly studied by Sherman[28] who proved, among other things, that they can be solved by the method of successive approximations. Sokolnikoff[29] in his book has considered the solution to the problem of eccentric ring under uniform pressure and also concentric ring under concentrated forces, with the help of the same method.

(c) Schwarz's Alternating Method: Since elastostatic problems in multiply connected domains present serious computational difficulties, it is natural to attempt to reduce their solution to a sequence of problems in simply-connected domains. This can be done by making some rather obvious modifications in Schwarz's treatment [30] of the Dirichlet problem for the overlapping domains. The proof of convergence of the Schwarz algorithm in the

* While obtaining the transformed stress functions with the help of equations (88.6) in [29], Salerno has interpreted them in a wrong way. The value of $r$ in the third term is the boundary value, the radius of the hole, which he took as a variable radial coordinate instead. Then because of the third term $r^{2} / z \quad(=\bar{z})$ the function is no longer analytic and hence cannot be differentiated and which he did by taking $r^{2}$ outside the differentiation as a constant and thus the second mistake. 
solution of the second elastostatic boundary-value problems for a doubly connected domain for the case when the contours bounding this domain are sufficiently far apart has been supplied by Mikhlin[31]. In essence Mikhlin's proof is based on Neumann's modification[32]. A detalled and careful presentation of Schwarz-Neumann method of solution of the Dirichlet problem for a class of elliptic partial differential equations in two dimensions and in solving certain systems of integral equations w11l be found in the book by Kantorovich and Krylov[33].

A general proof of Schwarz algorithm for the second boundary value problem of elasticity in three dimensions was sketched out by Soboleff[34]. This reduces the consideration of convergence of sequences of approximate solutions, to a study of convergence of sequences that minimize the integral for the strain energy.

I-2. STATEMENT OF THE PROBLEM:

(a) Problem: Plane stress analysis of an infinite plate 'S' with two rigid circular inclusions of different radii 'a+e,'

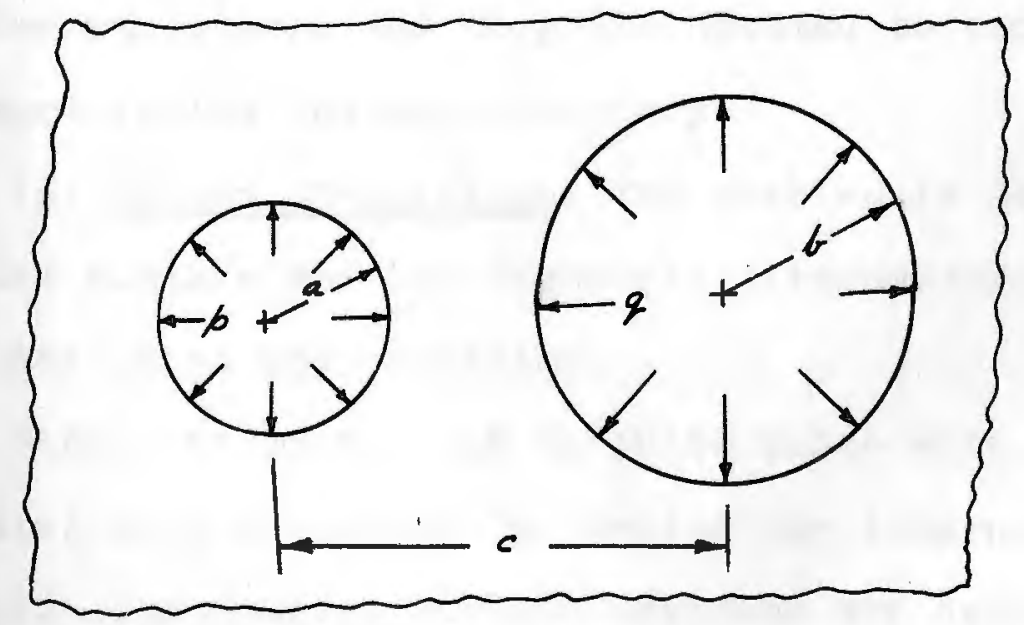

Figure 1- Infinite Plate With Two Inclusions. and ' $b+\varepsilon_{2}$ ' being inserted in the two holes of radil ' $a$ ' and ' $b$ ' 
respectively, where ' $\epsilon$ ' is very small as compare to the radil and radius ' $b$ ' is greater than radius ' $a$ '. ' $c$ ' is the center to center distance between the two holes. These two inclusions inserted without any rotation produce different uniform radial pressures ' $p$ ' and ' $q$ ' respectively at the hole boundaries 'a' and 'b', as shown in Fig. 1.

The purpose of this study is to determine the stress distribution around the two unequal holes.

(b) Assumptions:

i) Material of the plate is stressed within elastic limit. Only the elastostatic problem is considered.

1i) No deformation in the rigid inclusions.

iii) Plate material is assumed to be linear-elastic, homogeneous and isotropic.

iv) The displacements in the plate are infinitesimal so that the classical theory of elasticity is applicable.

v) The two rigid inclusions are inserted without any rotation and with no slip so that the shear stress at the hole boundaries is zero and they are assumed to produce uniform pressure inside the hole boundary.

(c) Method of Solution: The problem is defined on the complex z-plane and the Schwarz's Alternating method is used upto the third approximation.

First the problem of infinite plate with the smaller circular hole of radius ' $a$ ' having the internal pressure 'p' is solved. The complex stress functions are determined. They are transformed to the center of other hole and the stresses along the boundary of radius ' $b$ ' are calculated. Let them be $f$. Then 
the corrected boundary value at radius $\mathrm{b}$ will be given by $f_{1}=-q t-f$, where $t=b e^{i \theta_{2}}$. This value is substituted in the equations (88.6) given in [29] to give the new stress functions which when added to the previous transformed ones give the second approximation. Same procedure is followed starting from the bigger hole of radius $b$ and finding the second approximation with respect to the smaller hole 'a'. On the similar basis successive approximations can be obtained.

(d) Scope and Limitations: Apart from the obvious practical limits the following limitations were observed in solution of the problem:

When the method of conformal mapping is used in solving this problem, the given multiply connected region, with the help of suitable bilinear transformation, can be mapped into a concentric ring. The point of infinity maps into a single point inside the ring, thus the singularity where the stress should be zero. The extreme circles represent the two circular hole boundaries in the infinite plate. The uniform pressure boundary-condition need not be a harmonic function and hence is difficult to transform.

With the Schwarz's Alternating method, while solving for the third approximation the algebra involved becomes unmanageable and requires lot of paper work. Hence the numerical results are obtained upto the second approximation.

It is generally recognized that penetration constitutes a source of weakness in the submarine pressure hull, aeronautical structures, nuclear reactors and boilers. In the 
vicinity of the openings, there is a perturbation zone where stresses may greatly exceed the nominal values. The effect of such localized stress concentrations on overall collapse strength may be negligible for small holes; however, the importance of hole penetrations lies in the fact that fatigue and fracture start at localized stress raisers which may well precipitate failure before the static collapse strength is reached.

\section{I-3 NOMENCLATURE:}

a Radius of the smaller hole.

b Radius of the bigger hole.

c Center to center distance between the two holes.

d Shortest distance between the two holes $\{=c-(a+b)\}$.

$\epsilon$ Difference between the radius of inclusion and corresponding hole.

p Uniform pressure inside the hole of radius a.

q Uniform pressure inside the hole of radius b.

S Infinite plate.

D Inclusion.

0 Origin of the polar co-ordinates and center of corresponding hole.

$\mathrm{x}, \mathrm{y} \quad$ Rectangular Cartesian Co-ordinates.

$r, \theta$ Polar Co-ordinates.

z Complex number.

$r e^{i \theta} \quad$ Polar form of complex number.

$\nabla^{2} \quad$ Laplace operator. 
F Rectangular component of external force.

$b_{k}, b_{\theta} \quad$ Radial and tangential normal stresses respectively in polar co-ordinates.

$\tau_{\text {ro }} \quad$ Shearing stress in polar co-ordinates.

$f$ Boundary value of stresses.

$t$ Boundary value of complex number.

I6 Complex contour integral. 6 indicates the order in which it occures.

E Young's modulus.

$v$ Poisson's ratio.

G Torsional rigity, $\left\{=\frac{E}{2(1+v)}\right\}$.

$\phi(z), x(z) \quad$ Complex stress functions.

$\phi_{1}^{\prime}\left(z_{1}\right)$ First derivative w.r.t. $z_{1}$ of the stress function
w.r.t. $O_{1}$.

$x_{12}^{\prime}\left(z_{2}\right) \quad$ Complex stress function transformed to origin $\mathrm{O}_{2}$ from origin $\mathrm{O}_{1}$.

$\phi_{11}\left(\boldsymbol{z}_{1}\right) \quad$ Complex stress function w.r.t. $\mathrm{O}_{1}$ calculated from the equations (6) and (7).

Subscript 1 w.r.t. origin $O_{1}$, center of hole of radius a.

Subscript. 2 w.r.t. origin $\mathrm{O}_{2}$, center of hole of radius $b$.

Nomenclature used in the FORTRAN PROGRAM:

All the quantities are in non dimensional form, unless specified.

TANST Tangential stress.

RADST Radial stress.

SHEST Shearing stress.

Suffix 1 stress in $1 b / i^{2}$. 
Suffix 2 Stress divided by G. Nondimensional.

Solution w.r.t. $\mathrm{O}_{1}$ :

$\begin{array}{ll}\mathrm{R} & =\mathrm{r}_{1} / \mathrm{a} . \\ \mathrm{B} & =\mathrm{b} / \mathrm{a} . \\ \mathrm{C} & =c / a . \\ \mathrm{E} & =\epsilon / \mathrm{a} .\end{array}$

$A P, B P, C P, D P, E P$ and FP are as defined on page 50.

Solution w.r.t. $\mathrm{O}_{2}$ :

$$
\begin{aligned}
\mathrm{R} & =r_{2} / b . \\
A & =a / b . \\
C & =c / b . \\
E & =\epsilon / b .
\end{aligned}
$$

SP, TP, UP, VP, WP and XP are as defined, on page 51. 
SOLUTION APPROACH VIA COMPLEX VARIABLES

II-1. GENERAL THEORY: The Airy stress function $\hat{\phi}$, which is defined in plane elasticity satisfies the biharmonic equation

$$
\nabla^{4} \hat{\phi}=\nabla^{2} \nabla^{2} \hat{\phi}=0 \text {. }
$$

where

$$
\nabla^{2}=\frac{\partial^{2}}{\partial x^{2}}+\frac{\partial^{2}}{\partial y^{2}}
$$

If we put $\nabla^{2 \hat{\phi}}=P(x, y)$, then the function $P(x, y)$ is a harmonic function since it satisfies the Laplace equation. Hence, there exists a conjugate harmonic function $Q$ such that $f(z)=P+1 Q$ is an analytic function in complex $z$-plane. It can also be easily shown that $P_{1}=\hat{\phi}-x p-y q$ is a harmonic function, where

$$
\frac{\partial p}{\partial x}=\frac{1}{4} p \quad \text { and } \quad \frac{\partial q}{\partial x}=\frac{1}{4} Q .
$$

Now if one introduces the functions $\phi(z)$ and $\chi(z)$, which are known as the complex stress functions, as

$$
\begin{aligned}
& \phi(z)=\frac{1}{4} \int(P+i Q) d z \\
& x(z)=P_{1}+i Q_{1}
\end{aligned}
$$

where $Q_{1}$ is a conjugate harmonic function of $P_{1}$, then $\phi(x)$ and $\chi(z)$ are analytic functions.

Stress field in polar co-ordinates, in terms of these stress functions, are given by

$$
\begin{aligned}
\sigma_{r}+\sigma_{\theta} & =4 \operatorname{le}\left[\phi^{\prime}\left(z^{z}\right)\right] \\
\sigma_{\theta}-b_{\mu}+2 \dot{\tau_{r \theta}} & =2 e^{2 i \theta}\left[\bar{z} \phi^{\prime \prime}(z)+x^{\prime \prime}(z)\right]
\end{aligned}
$$

and 
where $\boldsymbol{z}=\boldsymbol{r} e^{i \theta}$. Equating real and imaginary parts of equation (2), two separate equations can be obtained and thus knowing the stress functions the three unknown stresses can be determined from equations (1) and (2).

Let $S$ be a closed smooth contour. $f_{x}$ and $f_{y}$ be the component of stresses acting on the small element ds of the contour, parallel to the $\mathrm{x}$ and $\mathrm{y}$ axes respectively. The stress boundary condition on $S$ can be expressed in terms of the above stress functions as

$$
\begin{aligned}
f & =i \int\left(f_{x}+i f_{x}\right) d s \\
& =\phi(z)+z\left\{\overline{\phi^{\prime}(z)}\right\}+\left\{\overline{x^{\prime}(z)}\right\}
\end{aligned}
$$

II-2 SCHWARZ'S ALTERNATING METHOD: Consider a region(Fig.-2) formed by the overlapping domalns $R_{1}$ and $R_{2}$, each of which is bounded by a simple closed contour. Let the portion of the contour $C_{1}$ bounding $R_{1}$ that lies within the region $R_{2}$ be $C_{1}$ and the part that is outside $B_{2}$ be $C_{1}^{\prime \prime}$. Then $C_{1}=C_{1}^{\prime}+C_{1}^{\prime \prime}$.

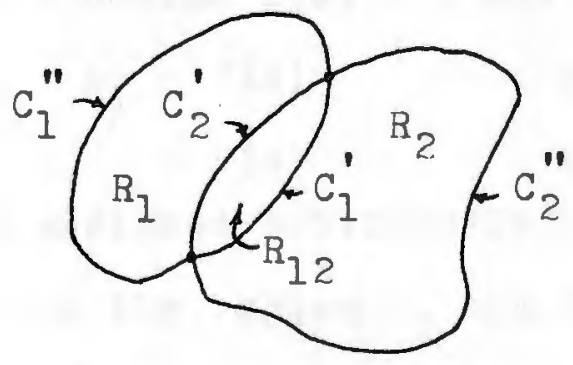

Figure 2 - Overlapping Domains. Similarly, denoting the part of the boundary $C_{2}$ of $R_{2}$ that is interior to $\mathrm{R}_{1}$ by $\mathrm{C}_{2}^{\prime}$ and the remaining part by $\mathrm{C}_{2}$, it can be written as $C_{2}=C_{2}^{\prime}+C_{2}^{\prime \prime}$. The region $R_{12}$ that is common to $R_{1}$ and $R_{2}$ is thus bounded by $C_{1}^{\prime}$ and $C_{2}^{\prime}$, while the region $R_{1}+R_{2}$ 
has the curve $C_{1}+C_{2}$ for its boundary, as shown in Figure 2. Let the values of some function $\phi$ be specified on the boundary $C_{1} "+C_{2}$ and $\phi$ in the region $\mathrm{R}_{1}+\mathrm{R}_{2}$ is to be determined such that $\phi$ satisfies in this region the functional equation $L(\phi)=0$, where the operator $L$ is linear. In the classical Dirichlet problem, I is the Laplace operator. In other problems it may denote an integral or integrodifferential equation.

An algorithm for the solution of the boundary-value problem

$$
\left.\begin{array}{rlrl}
L(\phi) & =0 & & \text { in } \mathrm{B}_{1}+\mathrm{B}_{2}, \\
& =F(\mathrm{~s}) & & \text { on } \mathrm{C}_{1}^{\prime \prime}+\mathrm{C}_{2}^{\prime \prime}
\end{array}\right\}
$$

from the solution of the corresponding boundary-value problems for the regions $\mathrm{R}_{1}$ and $\mathrm{R}_{2}$, can be constructed as follows :

Determine in the region $\mathrm{R}_{1}$ the function $\mathrm{u}_{1}$, which satisfies the equation $L(\phi)=0$ and is such that

$$
\begin{aligned}
u_{1} & =F(s) \\
& =f(s)
\end{aligned}
$$

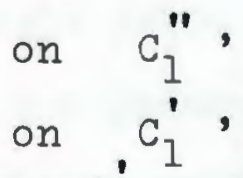

where $f(s)$ is assigned arbitrarily on $C_{1}^{\prime}$. Having determined $u_{1}$, construct in the region $B_{2}$ the function $v_{1}$ which satisfies the equation $L(\phi)=0$ and which assumes on $C_{2}$ the values

$$
\begin{aligned}
v_{1} & =F(s) & & \text { on } c_{2}^{\prime \prime}, \\
& =u_{1}(s) & & \text { on } c_{2}^{\prime} .
\end{aligned}
$$

Next the solution $u_{2}$ of $L(\phi)=0$ in $R_{1}$ is determined such that

$$
\begin{aligned}
u_{2} & =F(s) & & \text { on } c_{1}^{\prime \prime}, \\
& =v_{1}(s) & & \text { on } c_{1}^{\prime},
\end{aligned}
$$

and then obtained the solution $\mathrm{v}_{2}$ of $\mathrm{L}(\phi)=0$ in $\mathrm{R}_{2}$, subjected 
to the condition

$$
\begin{aligned}
\mathrm{v}_{2} & =F(s) & & \text { on } c_{2}^{\prime \prime}, \\
& =u_{2}(s) & & \text { on } c_{2}^{\prime} .
\end{aligned}
$$

The successive approximations of this alternating procedure would yeild two sequences of functions, $\left\{u_{n}\right\}$ in $B_{1}$ and $\left\{v_{n}\right\}$ in $R_{2}$, such that

$$
\begin{aligned}
u_{n} & =F(s) & & \text { on } c_{1}^{\prime \prime}, \\
& =v_{n-1}(s) & & \text { on } c_{1}^{\prime},
\end{aligned}
$$

and

$$
\begin{aligned}
& \mathrm{v}_{\mathrm{n}}=\mathrm{F}(\mathrm{s}) \\
& =u_{n}(s) \\
& \text { on } c_{2}^{\prime \prime} \text {, }
\end{aligned}
$$

If the solution of the equation $L(\phi)=0$ posseses suitable properties, the sequences $\left\{u_{n}\right\}$ and $\left\{v_{n}\right\}$ may converge to $u$ and $v$, respectively, with $u=v$ in the common region $R_{12}$. Also, on the boundary $C_{1} " C_{2}$ of ${ }_{1}+B_{2}$ the functions $u$ and $v$ assume the specified values, $F(s)$, and if they also satisfy the equation $L(\phi)=0$, the problem (4) is solved.

Whether this formal process would yeild the desired solution or not clearly depends on the properties of the operator $L$ and on the nature of assigned boundary values. If $L$ is the Laplace operator and $F(s)$ is a continuous function defined on a sufficiently smooth boundary of the region, this process actually yeilds the solution of the Dirichlet problem.

It was observed by Neumann that the Schwarz method can be modified to yeild the solution of the Dirichlet problem for the domain $R_{12}$ formed by the intersection of $R_{1}$ and $R_{2}$, and 
hence for the doubly connected domains. The region $\mathrm{R}_{12}$ can be considered as the intersection of the infinite region $B_{1}$ bounded by $C_{1}$ with the finite region $B_{2}$ interior to $C_{2}$.

Now the alternating method of Schwarz can be made to yeild the solution of the basic problems of elasticity for doubly connected regions.

The operator $\mathrm{L}$ is given by the equation (3)

$$
L\left(\phi, \chi^{\prime}\right)=f
$$

and the boundary condition on $\mathrm{C}_{1}+\mathrm{C}_{2}$ by

$$
L\left[\phi(t), x^{\prime}(t)\right]=\phi(t)+t\left\{\overline{\phi^{\prime}(t)}\right\}+\left\{\overline{\chi^{\prime}(t)}\right\}=f(t)
$$

To obtain the first approximation $\left(\phi_{1}, \chi_{1}^{\prime}\right)$ to $\left(\phi, \chi^{\prime}\right)$ the functions $\phi_{1}, \chi_{1}^{\prime}$ in $R_{1}$ are determined, so that

$$
\left.\mathrm{L}\left\{\phi_{1}, x_{1}^{\prime}\right\}\right|_{c_{1}}=f / c_{1}
$$

To get the second approximation $\left(\phi_{2}, \chi_{2}^{\prime}\right)$, the solution in $\mathrm{R}_{2}$ is considered, such that

$$
L\left(\phi_{2}, x_{2}^{\prime}\right) /_{c_{2}}=f / c_{2}-\left.L\left(\phi_{1}, x_{1}^{\prime}\right)\right|_{c_{1}}
$$

For the third approximation, the solution is determined in $\mathrm{R}_{1}$, satisfying the condition

$$
\left.L\left(\phi_{3}, x_{3}^{\prime}\right)\right|_{c_{1}}=f / c_{1}-L\left(\phi_{2}, x_{2}^{\prime}\right) / c_{2}
$$

and so on.

The use of this procedure in constructing the approximate solution of special elastostatic problems in doubly connected domains is presented in detail in [29].

II-3. THE COMPLEX FUNCTIONS IN THE FORM OF COMPLEX INTEGRALS:

The simply connected region can be mapped conformally into 
a circular region, with the help of a suitable mapping function. Let 1 t be

$$
z=\omega(\zeta) .
$$

The boundary condition at ' $t$ ' will now be

$$
f(t)=\phi(t)+\frac{\omega(t)}{\left\{\overline{\omega^{\prime}(t)}\right\}}\left\{\overline{\phi^{\prime}(t)}\right\}+\left\{\overline{\chi^{\prime}(t)}\right\} .
$$

From this equation it can be easily shown that

$$
\begin{gathered}
\phi(s)=-\frac{1}{2 \pi i} \int_{r} \frac{\phi(t) d t}{(t-5)} \\
x^{\prime}(s)=\frac{1}{2 \pi i} \int_{r} \frac{(\overline{f(t)\}}}{(t-5)} d t-\frac{1}{2 \pi i} \int_{r} \frac{\{\overline{\omega(t)\}}}{\omega^{\prime}(t)} \cdot \frac{\phi^{\prime}(t)}{(t-5)} d t
\end{gathered}
$$

provided that $\phi(\zeta)$ and $\chi^{\prime}(\zeta)$ are analytic at every point $\zeta$ outside $\gamma$, including infinity.

In case of multiply connected regions, the stress functions $\phi\left(z_{1}\right)$ and $\chi^{\prime}\left(z_{1}\right)$, with respect to the first origin $O_{1}$, analytic in the region $z_{1} \geqq a$, and which satisfy the boundary condition

$$
f_{2}\left(t_{1}\right)=\phi\left(t_{1}\right)+t_{1}\left\{\overline{\phi^{\prime}\left(t_{1}\right)}\right\}+\left\{\overline{x^{\prime}\left(t_{1}\right)}\right\} \text { on } c_{1}
$$

where $t_{1}=a e^{1 \theta_{1}}$, are determined by the equations

$$
\begin{gathered}
\phi\left(z_{1}\right)=-\frac{1}{2 \pi i} \int_{c_{1}} \frac{f_{1}\left(t_{1}\right)}{t_{1}-z_{1}} d t_{1} \\
x^{\prime}\left(z_{1}\right)=-\frac{1}{2 \pi i} \int_{c_{1}} \frac{\left\{\overline{\left.f_{1}\left(t_{1}\right)\right\}}\right.}{t_{1}-z_{1}} d t_{1}+\frac{1}{2 \pi i} \int_{c_{1}} \frac{\left\{\overline{\left.f_{1}\left(t_{1}\right)\right\}}\right.}{t_{1}} d t_{1} \\
\text { where } z_{1}=r_{1} e^{1 \theta_{1}=z_{2}+c .}
\end{gathered}
$$

Similar equations can be written for the second origin $\mathrm{O}_{2}$ by changing the suffixes to 2 from 1 in the equations (6) and $(7)$ and to $b$ from $a$. Now on $c_{2}$ we have $t_{2}=b e^{i \theta_{2}}$.

These equations, (6) and (7), are similar to the equations 
(88.6) on page 324 of [29] and it may be noted equation (7) does not correspond to its counter part, because of a typographical error in [29] which is corrected herein. II-4. CAUCHY INTEGRAL THEOREMS:

Integrals of the type which occur in equations (6) and (7) are called Cauchy Integrals. Simple formulas for several cases of these integrals are given below [3].

Let $I$ be a simple smooth contour as shown in Figure 3 . Denote by $\mathrm{S}^{+}$the finite part of the plate bounded by $\mathrm{L}$, and by $\mathrm{S}^{-}$the infinite part of the plate bounded by points lying outside I. The positive direction of $L$ will be chosen such that the region $\mathrm{S}^{+}$lies to its left.

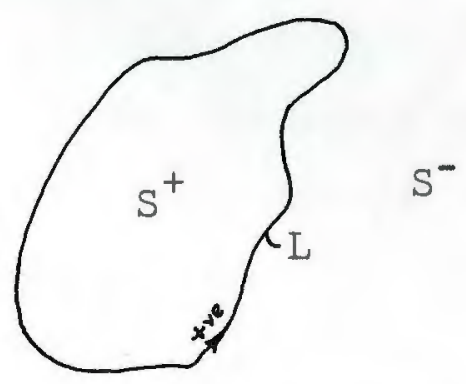

Figure 3 - Simply Connected Region.

i) Let $f(z)$ be a function, single valued, holomorphic in $\mathrm{S}^{+}$ and continuous at $S^{+}+I\left(\right.$ region $S^{+}$and points on $\left.L\right)$, then

$$
\frac{1}{2 \pi i} \int_{L} \frac{f(t) d t}{(t-z)}=0 \quad \text { for } z \text { in } S^{-}
$$

1i) Let $f(z)$ be a function, holomorphic in $S^{-}$including the point at infinity and continuous in $\mathrm{S}^{-}+\mathrm{L}$. This means that

$$
f(z)=c_{0}-\frac{c_{1}}{z}+\frac{c_{2}}{z^{2}}+\cdots
$$

and for sufficiently large $z, C_{0}=f(\infty)$, then 


$$
\frac{1}{2 \pi i} \int_{L} \frac{f(t) d t}{(t-z)}=-f(z)+f(\infty) \text { for } z \text { in } S^{-}
$$

1i1) Let $f(z)$ be a function, holomorphic in $S^{+}$, except for a finite number of singular points $z_{1}, z_{2}, \ldots, z_{n}$ in $S^{+}$. If $K_{1}$, $K_{2}, \ldots, K_{n}$ denote the residues of $f(z)$ at these points, then

$$
\frac{1}{2 \pi i} \int_{L} f(z) d z=k_{1}+k_{2}+\cdots+k_{n}
$$

where

$$
k_{p}=\frac{1}{(m-1) !} \lim _{z \rightarrow z_{p}} \frac{d^{(m-1)}}{d z^{(m-1)}}\left[\left(z-z_{\beta}\right)^{m} f(z)\right]
$$

$m$ being the order of the pole at a point $z_{p}$. 
III

METHOD OF SOLUTION

Ftrst the solution is obtained starting from the hole of radius $a$, which is subjected to a uniform pressure distribution of $\mathrm{p}$ along its boundary and the same problem is solved starting from the hole of radius $b$ with pressure $q$. III- Commencing with the Stress Field Around a Hole of Radius a:

If the infinite plate contains only one hole of radius a, with the uniform normal pressure $p$ applied to its boundary then the stress functions describing the state of stress in the plate can be written in the form:

$$
\left.\begin{array}{l}
\phi_{1}\left(z_{1}\right)=\phi_{0}\left(z_{1}\right)+\phi_{01}\left(z_{1}\right) \\
x_{1}^{\prime}\left(z_{1}\right)=x_{0}^{\prime}\left(z_{1}\right)+x_{01}^{\prime}\left(z_{1}\right)
\end{array}\right\}
$$

where $\phi_{0}\left(z_{1}\right)$ and $x_{0}^{\prime}\left(z_{1}\right)$ are the stress functions describing the state of stress in unpenetrated plate and $\phi_{0}\left(z_{1}\right)$ and $\boldsymbol{\chi}_{01}^{\prime}\left(\boldsymbol{z}_{1}\right)$ are the functions holomorphic in infinite region and describe the effect of penetration.

The functions $\boldsymbol{\phi}_{0}(\boldsymbol{z})$ and $\boldsymbol{x}_{0}^{\prime}(\boldsymbol{z})$ are determined first and next the boundary function $f_{I}$ is found from equation (3) 
and from the corresponding corrected boundary value. Substituting these into equations (6) and (7), the functions $\phi_{0},(\boldsymbol{Z}$,$) and \boldsymbol{\chi}_{0}^{\prime}(\boldsymbol{Z}$,$) are obtained. With these values the$ final state of stress is calculated from equations (1) and (2).

(a) Determination of $\phi,\left(\boldsymbol{z}_{1}\right)$ and $\boldsymbol{x}_{1}^{\prime}(\boldsymbol{z}$,$) :$

For the unpenetrated plate the external force obviously vanishes and hence the stresses are zero, leading to the results,

$$
\left.\begin{array}{l}
\phi_{0}\left(\boldsymbol{x}_{1}\right)=0 \\
\boldsymbol{x}_{0}^{\prime}\left(\boldsymbol{z}_{1}\right)=0
\end{array}\right\}
$$

The pressure $p$ can be decomposed into two rectangular

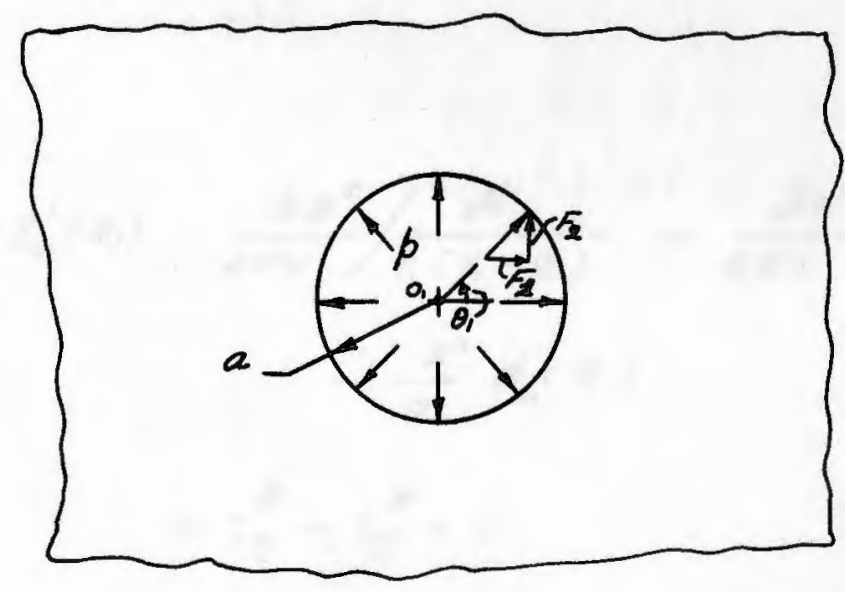

Figure 4 - Single Hole of Radius 'a'.

components as shown in Figure 4

$$
\begin{aligned}
& F_{1}=-p \cos \theta_{1} \\
& F_{2}=-p \sin \theta_{1}
\end{aligned}
$$

Under this condition the boundary stress function $f$ can 
be expressed as

$$
\begin{aligned}
f_{1} & =i \int_{s}\left(F_{1}-i F_{2}\right) d s \\
& =-\phi b t_{1}
\end{aligned}
$$

where $t_{1}=a e^{i \theta_{1}}$, the points on the boundary of the hole, and also

$$
\bar{f}_{1}=-\phi \bar{t}_{1}=-\phi \frac{a^{2}}{t_{1}} .
$$

Substituting (13) and (14) into equation (6) and (7) the transformed stress functions are obtained as,

$$
\begin{aligned}
\phi_{0,}(z) & =\frac{p}{2 \pi i} \int \frac{t_{1} d t_{1}}{\left(t_{1}-Z_{1}\right)} \\
& =I_{1}^{*} \\
& =0
\end{aligned}
$$

and

$$
\begin{aligned}
\chi_{0 \prime}^{\prime}\left(z_{1}\right)= & \frac{p a^{2}}{2 \pi i} \int \frac{d t_{1}}{t_{1}\left(t_{1}-z_{1}\right)}-\frac{p a^{2}}{2 \pi i} \int \frac{d t_{1}}{t_{1}^{2}} \\
& -\frac{a^{2}}{Z_{1}} \phi_{01}^{\prime}\left(z_{1}\right) \\
= & I_{2}^{*}+I_{3}^{*}+0 \\
= & -\frac{p a^{2}}{z_{1}} .
\end{aligned}
$$

Putting (12), (15) and (16) into equations (11) the stress functions for the single hole case can be written as

$7 I_{1}, I_{2}$, etc. Integrals are evaluated in the Appendix $B$ and they are numbered in the same order in which they occure in this Chapter. 


$$
\begin{aligned}
& \phi_{1}\left(z_{1}\right)=0 \\
& x_{1}^{\prime}\left(z_{1}\right)=-\frac{p a^{2}}{z_{1}}
\end{aligned}
$$

(b) The Effect of Other Hole of Radius b:

The stress function (17) are transformed from origin $\mathrm{O}_{1}$ to the other origin $\mathrm{O}_{2}$, the center of the larger hole of radius $b$, at a distance of $c$ from $O_{1}$. The stresses along the circle of radius $b$ are then evaluated as the boundary condition $f$. Now, the corrected boundary value at $r_{2}=b$ will be

$$
f_{2}=-q t_{2}-f
$$

where $t_{2}=b e^{i \theta_{2}}$, the points on the boundary of the larger hole. Substituting these into equations (6) and (7) one can obtain the stress functions $\phi_{22}\left(\boldsymbol{z}_{2}\right)$ and $\boldsymbol{x}_{22}^{\prime}\left(\boldsymbol{z}_{2}\right)$, which when added to the previous transformed stress functions $\phi_{12}\left(z_{2}\right)$ and $x_{12}^{\prime}\left(z_{2}\right)$ give the second approximation to the solution of the problem.

1) Transformation of co-ordinates: The transformation

used is

$$
z_{1}=z_{2}+c
$$

to transform (I7) to $\mathrm{O}_{2}$ as shown in Figure (5).

Since the stress components are not altered by translation, one can write

$$
\text { i.e., } \quad \begin{aligned}
4 \ell_{e}\left\{\phi_{1}^{\prime}\left(z_{1}\right)\right\} & =4 \operatorname{ll}_{e}\left\{\phi_{12}^{\prime}\left(z_{2}\right)\right\} \\
\phi_{1}\left(z_{1}\right) & =\phi_{1,}\left(z_{2}\right)
\end{aligned}
$$

The constants of integration and the purely imaginary 


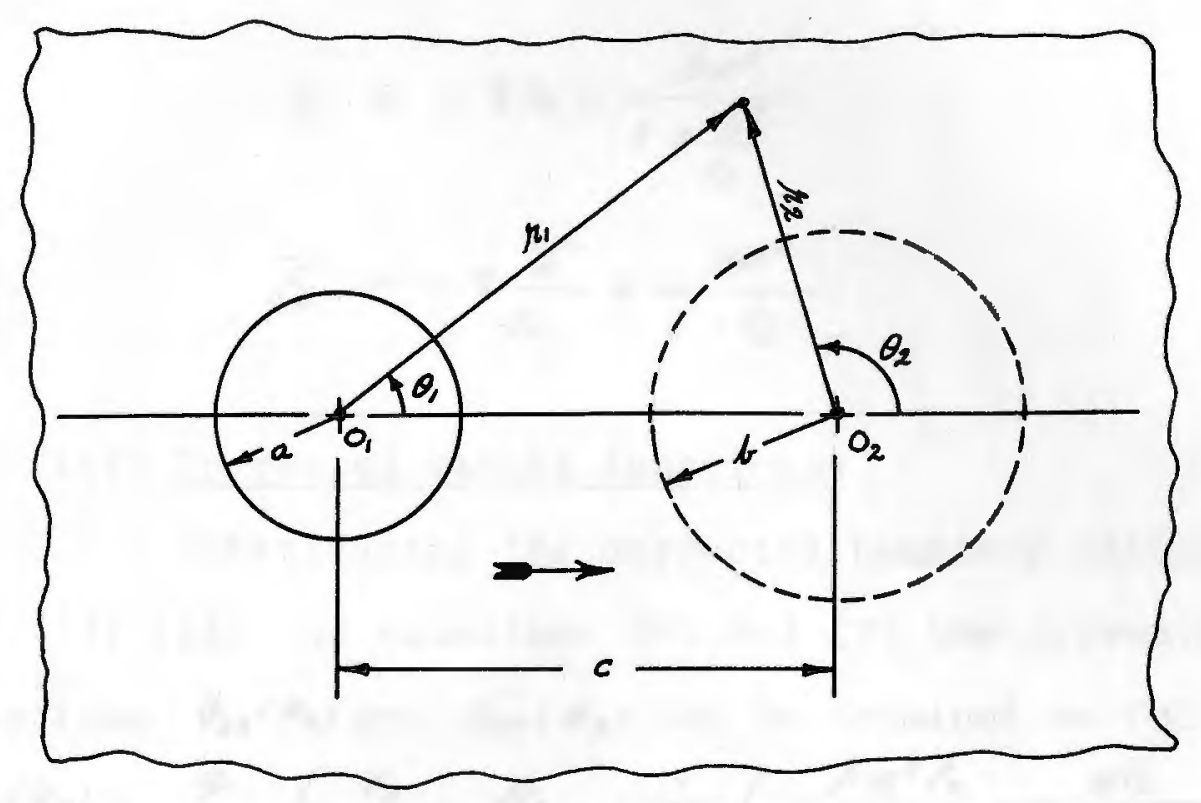

Figure 5 - Transformation of Co-ordinates.

constant which one might have added, are neglected as they do not influence the distribution of stress. Hence we get,

$$
\phi_{12}\left(z_{2}\right)=0
$$

The other transformed stress function $\chi_{12}^{\prime}\left(z_{2}\right)$ is found out from the following formula

$$
\begin{aligned}
x_{12}^{\prime}\left(z_{2}\right) & =c \phi_{1}^{\prime}\left(z_{1}\right)+x_{1}^{\prime \prime}\left(z_{1}\right) \\
& =-\frac{p a^{2}}{z_{2}+c} .
\end{aligned}
$$

ii) The boundary value at radius b:

Substituting the transformed stress functions given by (20) and (21) into equation (3) the corrected boundary value at $r_{2}=b$ or $t_{2}=b e^{i k}$ and $\bar{t}_{2}=\frac{b^{2}}{t_{2}}$ can be obtained from the equation (18), as 


$$
\begin{aligned}
& f_{2}=-q t_{2}+\frac{b a^{2}}{c+\frac{b^{2}}{t_{2}}} \\
& \bar{f}_{2}=-q \frac{b^{2}}{t_{2}}+\frac{p a^{2}}{c+t_{2}}
\end{aligned}
$$

\section{iii) Corrected stress functions:}

Substituting the corrected boundary values from (22) and (23) into the equations (6) and (7) the corrected stress functions $\phi_{22}\left(z_{2}\right)$ and $x_{22}^{\prime}\left(z_{2}\right)$ can be obtained as follows

$$
\begin{aligned}
\phi_{22}\left(z_{2}\right) & =\frac{q}{2 \pi i} \int \frac{t_{2}}{\left(t_{2}-z_{2}\right)} d t_{2}-\frac{1}{2 \pi i} \int \frac{p a^{2} t_{2}}{\left(c t_{2}-b^{2}\right)} \cdot \frac{d t_{2}}{\left(t_{2}-z_{2}\right)} \\
& =I_{4}+I_{5} \\
& =-\frac{p a^{2} b^{2}}{c\left(c z_{2}+b^{2}\right)} .
\end{aligned}
$$

and

$$
\begin{aligned}
x_{22}^{\prime}\left(z_{2}\right)= & \frac{q b^{2}}{2 \pi i} \int \frac{d t_{2}}{t_{2}\left(t_{2}-z_{2}\right)}-\frac{p a^{2}}{2 \pi i} \int \frac{d t_{2}}{\left(c+t_{2}\right)\left(t_{2}-z_{2}\right)} \\
& -\frac{q b^{2}}{2 \pi i} \int \frac{d t_{2}}{t_{2}^{2}}+\frac{p a^{2}}{2 \pi i} \int \frac{d t_{2}}{\left(c+t_{2}\right)\left(t_{2}\right)}-\frac{b^{2}}{z_{2}} \phi_{22}^{\prime}\left(z_{2}\right) \\
= & I_{6}+I_{7}+I_{8}+I_{9}-\frac{b^{2}}{z_{2}} \cdot \frac{p a^{2} b^{2}}{\left(c z_{2}+b^{2}\right)^{2}} \\
= & \frac{p a^{2}}{c}-\frac{q b^{2}}{z_{2}}-\frac{p a^{2} b^{4}}{z_{2}\left(c z_{2}+b^{2}\right)} .
\end{aligned}
$$

The stress functions with respect to the origin $\mathrm{O}_{2}$ are expressed as the sum of the transformed stress functions and. the corrected ones and they are

$$
\phi_{2}\left(z_{2}\right)=\phi_{12}\left(z_{2}\right)+\phi_{22}\left(z_{2}\right)
$$


and

$$
x_{2}^{\prime}\left(z_{2}\right)=x_{12}^{\prime}\left(z_{2}\right)+x_{22}^{\prime}\left(z_{2}\right)
$$

Substituting the equations (20), (21), (24) and (25) into the above expressions, the functions $\phi_{2}\left(\boldsymbol{z}_{2}\right)$ and $\boldsymbol{\chi}_{2}^{\prime}\left(\boldsymbol{x}_{2}\right)$ are obtained as

$$
\phi_{2}\left(z_{2}\right)=-\frac{p a^{2} b^{2}}{c\left(c z_{2}+b^{2}\right)}
$$

and

$$
\begin{aligned}
x_{2}^{\prime}\left(z_{2}\right)= & -\frac{p a^{2}}{z_{2}+c}+\frac{p a^{2}}{c}-\frac{q b^{2}}{z_{2}} \\
& -\frac{p a^{2} b^{4}}{z_{2}\left(c z_{2}+b^{2}\right)^{2}}
\end{aligned}
$$

These functions are summarized in Group I of the Appendix A.

(c) Boundary Condition Check at Radius b:

In order to check the boundary condition at the hole with radius b, stress functions (26) and (27) are substituted into the equation (3), which gives

$$
\begin{aligned}
f=- & \frac{p a^{2} b^{2}}{c\left(c z_{2}+b^{2}\right)}+\frac{z_{2} p a^{2} b^{2}}{\left(c \overline{\bar{z}_{2}}+b^{2}\right)^{2}}-\frac{p a^{2}}{\left(\overline{z_{2}}+c\right)} \\
& +\frac{p a^{2}}{c}-\frac{q b^{2}}{\bar{z}_{2}}-\frac{b a^{2} b^{4}}{\overline{\bar{z}_{2}}\left(c \bar{z}_{2}+b^{2}\right)^{2}}
\end{aligned}
$$

For the boundary value at $r_{2}=b$, putting $z_{2}=t_{2}=b e^{i \theta_{2}}$ we get

$$
\left.f\right|_{k_{2}=b}=-\frac{\beta a^{2} b^{2}}{c\left(c b e^{i \theta_{2}}+b^{2}\right)}+\frac{b e^{i \theta_{2}} \beta a^{2} b^{2}}{\left.c c b e^{-i d^{2}}+b^{2}\right)^{2}}
$$




$$
\begin{array}{r}
-\frac{p a^{2}}{\left(b e^{i \theta_{2}}+c\right)}+\frac{p a^{2}}{c}-\frac{q b^{2}}{b e^{-i \theta_{2}}} \\
-\frac{p a^{2} b^{4}}{b e^{-i \theta_{2}}\left(c b e^{-i \theta_{2}}+b^{2}\right)^{2}} .
\end{array}
$$

Simplifying this one can obtain

$$
\left.f\right|_{r_{2}=b}=-q t_{2}
$$

Thus the stress functions given by (26) and (27) satisfy the boundary condition at the bigger hole of radius $b$.

\section{III-2. Commencing with the Stress Field Around a Hole of Radius b:}

Now in the similar way the problem is solved starting from the hole of radius $b$.

Considering the infinite plate, containing only one hole of radius $b$ with uniform normal pressure $q$ applied along its

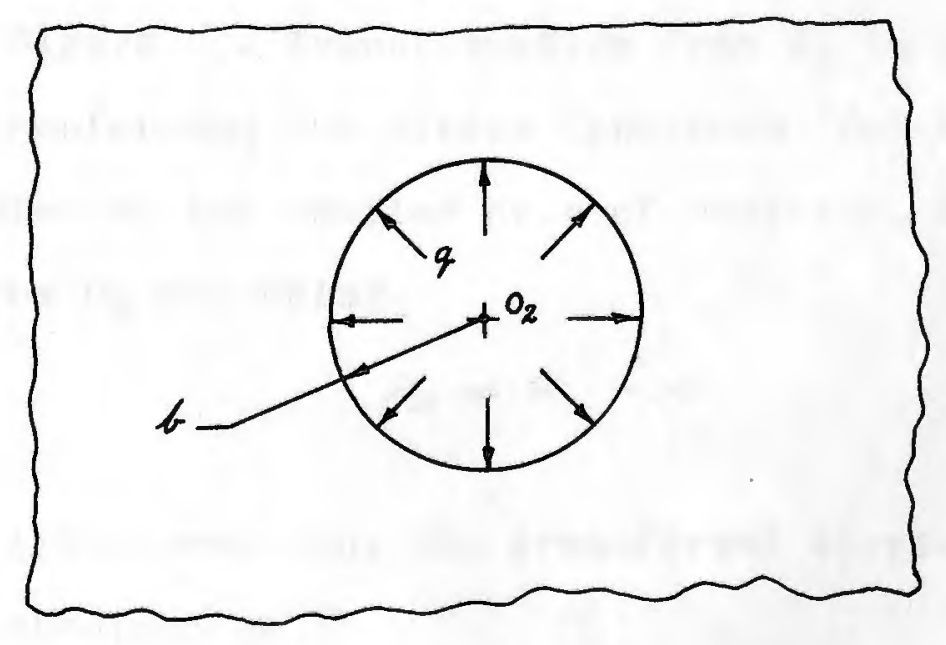

Figure 6 - Single Hole of Radius b. boundary as shown in figure 6 and using the same method as 
given in III-I(a), the stress functions describing the state of stress in the plate can be written as

$$
\left.\begin{array}{l}
\phi_{2}\left(z_{2}\right)=0, \\
x_{2}^{\prime}\left(z_{2}\right)=-\frac{q b^{2}}{z_{2}}
\end{array}\right\}
$$

(a) The Effect of Other Hole of Radius a:

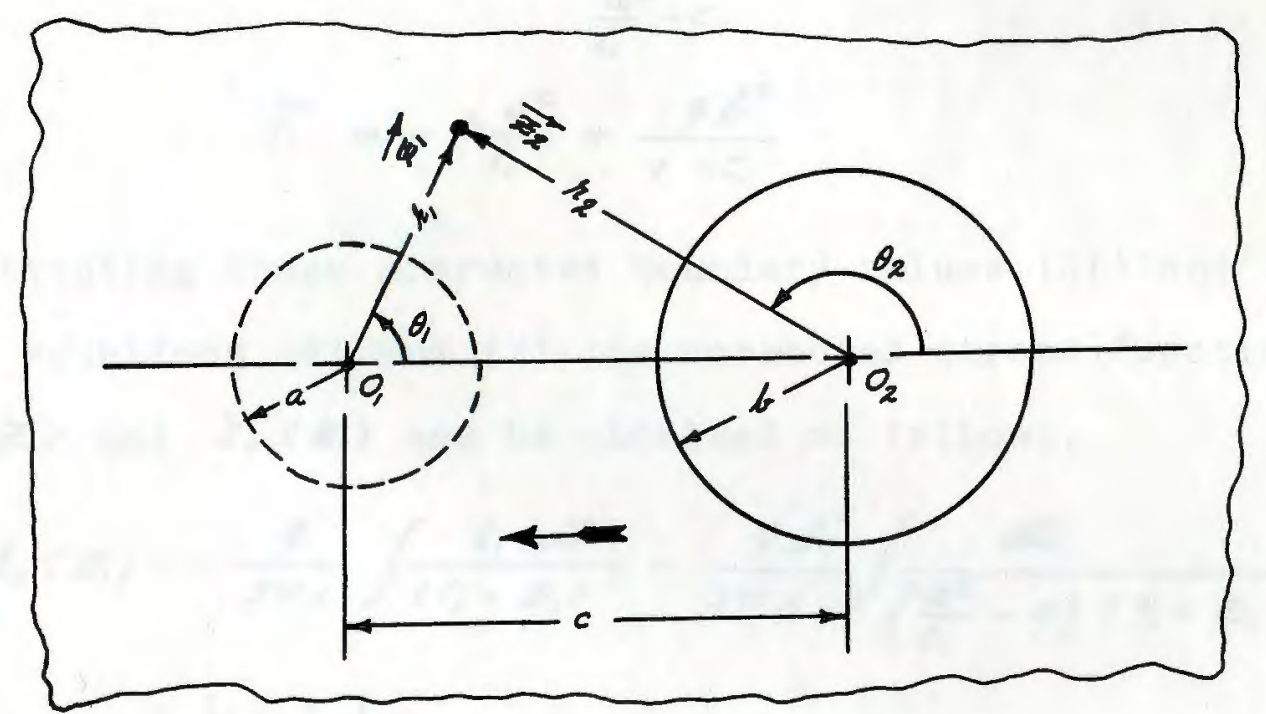

Figure 7 - Transformation from $\mathrm{O}_{2}$ to $\mathrm{O}_{1}$.

Transforming the stress functions (29) to the origin $0_{1}$, the center of the smaller hole of radius a, at a distance of '-c' from $\mathrm{O}_{2}$ and using

$$
z_{2}=z_{1}-c
$$

as the transformation, the transformed stress functions can be easily obtained as

$$
\left.\begin{array}{l}
\phi_{2},(z,)=0 \\
x_{2} ;(z,)=-\frac{q b^{2}}{z_{1}-c}
\end{array}\right\}
$$


Substituting these transformed stress functions (30) into equation (3), the boundary value $f$, at $r_{1}=a$ or $t_{1}=a e^{i \theta_{1}}$ and $\bar{t}_{1}=\frac{a^{2}}{t_{1}}$, can be obtained. The corrected boundary value is now given by

and

$$
\begin{aligned}
f_{1} & =-p t_{1}-f \\
& =-p t_{1}+\frac{q b^{2}}{\frac{a^{2}}{t_{1}}-c} \\
\bar{f}_{1} & =-p \frac{a^{2}}{t_{1}}+\frac{q b^{2}}{t_{1}-c} .
\end{aligned}
$$

Substituting these corrected boundary values (31) and (32) into equations (6) and (7) the corrected stress functions $\phi_{11}(\boldsymbol{z})$ and $\chi_{11}^{\prime}\left(\boldsymbol{z}_{,}\right)$can be obtained as follows,

$$
\begin{aligned}
\phi_{11}\left(z_{1}\right) & =-\frac{q}{2 \pi i} \int \frac{t_{1} d t_{1}}{\left(t_{1}-z_{1}\right)}-\frac{q b^{2}}{2 \pi i} \int \frac{d t_{1}}{\left(\frac{a^{2}}{t_{1}}-c\right)\left(t_{1}-z_{1}\right)} \\
& =I_{10}+I_{11} \\
& =-\frac{q b^{2} a^{2}}{c\left(c z_{1}-a^{2}\right)}
\end{aligned}
$$

and $x_{11}^{\prime}\left(z_{1}\right)=\frac{b a^{2}}{2 \pi i} \int \frac{d t_{1}}{t_{1}\left(t_{1}-z_{1}\right)}-\frac{q b^{2}}{2 \pi i} \int \frac{d t_{1}}{\left(t_{1}-c\right)\left(t_{1}-z_{1}\right)}$

$$
\begin{aligned}
& -\frac{p a^{2}}{2 \pi i} \int \frac{d t_{1}}{t_{1}^{2}}+\frac{q b^{2}}{2 \pi i} \int \frac{d t_{1}}{t_{1}\left(t_{1}-c\right)}-\frac{a^{2}}{z_{1}} \phi_{11}^{\prime}\left(z_{1}\right) \\
= & I_{12}+I_{13}+I_{14}+I_{15}-\frac{q a^{4} b^{2}}{z_{1}\left(c z_{1}-a^{2}\right)^{2}} \\
= & -\frac{p a^{2}}{Z}-\frac{q b^{2}}{c}-\frac{q a^{4} b^{2}}{Z,\left(c z_{1}-a^{2}\right)^{2}} .
\end{aligned}
$$


The stress functions with respect to the origin $O_{1}$ are expressed as the sum of the transformed stress functions and the corrected ones, and they are

$$
\phi_{1}\left(z_{1}\right)=\phi_{2}\left(z_{1}\right)+\phi_{11}\left(z_{1}\right)
$$

and

$$
x_{1}^{\prime}\left(z_{1}\right)=x_{21}^{\prime}\left(z_{1}\right)+x_{11}^{\prime}\left(z_{1}\right)
$$

Substituting the equations (30), (33) and (34) into the above expressions, the functions $\phi,(z$,$) and \boldsymbol{x}_{,}^{\prime}(\boldsymbol{z}$,$) are obtained as$

$$
\phi_{1}\left(z_{1}\right)=-\frac{q a^{2} b^{2}}{c\left(c z_{1}-a^{2}\right)}
$$

and

$$
\begin{aligned}
x_{1}^{\prime}\left(z_{1}\right)= & -\frac{q b^{2}}{z_{1}-c}-\frac{b a^{2}}{z_{1}}-\frac{q b^{2}}{c} \\
& -\frac{q a^{4} b^{2}}{z_{1}\left(c z_{1}-a^{2}\right)^{2}} .
\end{aligned}
$$

These stress functions are summarized in Group II of Appendix A.

(b) Boundary Condition Check at Radius a:

In order to check whether the stress functions (35) and (36) satisfy the boundary condition at the hole boundary of radius $a$, they are put in the equation (3), which gives

$$
\begin{aligned}
f= & -\frac{q a^{2} b^{2}}{c\left(c z_{1}-a^{2}\right)}+\frac{z_{1} q a^{2} b^{2}}{\left(\bar{z}_{1}-a^{2}\right)^{2}}-\frac{q b^{2}}{\left(\bar{z}_{1}-c\right)} \\
& -\frac{b a^{2}}{\bar{z}_{1}}-\frac{q b^{2}}{c}-\frac{q a^{4} b^{2}}{\bar{z}_{1}\left(c \bar{z}_{1}-a^{2}\right)^{2}}
\end{aligned}
$$

For the boundary value at $r_{1}=a$, putting $z_{1}=t_{1}=a e^{i \theta_{1}}$ in the above we get 


$$
\begin{aligned}
\left.f\right|_{1,=a}= & \frac{q a^{2} b^{2}}{c\left(c e^{i \theta_{1}}-a^{2}\right)}-\frac{a e^{i \theta_{1}} q a^{2} b^{2}}{\left(c a e^{-i \theta_{1}}-a^{2}\right)^{2}}-\frac{q b^{2}}{\left(a e^{-i \theta_{1}}-c\right)} \\
& -\frac{b a^{2}}{a e^{-i \theta_{1}}}-\frac{q b^{2}}{c}-\frac{q a^{4} b^{2}}{a e^{-i \theta_{1}}\left(c a e^{-i \theta_{1}}-a^{2}\right)^{2}} .
\end{aligned}
$$

Simplying this one can obtain

$$
\left.f\right|_{x_{1}=a}=-\not t_{1} .
$$

Thus the boundary condition at the smaller hole of radius a is satisfied as constant pressure $p$ by the stress functions (35) and (36).

III-3. FIRST AND SECOND APPROXIMATIONS:

The symmetric stress functions given by the equations (17) and (29) are considered as the first approximation (Group III, Appendix A).

This approximation does not take into account the interaction effect of the second hole. The single hole solution for an infinite plate for the case of the two different holes is simply added. This solution would be valid only If the distance between the two holes is fairly far.

The stress functions given by (26), (27) and (35), (36) are considered as the second approximation (Group IV, Appendix A). The solution obtained from these expressions gives fairly good results in the vicinity of the corresponding hole. 
III-4. THIRD APPROXIMATION:

(a) Transformation: Now from the Group IV the second approximation for the hole of radius a is considered, 1.e., equations (35) and (36), and their effect on the radius b w1ll be found out after transforming them into the co-ordinate system with respect to origin $\mathrm{O}_{2}$.

Transformation (19) is used for the following calculations. Using the transformation formulas for the rectilinear coordinates, it can be shown that

$$
\begin{aligned}
\phi_{112}\left(z_{2}\right) & =\phi_{11}\left(z_{2}\right) \\
& =-\frac{q a^{2} b^{2}}{c\left(c z_{2}+c^{2}-a^{2}\right)}
\end{aligned}
$$

and

$$
\begin{aligned}
& x_{112}^{\prime}\left(z_{2}\right)=c \phi_{11}^{\prime}\left(z_{2}\right)+x_{11}^{\prime}\left(z_{2}\right) \\
& =-\frac{p a^{2}}{z_{2}+c}-\frac{q b^{2}}{c}+\frac{q a^{2} b^{2}}{\left(z_{2}+c\right)\left(c z_{2}+c^{2}-a^{2}\right)} \cdot
\end{aligned}
$$

(b) Effect of the Other Hole of Radius b:

Substituting these transformed stress functions (37) and (38) into equation (3) and the resulting boundary condition $f$ into equation (18), the corrected boundary value at $r_{2}=b$ can be obtained as

$$
\begin{aligned}
f_{2}=-q t_{2} & +\frac{p a^{2}}{\left(\frac{b^{2}}{t_{2}}+c\right)}+\frac{q b^{2}}{c}-\frac{q a^{2} b^{2}}{c\left(c t_{2}+c^{2}-a^{2}\right)} \\
& -\frac{q a^{2} b^{2}\left(b^{2}+c t_{2}+\frac{c b^{2}}{t_{2}}+c^{2}-a^{2}\right)}{\left(\frac{b^{2}}{t_{2}}+c\right)\left(c \frac{b^{2}}{t_{2}}+c^{2}-a^{2}\right)^{2}}
\end{aligned}
$$


32

and

$$
\begin{aligned}
\bar{f}_{2}=-q \frac{b^{2}}{t_{2}}+\frac{p a^{2}}{t_{2}+c}-\frac{q b^{2}}{c}+\frac{q a^{2} b^{2}}{c\left(c \frac{b^{2}}{t_{2}}+c^{2}-a^{2}\right)} \\
-\frac{q a^{2} b^{2}\left(b^{2}+\frac{c b^{2}}{t_{2}}+c t_{2}+c^{2}-a^{2}\right)}{\left(t_{2}+c\right)\left(c t_{2}+c^{2}-a^{2}\right)^{2}} .
\end{aligned}
$$

Putting these corrected boundary values from equations (39) and (40) into (6) and (7) the corrected stress functions can be obtained as follows:

$$
\begin{aligned}
& \phi_{222}\left(z_{2}\right)=-\frac{p a^{2}}{2 \pi i} \int \frac{d t_{2}}{\left(\frac{b^{2}}{t_{2}}+c\right)\left(t_{2}-z_{2}\right)}-\frac{q b^{2}}{2 \pi i c} \int \frac{d t_{2}}{\left(t_{2}-z_{2}\right)} \\
& -\frac{q a^{2} b^{2}}{2 \pi i c} \int \frac{d t_{2}}{\left(c t_{2}+c^{2}-a^{2}\right)\left(t_{2}-z_{2}\right)}+\frac{q}{2 \pi i} \int \frac{t_{2} d t_{2}}{\left(t_{2}-z_{2}\right)} \\
& +\frac{q a^{2} b^{2}}{2 \pi i} \int \frac{\left(b^{2}+c t_{2}+\frac{c b^{2}}{t_{2}}+c^{2}-a^{2}\right) d t_{2}}{\left(\frac{b^{2}}{t_{2}}+c\right)\left(c \frac{b^{2}}{t_{2}}+c^{2}-a^{2}\right)^{2}\left(t_{2}-z_{2}\right)} \\
& =I_{16}+I_{17}+I_{18}+I_{19}+I_{20} \\
& =-\frac{p a^{2} b^{2}}{c\left(c z_{2}+b^{2}\right)}-\frac{q b^{4}}{c\left(b^{2}+c z_{2}\right)}+\frac{q b^{4} c^{2}\left\{\left(c^{2}-a^{2}\right)^{2}-3 a^{2} b^{2}\right\}}{\left(c^{2}-a^{2}\right)^{3}\left\{c b^{2}+z_{2}\left(c^{2}-a^{2}\right)\right\}} \\
& +\frac{q a^{2} b^{8} c^{3}}{\left(c \geq a^{2}\right)^{3}\left\{c b^{2}+z_{2}\left(c^{2}-a^{2}\right)\right\}^{2}} \\
& x_{222}^{\prime}\left(z_{2}\right)=-\frac{p a^{2}}{2 \pi i} \int \frac{d t_{2}}{\left(t_{2}+c\right)\left(t_{2}-z_{2}\right)}-\frac{q b^{6}}{2 \pi i c} \int \frac{d t_{2}}{\left(t_{2}-z_{2}\right)} \\
& -\frac{q a^{2} b^{2}}{2 \pi i c} \int \frac{d t_{2}}{\left(c \frac{b^{2}}{t_{2}}+c^{2}-a^{2}\right)\left(t_{2}-z_{2}\right)}+\frac{q b^{2}}{2 \pi i} \int \frac{d t_{2}}{t_{2}\left(t_{2}-z_{2}\right)}
\end{aligned}
$$


33

$$
\begin{aligned}
& +\frac{q a^{2} b^{2}}{2 \pi i} \int \frac{\left(b^{2}+c \frac{b^{2}}{t_{2}}+c t_{2}+c^{2}-a^{2}\right) d t_{2}}{\left(t_{2}+c\right)\left(c t_{2}+c^{2}-a^{2}\right)^{2}\left(t_{2}-z_{2}\right)} \\
& +\frac{p a^{2}}{2 \pi i} \int \frac{d t_{2}}{t_{2}\left(t_{2}+c\right)}+\frac{q b^{2}}{2 \pi i c} \int \frac{d t_{2}}{t_{2}}+\frac{q a^{2} b^{2}}{2 \pi i c} \int \frac{d t_{2}}{t_{2}\left(c \frac{b^{2}}{t_{2}}+c^{2}-a^{2}\right)} \\
& -\frac{q b^{2}}{2 \pi i} \int \frac{d t_{2}}{t_{2}^{2}}-\frac{q a^{2} b^{2}}{2 \pi i} \int \frac{\left(b^{2}+\frac{c b^{2}}{t_{2}}+c t_{2}+c^{2}-a^{2}\right) d t_{2}}{t_{2}\left(t_{2}+c\right)\left(c t_{2}+c^{2}-a^{2}\right)^{2}} \\
& -\frac{b^{2}}{z_{2}} \phi_{222}^{\prime}\left(z_{2}\right) \\
& =I_{21}+I_{22}+I_{23}+I_{24}+I_{25}+I_{26}+I_{27}+I_{28} \\
& +I_{29}+I_{30}-\frac{b^{2}}{z_{2}} \phi_{222}^{\prime}\left(z_{2}\right) \\
& =-\frac{q a^{2} b^{4}}{\left(c^{2}-a^{2}\right)\left\{\left(b^{2}+\left(c^{2}-a^{2}\right) z_{2}\right\}\right.}-\frac{q b^{2}}{z_{2}}-\frac{q a^{2} b^{4}}{\left(c^{2}-a^{2}\right)^{2} z_{2}} \\
& +\frac{p a^{2}}{c}+\frac{q b^{2}}{c}+\frac{2 q a^{2} b^{4} c^{2}}{c\left(c^{2}-a^{2}\right)^{3}}-\frac{p a^{2} b^{4}}{Z_{2}\left(b^{2}+c Z_{2}\right)^{2}} \\
& -\frac{q b^{6}}{z_{2}\left(b^{2}+c z_{2}\right)^{2}}+\frac{q b^{6} c^{2}\left\{\left(c^{2}-a^{2}\right)^{2}-3 a^{2} b^{2}\right\}}{\left(c^{2}-a^{2}\right)^{2}\left\{c b^{2}+\left(c^{2}-a^{2}\right) z_{2}\right\}^{2} z_{2}} \\
& +\frac{2 q a^{2} b^{10} c^{3}}{\left(c^{2} a^{2}\right)^{2}\left\{c b^{2}+\left(c^{2}-a^{2}\right) z_{2}\right\}^{3} z_{2}} \text {. }
\end{aligned}
$$

The third approximation to the stress functions is given by the following expressions, from equations (37), (38), and $(41),(42)$ :

$$
\phi_{2}\left(z_{2}\right)=\phi_{112}\left(z_{2}\right)+\phi_{222}\left(z_{2}\right)
$$


34

and

$$
x_{2}^{\prime}\left(z_{2}\right)=x_{112}^{\prime}\left(z_{2}\right)+x_{222}^{\prime}\left(z_{2}\right) .
$$

These stress functions are summarized in Group $V$ of Appendix A.

(c) Boundary Condition Check at Radius b:

Substituting from (43) and (44) into the equation (3) the stress functions give the boundary condition $f$ as

$$
\begin{aligned}
& f=-\frac{q a^{2} b^{2}}{c\left(c^{2}-a^{2}+c z_{2}\right)}-\frac{p a^{2} b^{2}}{c\left(b^{2}+c z_{2}\right)}-\frac{q b^{4}}{c\left(b^{2}+c Z_{2}\right)} \\
& -\frac{q b^{4} c^{2}\left\{\left(c^{2}-a^{2}\right)^{2}-3 a^{2} b^{2}\right\}}{\left(c^{2}-a^{2}\right)^{3}\left\{c b^{2}+\left(c^{2}-a^{2}\right) z_{2}\right\}}-\frac{q a^{2} b^{8} c^{5}}{\left(c^{2}-a^{2}\right)^{3}\left\{c b^{2}+\left(c^{2}-a^{2}\right) z_{2}\right\}^{2}} \\
& -\frac{q a^{2} b^{2}}{\left(c^{2}-a^{2}+c \overline{z_{2}}\right)^{2}}-\frac{b a^{2} b^{2} z_{2}}{\left(b^{2}+c \overline{z_{2}}\right)^{2}}-\frac{q b^{4} z_{2}}{\left(b^{2}+c \overline{Z_{2}}\right)^{2}} \\
& -\frac{9 b^{4} c^{2}\left\{\left(c^{2}-a^{2}\right)^{2}-3 a^{2} b^{2}\right\} Z_{2}}{\left(c^{2}-a^{2}\right)^{2}\left\{c b^{2}+\left(c^{2}-a^{2}\right) \overline{Z_{2}}\right\}^{2}}-\frac{29 a^{2} b^{8} c^{3} Z_{2}}{\left(c^{2}-a^{2}\right)^{2}\left\{c b^{2}+\left(c^{2}-a^{2}\right) \overline{Z_{2}}\right\}^{3}} \\
& -\frac{b a^{2}}{\left(c+\overline{Z_{2}}\right)}-\frac{q a^{2} b^{2}}{\left(c+\overline{Z_{2}}\right)\left(c^{2}-a^{2}+c \overline{Z_{2}}\right)}-\frac{q a^{2} b^{4}}{\left(c^{2}-a^{2}\right)\left\{c b^{2}+\left(c^{2}-a^{2}\right) \overline{Z_{2}}\right\}} \\
& -\frac{q b^{2}}{\bar{z}_{2}}-\frac{q a^{2} b^{4}}{\left(c^{2}-a^{2}\right)^{2} \overline{z_{2}}}-\frac{p a^{2}}{c}-\frac{2 q a^{2} b^{4} c^{2}}{c\left(c^{2}-a^{2}\right)^{3}} \\
& -\frac{p a^{2} b^{4}}{\bar{z}_{2}\left(b^{2}+c{\overline{z_{2}}}^{2}\right)^{2}}-\frac{q b^{6}}{\overline{z_{2}}\left(b^{2}+\left(\bar{z}_{2}\right)^{2}\right.} \\
& -\frac{q b^{6} c^{2}\left\{\left(c^{2}-a^{2}\right)^{2}-3 a^{2} b^{2}\right\}}{\left(c^{2}-a^{2}\right)^{2}\left\{c b^{2}+\left(c^{2}-a^{2}\right) \overline{x_{2}}\right\}^{2} \overline{z_{2}}} \\
& -\frac{2 q a^{2} b^{10} c^{3}}{\left(c^{2}-a^{2}\right)^{2}\left\{c b^{2}+\left(c^{2}-a^{2}\right) \bar{Z}_{2}\right\}^{3}{\overline{Z_{2}}}_{2}} \text {. }
\end{aligned}
$$


To evaluate the boundary value at the bigger hole of radius $b$, putting $z_{2}=t_{2}=b e^{i \theta_{2}}$ and $\bar{z}_{2}=\bar{z}_{2}=b e^{-i \theta_{2}}$ in the above expression and simplifying, it can be shown that

$$
\left.f\right|_{k_{2}=b}=-q t_{2} .
$$

Thus the boundary condition at the bigger hole of radius $b$ is satisfied as the constant pressure $q$ by the stress functions given by equations (43) and (44). 
RESULTS AND DISCUSSION

IV-1. STRESS FIELD DUE TO THE RIGID INCLUSION IN SINGLE HOLE:

If a rigid circular disc of radius $a+\varepsilon_{1}$ is inserted into a circular hole of radius a in an infinite plate $S$, then the
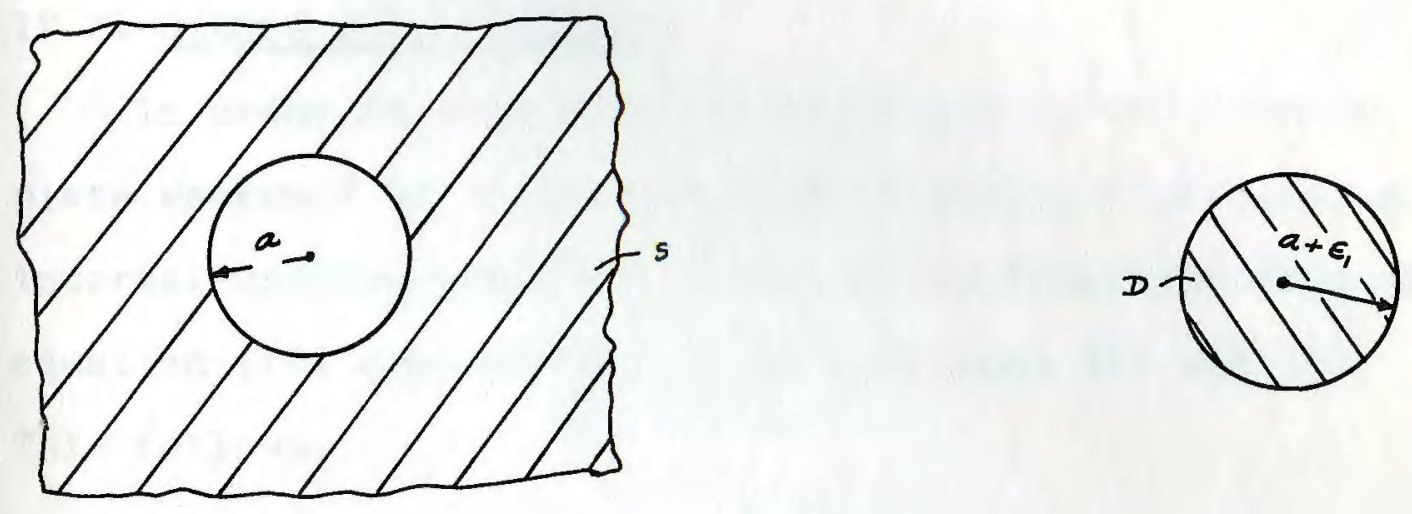

Figure 8 - Hole and Inclusion.

inclusion $D$ will produce some pressure assumed to be uniform along the boundary of contact.

In this case the radial displacement in the plate can be written as $[3]$,

$$
v_{k}^{s}=\frac{p a^{2}}{2 G r}
$$


and

$$
\varepsilon_{1}=\left.\left(v_{k}^{\delta}-v_{k}^{D}\right)\right|_{\lambda_{1}=a}=\frac{p_{a}}{2 G} .
$$

From this the pressure $p$ can be expressed in terms of $\epsilon_{1}$ as

$$
p=\frac{2 \epsilon_{1} G}{a} .
$$

Similarly if a rigid disc of radius $b+\varepsilon_{2}$ is inserted in the infinite plate having the hole of radius $b$, then the uniform pressure produced by this inclusion can be written as

$$
q=\frac{2 \epsilon_{2} G}{b} .
$$

IV-2. SINGLE HOLE SOLUTION:

In order to obtain the stress field in an infinite plate weakened by a circular hole of radius a and having the internal uniform pressure $p$, the stress functions from the equation (17) are substituted in equations (1) and (2). This follows,

$$
\left.\begin{array}{c}
b_{k_{1}}+b_{\theta_{1}}=0, \\
b_{\theta_{1}}-b_{k_{1}}+2 i \tau_{k_{1} \theta_{1}}=\frac{2 p a^{2}}{k_{1}^{2}} . \\
\tau_{k_{1} \theta_{1}}=0 \\
\left.\sigma_{\theta_{1}}=-b_{k_{1}}=\frac{\not a^{2}}{k_{1}^{2}}=\frac{p}{\left(\frac{k_{1}}{a}\right)^{2}} \cdot\right\}
\end{array}\right\}
$$

Hence

and 
The table $I$ shows the results from the equation (48).

Table 1

Single Hole Solution.

\begin{tabular}{|c|ll|}
\hline$\frac{r_{1}}{a}$ & $b_{\theta_{1}}=-b_{\mu_{1}}$ \\
\hline 1.0 & 1.0 & $p$ \\
1.25 & 0.64 & $p$ \\
1.5 & 0.445 & $p$ \\
2.0 & 0.25 & $p$ \\
3.0 & 0.111 & $p$ \\
4.0 & 0.0625 & $p$ \\
5.0 & 0.04 & $p$ \\
10.0 & 0.01 & $p$ \\
\hline
\end{tabular}

IV-3. FIRST APPROXIMATION:

(a) Special Case: Stresses along the line FG, 1.e. $\theta_{1}=0$ and $\theta_{2}=\pi$, are determined in this special case for the bigger hole radius $b$ to be twice of the smaller hole radius a, as shown in Figure 9. The distance between the two holes is varied from 3.1 to 9 times the radius $a$.

The stress functions from the Group (III) are substituted in equations (1) and (2) to give the following results in 
the nondimensional form:

$$
\sigma_{\theta,}=-\sigma_{k_{1}}=\frac{p}{\left(\frac{\phi_{1}}{a}\right)^{2}}
$$

$$
\tau_{R_{1}, \theta_{1}}=\tau_{R_{2} \theta_{2}}=0,
$$$$
\sigma_{\theta_{2}}=-b_{r_{2}}=\frac{q}{\left(\frac{k_{2}}{b}\right)^{2}} .
$$

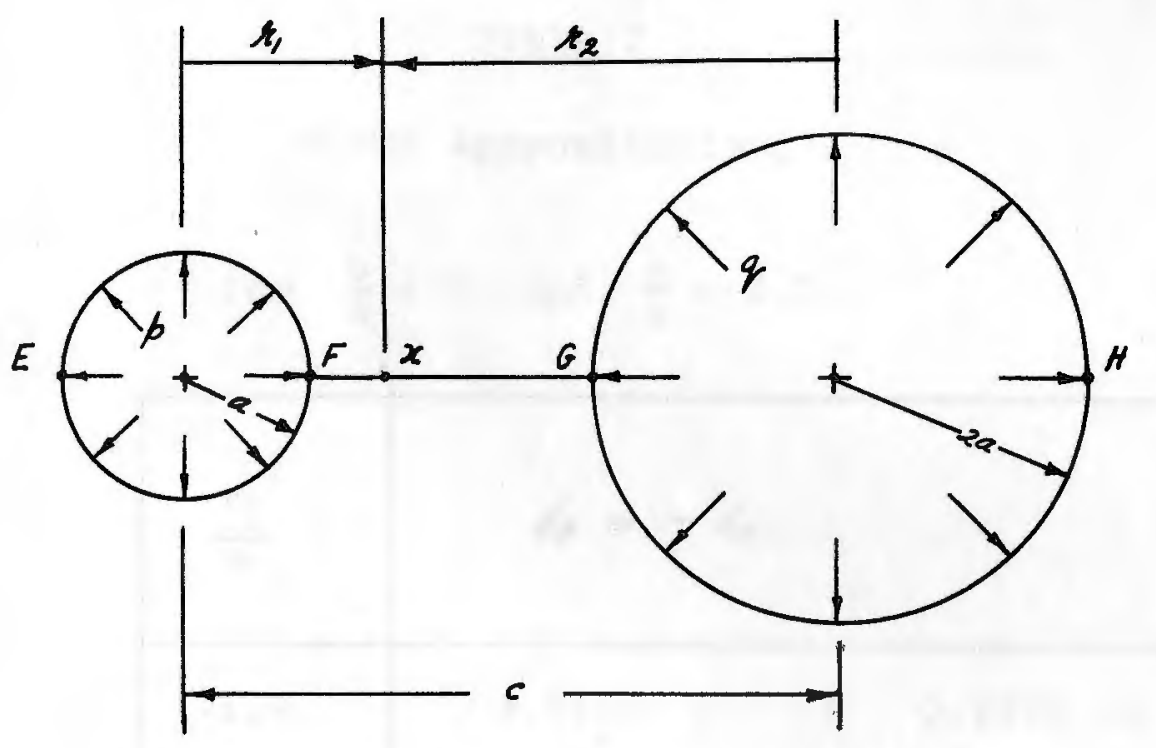

Figure 9 - Special Case $\mathrm{b}=2 \mathrm{a}$.

For a point $x$ on the line $F G$

$$
r_{2}=c-r_{1} \text {. }
$$

Substituting this in equation (50), one can write

$$
\sigma_{\theta_{2}}=-\sigma_{k_{2}}=\frac{\left(\frac{k}{a}\right)^{2} q}{\left(\frac{c}{a}-\frac{k_{1}}{a}\right)^{2}} \text {. }
$$

For the first approximation the two solutions are added, neglecting the mutual effects of the two holes. Thus the stresses with respect to origin $\mathrm{O}_{1}$ are given by, 


$$
\begin{aligned}
b_{\theta}=-b_{n} & =\frac{\left(\frac{b}{a}\right)^{2} q}{\left(\frac{c}{a}-\frac{s_{1}}{a}\right)^{2}}+\frac{p}{\left(\frac{a_{1}}{a}\right)^{2}} \\
& =b_{\theta_{1}}+6 \theta_{2}=-\left(b_{k_{1}}+b_{k_{2}}\right) .
\end{aligned}
$$

Putting different values in equation (51) the tables 2 and 3 are formed.

\section{Table 2}

First Approximation,

\begin{tabular}{|c|c|c|c|c|c|}
\hline$\frac{r_{1}}{a}$ & $\sigma_{\theta}=$ & $-\sigma_{1}$ & & & \\
\hline-1.4 & 0.5102 & $p$ & + & 0.1975 & $q$ \\
\hline-1.2 & 0.6944 & $p$ & + & 0.2163 & $q$ \\
\hline-1.0 & 1.0 & $p$ & + & 0.2380 & $q$ \\
\hline 1.0 & 1.0 & $p$ & + & 0.9070 & $q$ \\
\hline 1.1 & 0.8264 & $p$ & + & 1.0 & $q$ \\
\hline 5.1 & 0.0384 & $p$ & + & 1.0 & $q$ \\
\hline 5.3 & 0.0356 & $\mathrm{p}$ & + & 0.8264 & $q$ \\
\hline 5.5 & 0.0331 & $p$ & + & 0.6944 & $\mathrm{q}$ \\
\hline
\end{tabular}

$$
\text { for } \frac{b}{a}=2 \text { and } \frac{c}{a}=3.1 \text {. }
$$


Table 3

First Approximation,

for $\frac{b}{a}=2$ and $\frac{c}{a}$ varying.

\begin{tabular}{|c|c|c|c|c|c|c|}
\hline$\frac{c}{a}$ & $\frac{r_{1}}{a}$ & $\sigma_{\theta}=$ & & $b_{r}$ & & \\
\hline \multirow[t]{4}{*}{4.0} & -1.0 & 1.0 & $p$ & + & 0.1600 & $q$ \\
\hline & 1.0 & 1.0 & $p$ & + & 0.4444 & $q$ \\
\hline & 2.0 & 0.2500 & $p$ & + & 1.0 & $q$ \\
\hline & 6.0 & 0.0310 & $\mathrm{p}$ & + & 1.0 & $q$ \\
\hline \multirow[t]{4}{*}{5.0} & -1.0 & 1.0 & $\mathrm{p}$ & + & 0.1111 & $q$ \\
\hline & 1.0 & 1.0 & $\mathrm{p}$ & + & 0.2500 & $q$ \\
\hline & 3.0 & 0.1111 & $\mathrm{p}$ & + & 1.0 & $q$ \\
\hline & 7.0 & 0.0210 & $p$ & + & 1.0 & $q$ \\
\hline \multirow[t]{4}{*}{6.0} & -1.0 & 1.0 & $p$ & + & 0.0816 & $q$ \\
\hline & 1.0 & 1.0 & $p$ & + & 0.1600 & $q$ \\
\hline & 4.0 & 0.0625 & $p$ & + & 1.0 & $q$ \\
\hline & 8.0 & 0.0160 & $p$ & + & 1.0 & $q$ \\
\hline \multirow[t]{4}{*}{7.0} & -1.0 & 1.0 & $\mathrm{p}$ & $t$ & 0.0625 & $q$ \\
\hline & 1.0 & 1.0 & $p$ & + & 0.1111 & $q$ \\
\hline & 5.0 & 0.0400 & $p$ & + & 1.0 & $q$ \\
\hline & 9.0 & 0.0130 & $p$ & + & 1.0 & $q$ \\
\hline
\end{tabular}


(b) General Solution:

Let $\mathrm{x}$ be any point, given by $\mu^{i \theta_{1}}$ w.r.t. $o_{1}$ and $r_{2} e^{i \theta_{2}} \quad$ w.r.t. $\mathrm{O}_{2}$, then by simple geometry as shown in the Figure $10\left(\mathrm{XN} \perp \mathrm{O}_{1} \mathrm{O}_{2}\right)$, it can be shown that

$$
\mu_{2}^{2}=c^{2}-2 c \mu_{1} \cos \theta_{1}+\mu_{1}^{2} \text {. }
$$

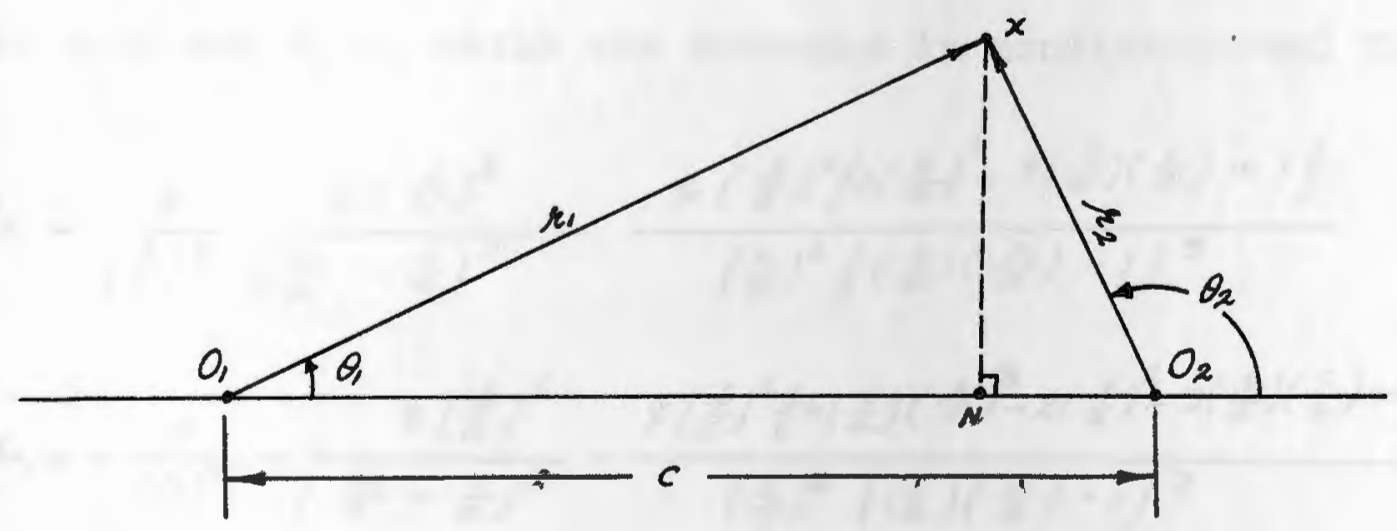

Figure 10 - Simple Geometry.

Using the equation (52) and the results from the section (a) the stresses are obtained as

$$
b_{\theta}=-b_{\mu}=\frac{p}{\left(\frac{k_{1}}{a}\right)^{2}}+\frac{\left(\frac{b}{a}\right)^{2} q}{\left\{\left(\frac{c}{a}\right)^{2}-2\left(\frac{c}{a}\right)\left(\frac{k_{1}}{a}\right) \cos \theta_{1}+\left(\frac{k_{1}}{a}\right)^{2}\right\}} .
$$

Substituting for $p$ and $q$ from equations (46) and (47) this can be written in the nondimensional form as given below:

$$
\frac{b_{\theta}}{G}=-\frac{b_{k}}{G}=\frac{2\left(\frac{\epsilon_{1}}{a}\right)}{\left(\frac{k_{1}}{a}\right)^{2}}+\frac{2\left(\frac{\epsilon_{2}}{a}\right)\left(\frac{b_{1}}{a}\right)}{\left\{\left(\frac{c}{a}\right)^{2}-\left(\frac{c}{a}\right)\left(\frac{r_{1}}{a}\right) \cos \theta_{1}+\left(\frac{k_{1}}{a}\right)^{2}\right\}} .
$$

The numerical calculations are carried out by means of digital computer for different values of $\frac{r_{1}}{a}, \theta_{1}, \frac{c}{a}, \varepsilon_{1}, \varepsilon_{2}$ and $\frac{b}{a}$. 
IV-4 SECOND APPROXIMATION:

(a) Special Case: Stresses along the line FG, Figure 9, i.e., $\theta_{1}=0$ and $\theta_{2}=\pi$ are calculated. Special case is taken into consideration for the calculations as $\mathrm{b}=2 \mathrm{a}$.

The stress functions from the Group IV are substituted in the equations (1) and (2) to give the following results for $\theta_{1}=0$ and $\theta_{2}=\pi$, which are arranged in nondimensional form.

$$
\begin{aligned}
& \sigma_{\theta_{1}}=\frac{p}{\left(\frac{k_{1}}{a}\right)^{2}}-\frac{q\left(\frac{b}{a}\right)^{2}}{\left(\frac{k_{1}}{a}-\frac{c}{a}\right)^{2}}-\frac{q\left(\frac{b}{a}\right)^{2}\left\{2\left(\frac{k_{1}}{a}\right)^{2}-3\left(\frac{k^{2}}{a}\right)\left(\frac{c}{a}\right)+1\right\}}{\left(\frac{k_{1}}{a}\right)^{2}\left\{\left(\frac{c}{a}\right)\left(\frac{k_{1}}{a}\right)-1\right\}^{3}} \\
& \sigma_{n_{1}}=-\frac{p}{\left(\frac{k_{1}}{a}\right)^{2}}-\frac{q\left(\frac{b}{a}\right)^{2}}{\left(\frac{k_{1}}{a}-\frac{c}{a}\right)^{2}}-\frac{q\left(\frac{b}{a}\right)^{2}\left\{4\left(\frac{c}{a}\right)\left(\frac{k_{1}}{a}\right)^{3}-2\left(\frac{k_{1}}{a}\right)^{2}-3\left(\frac{k_{1}}{a}\right)\left(\frac{c}{a}\right)+1\right\}}{\left(\frac{k_{1}}{a}\right)^{2}\left\{\left(\frac{c}{a}\right)\left(\frac{k_{1}}{a}\right)-1\right\}^{3}} \\
& \tau_{n_{1} \theta_{1}}=\tau_{r_{2} \theta_{2}}=0 \\
& \sigma_{\theta_{2}}=\frac{q}{\left(\frac{k_{1}}{b}\right)^{2}}-\frac{p\left(\frac{a}{b}\right)^{2}}{\left(\frac{k_{2}}{b}-\frac{c}{b}\right)^{2}}-\frac{p\left(\frac{a}{b}\right)^{2}\left\{2\left(\frac{k_{2}}{b}\right)^{2}-3\left(\frac{c}{b}\right)\left(\frac{k_{2}}{b}\right)+1\right\}}{\left(\frac{k_{2}}{b}\right)^{2}\left\{\left(\frac{c}{b}\right)\left(\frac{k_{2}}{b}\right)-1\right\}^{3}} \\
& \sigma_{r_{2}}=-\frac{q}{\left(\frac{k_{2}}{b}\right)^{2}}-\frac{p\left(\frac{a}{b}\right)^{2}}{\left(\frac{k_{2}}{b}-\frac{c}{b}\right)^{2}}-\frac{p\left(\frac{a}{b}\right)^{2}\left\{4\left(\frac{c}{b}\right)\left(\frac{k_{2}}{b}\right)^{3}-2\left(\frac{k_{2}}{b}\right)^{2}-3\left(\frac{c}{b}\right)\left(\frac{k_{2}}{b}\right)+1\right\}}{\left(\frac{k_{2}}{b}\right)^{2}\left\{\left(\frac{c}{b}\right)\left(\frac{k_{2}}{b}\right)-1\right\}^{3}}(59)
\end{aligned}
$$

From (55) and (58) the tangential stresses are calculated. $\sigma_{\theta_{1}}$ is valid near the hole of radius a and $\sigma_{\theta_{2}}$ near $b$. Both of them are matched at a certain point along FG. This gives a continuous solution along $P Q$.

Similar procedure is adopted for the radial stresses from (56) and (59). 
Putting different values for the variables in the above equations, following tables are calculated..

It can be seen that the above equations satisfy the particular case for only one hole in the infinite plate. Substituting $b=0$ in equations (55) and (56) and $a=0$ in the equations (58) and (59), it is observed that these equations reduce to (49) and (50) which are the results for the single hole solution.

\section{Table 4}

Second Approximation, for $c=4.0, p=q, b / a=2.0$.

\begin{tabular}{|c|l|l|l|}
\hline$\frac{r_{1}}{2}$ & $\frac{6 \theta_{1}}{b}$ & \multicolumn{2}{|l|}{} \\
\hline-2.0 & 0.4064 & & \\
-1.5 & 0.6984 & & \\
-1.0 & 1.6400 & 1.4858 & -1.5 \\
1.0 & 2.7778 & 1.2719 & -1.4 \\
1.2 & 1.7372 & 1.2336 & -1.25 \\
1.5 & 1.2622 & 1.2842 & -1.1 \\
1.6 & 1.2148 & 1.5064 & -1.0 \\
\hline 1.8 & 1.2082 & 2.0000 & 1.0 \\
\hline .0 & 1.2937 & 1.1111 & 1.25 \\
& & 0.7051 & 1.5 \\
\hline & & 0.4882 & Matching \\
\hline
\end{tabular}


Table 5

Second Approximation,

for $b / a=2.0$ and $c / a$ varying.

\begin{tabular}{|c|c|c|c|c|c|c|c|c|}
\hline$\frac{c}{a}$ & $\begin{array}{c}\frac{\mathrm{c}}{\mathrm{b}} \\
\text { (equivalent) }\end{array}$ & $\begin{array}{l}\text { Point } \\
\text { (Fig.9) }\end{array}$ & & $b_{c}$ & & & & $b_{r}$ \\
\hline \multirow[t]{4}{*}{3.1} & \multirow[t]{4}{*}{1.55} & $E$ & 1.0 & & + & 0.9518 & $q$ & $-1.0 p$ \\
\hline & & F & 1.0 & $p$ & + & 3.6281 & $q$ & $-1.0 \mathrm{p}$ \\
\hline & & G & 3.3058 & $\mathrm{p}$ & + & 1.0 & q & $-1.0 \mathrm{~g}$ \\
\hline & & $\mathrm{H}$ & 0.1538 & $\mathrm{p}$ & + & 1.0 & $q$ & $-1.0 \mathrm{~g}$ \\
\hline \multirow[t]{4}{*}{4.0} & \multirow[t]{4}{*}{2.0} & $E$ & 1.0 & $p$ & + & 0.6400 & $q$ & $-1.0 \mathrm{p}$ \\
\hline & & $F$ & 1.0 & $p$ & + & 1.7778 & $q$ & $-1.0 \mathrm{E}$ \\
\hline & & G & 1.0 & $p$ & + & 1.0 & $q$ & $-1.0 \mathrm{q}$ \\
\hline & & $\mathrm{H}$ & 0.1111 & $p$ & + & 1.0 & q & $-1.0 \mathrm{~g}$ \\
\hline \multirow[t]{4}{*}{5.0} & \multirow[t]{4}{*}{2.5} & $E$ & 1.0 & $\mathrm{p}$ & + & 0.4444 & $q$ & $-1.0 \mathrm{p}$ \\
\hline & & $\mathrm{F}$ & 1.0 & $p$ & + & 1.0 & $q$ & $-1.0 \mathrm{~F}$ \\
\hline & & $G$ & 0.4444 & $p$ & + & 1.0 & $q$ & $-1.0 \mathrm{~g}$ \\
\hline & & $\mathrm{H}$ & 0.0816 & $p$ & + & 1.0 & q & -1.00 \\
\hline \multirow[t]{4}{*}{6.0} & \multirow[t]{4}{*}{3.0} & $E$ & 1.0 & $\mathrm{p}$ & + & 0.3265 & $q$ & $-1.0 \mathrm{p}$ \\
\hline & & $F$ & 1.0 & $p$ & + & 0.6400 & $q$ & $-1.0 \mathrm{p}$ \\
\hline & & G & 0.2500 & $\mathrm{p}$ & + & 1.0 & $q$ & $-1.0 \mathrm{q}$ \\
\hline & & $\mathrm{H}$ & 0.0625 & $\mathrm{p}$ & + & 1.0 & $q$ & $-1.0 \mathrm{q}$ \\
\hline \multirow[t]{4}{*}{7.0} & \multirow[t]{4}{*}{3.5} & $E$ & 1.0 & $p$ & + & 0.2500 & $q$ & $-1.0 \mathrm{p}$ \\
\hline & & $\mathrm{F}$ & 1.0 & $p$ & + & 0.4444 & q & $-1.0 \mathrm{p}$ \\
\hline & & G & 0.1600 & $p$ & + & 1.0 & q & $-1.0 \mathrm{q}$ \\
\hline & & $\mathrm{H}$ & 0.0494 & $\mathrm{p}$ & + & 1.0 & q & $-1.0 \mathrm{q}$ \\
\hline \multirow[t]{4}{*}{8.0} & \multirow[t]{4}{*}{4.0} & $E$ & 1.0 & $p$ & + & 0.1975 & q & $-1.0 \mathrm{p}$ \\
\hline & & $\mathrm{F}$ & 1.0 & $p$ & + & 0.3265 & q & $-1.0 p$ \\
\hline & & G & 0.1111 & $p$ & + & 1.0 & q & $-1.0 \mathrm{q}$ \\
\hline & & $\mathrm{H}$ & 0.0400 & $p$ & + & 1.0 & $q$ & $-1.0 \mathrm{q}$ \\
\hline
\end{tabular}


Table 6

Maximum Tangential stress for $b / a$ varying.

Second Approximation.

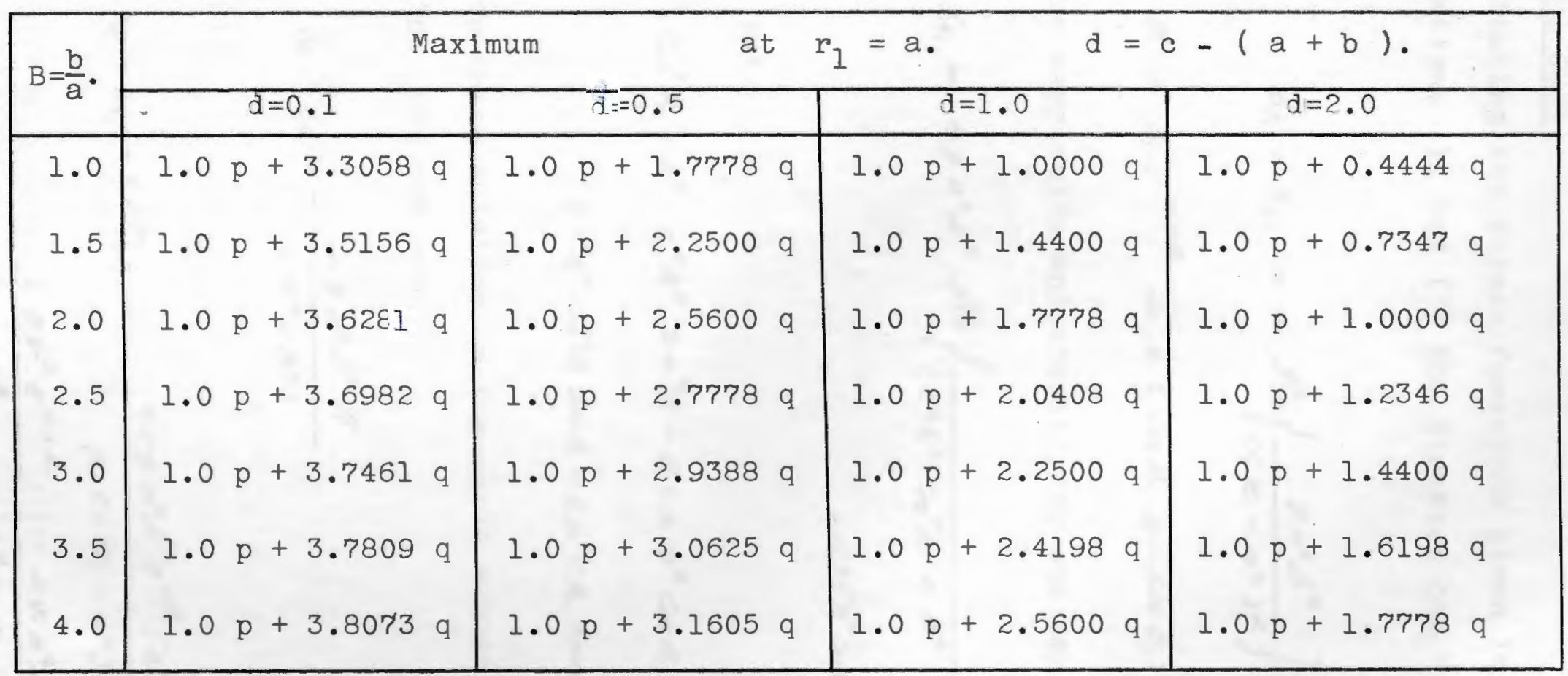


(b) General Case:

Substituting the stress functions given in the Group IV in the equations (1) and (2) the stresses can be calculated as follows,

from (1):

$$
b_{\theta_{1}}+b_{r_{1}}=4 \operatorname{Re}\left\{\frac{q a^{2} b^{2}}{\left(c x_{1}-a^{2}\right)^{2}}\right\} .
$$

Putting $z_{1}=k_{1} e^{ \pm i \theta_{1}}=k_{1}\left(\cos \theta_{1} \pm \sin \theta_{1}\right)$

in the above expression and simplifying one can get,

$$
\left.\begin{array}{rl}
b_{\theta_{1}}+b_{n_{1}}=4 q a^{2} b^{2} \operatorname{Re}\left\{\frac{1}{\left(c^{2} s_{1}^{2} \cos ^{2} \theta_{1}+a^{-4}-c^{2} s_{1}{ }^{2} \sin ^{2} \theta_{1}-2 c \lambda_{1} a^{2} \cos \theta_{1}\right.}\right. \\
\\
+i\left(2 c^{2} h_{1}^{2} \cos \theta_{1} \sin \theta_{1}-2 a^{2} c \lambda_{1} \sin \theta_{1}\right)
\end{array}\right\} .
$$

Now let us put

$$
c^{2} s_{1}^{2} \cos ^{2} \theta_{1}+a^{4}-c^{2} s_{1}^{2} \sin ^{2} \theta_{1}-2 c r_{1} a^{2} \cos \theta_{1}=A
$$

and

$$
2 c^{2} r_{1}^{2} \cos ^{2} \theta_{1} \sin \theta_{1}-2 a^{2} c r_{1} \sin \theta_{1}=B \text {. }
$$

Substituting these notation in the above expression and rationalizing, one can obtain

$$
b_{\theta_{1}}+b_{\mu_{1}}=-\frac{4 q a^{2} b^{2} A}{\left(A^{2}+B^{2}\right)} .
$$

And from (2):

$$
\begin{gathered}
b_{\theta_{1}}-b_{k_{1}}+2 i \tau_{n_{1} \theta_{1}}=-\frac{4 c q a^{2} b^{2} e^{i \theta_{1}}\left(x_{1}^{2}-a^{2}\right)}{\mu_{1}\left(c z_{1}-a^{2}\right)^{3}}+\frac{2 p a^{2}}{k_{1}^{2}} \\
-\frac{2 q b^{2} e^{2 i \theta_{1}}}{\left(z_{1}-c\right)^{2}}-\frac{2 q a^{4} b^{2}}{\mu_{1}^{2}\left(c z_{1}-a^{2}\right)^{2}} .
\end{gathered}
$$


Substituting for $z_{1}$ from (60), then simplifying and rationalizing, it can be obtained as,

$$
\begin{aligned}
b_{\theta_{1}}-b_{r_{1}} & +2 i \tau_{r_{1} \theta_{1}}=\frac{2 \beta a^{2}}{k_{1}^{2}}-\frac{4 q a^{2} b^{2} c\left(E \cos \theta_{1}+F \sin \theta_{1}\right)\left(r_{1}^{2}-a^{2}\right)}{r_{1}\left(E^{2}+F^{2}\right)} \\
& -\frac{2 q b^{2}\left(C \cos 2 \theta_{1}+D \sin 2 \theta_{1}\right)}{\left(G^{2}+D^{2}\right)}-\frac{2 q a^{2} b^{2} A}{r_{1}^{2}\left(A^{2}+B^{2}\right)} \\
& -i\left[-\frac{4 q a^{2} b^{2} c\left(E \sin \theta_{1}-F \cos \theta_{1}\right)\left(R_{1}^{2}-a^{2}\right)}{r_{1}\left(E^{2}+F^{2}\right)}\right. \\
& \left.-\frac{2 q b^{2}\left(G \sin 2 \theta_{1}-D \cos 2 \theta_{1}\right)}{\left(C^{2}+D^{2}\right)}-\frac{2 q a^{4} b^{2} B}{R_{1}^{2}\left(A^{2}+B^{2}\right)}\right]
\end{aligned}
$$

where $A$ and $B$ are given by (61) and (62) respectively and

$$
\begin{gathered}
C=r_{1}^{2} \cos ^{2} \theta_{1}+c^{2}-r_{1}^{2} \sin ^{2} \theta_{1}-2 c r_{1} \cos \theta_{1}, \\
D=2 r_{1}^{2} \sin \theta_{1} \cos \theta_{1}-2 c r_{1} \sin \theta_{1}, \\
E=c^{3} r_{1}^{3} \cos ^{3} \theta_{1}-a^{6}+3 a^{4} c r_{1} \cos \theta_{1}-3 a^{2} c^{2} r_{1}^{2} \cos ^{2} \theta_{1}, \\
\quad-3 c^{3} r_{1}^{3} \sin ^{2} \theta_{1} \cos \theta_{1}+3 a^{2} c^{2} r_{1}^{2} \sin ^{2} \theta_{1}, \\
F=3 c^{3} r_{1}^{3} \cos ^{2} \theta_{1} \sin \theta_{1}+3 a^{4} c r_{1} \sin \theta_{1} \\
\quad-6 a^{2} c^{2} r_{1}^{2} \sin \theta_{1} \cos \theta_{1}-c^{3} r_{1}^{3} \sin ^{3} \theta_{1} .
\end{gathered}
$$

Separating the real and imaginary parts of equation (64) two equations can be obtained and with the third equation (63) the three stresses can be determined as follows, 
49

$$
\begin{aligned}
& \sigma_{\theta,}=\frac{p a^{2}}{k_{1}^{2}}-\frac{2 q a^{2} b^{2} c\left(r_{1}^{2}-a^{2}\right)\left(E \cos \theta_{1}+F \sin \theta_{1}\right)}{r_{1}\left(E^{2}+F^{2}\right)} \\
& +\frac{q b^{2}\left(G \cos 2 \theta_{1}+D \sin 2 \theta_{1}\right)}{\left(C^{2}+D^{2}\right)}+\frac{q a^{2} b^{2} A\left(2 b^{2}+a^{2}\right)}{\beta_{1}^{2}\left(A^{2}+B^{2}\right)}, \\
& b_{k,}=-\frac{p a^{2}}{\xi_{1}^{2}}+\frac{2 q a^{2} b^{2} c\left(\mu_{1}^{2}-a^{2}\right)\left(E \cos \theta_{1}+f \sin \theta_{1}\right)}{\xi_{1}\left(E^{2}+F^{2}\right)} \\
& -\frac{q b^{2}\left(G^{\prime} \cos 2 \theta_{1}+D \sin 2 \theta_{1}\right)}{\left(G^{2}+D^{2}\right)}+\frac{q a^{2} b^{2} A\left(2 A_{1}^{2}-a^{2}\right)}{t_{1}^{2}\left(A^{2}+B^{2}\right)} \\
& \tau_{h, \theta_{1}}=-\frac{2 q a^{2} b^{2} c\left(E \sin \theta_{1}-F \cos \theta_{1}\right)\left(H_{1}^{2}-a^{2}\right)}{r_{1}\left(\sigma^{2}+F^{2}\right)} \\
& +\frac{q b^{2}\left(C \sin 2 \theta_{1}-D \cos 2 \theta_{1}\right)}{\left(C^{2}+D^{2}\right)}-\frac{q a^{4} b^{2} B}{R_{1}^{2}\left(A^{2}+B^{2}\right)} .
\end{aligned}
$$

The above results can be put in the non dimensional form by dividing the four terms of equations (65) and (66) respectively by $\mathrm{a}^{2}, \mathrm{a}^{13}, \mathrm{a}^{4}, \mathrm{a}^{10}$ and the three terms of equation (6?) by $\mathrm{a}^{13}, \mathrm{a}^{4}$ and $\mathrm{a}^{10}$ respectively. These equations are solved by computer and while programing the notation given in the Nomenclature $(I-3)$ is used. Thus the equations (65), (66) and (6?) will now reduce to the following.

$$
\begin{aligned}
\sigma_{\theta_{1}} & =\left[\frac{1}{R^{2}}\right] p+\left[-\frac{2 B^{2} C\left(R^{2}-1\right)\left(E P\left(\cos \theta_{1}+F P \sin \theta_{1}\right)\right.}{R\left(E P^{2}+F P^{2}\right)}\right. \\
& \left.-\frac{B^{2}\left(C P \cos 2 \theta_{1}+D P \sin 2 \theta_{1}\right)}{\left(C P^{2}+D P^{2}\right)}-\frac{B^{2}(A P)\left(2 P^{2}+1\right)}{R^{2}\left(A P^{2}+B P^{2}\right)}\right] q, \\
\sigma_{k_{1}} & =\left[-\frac{1}{R^{2}}\right] p+\left[\frac{2 B^{2} C\left(R^{2}-D\left(E P \cos \theta_{1}+F P \sin \theta_{1}\right)\right.}{R\left(E P^{2}+F P^{2}\right)}\right. \\
& \left.-\frac{B^{2}\left(G P \cos 2 \theta_{1}+D P \sin 2 \theta_{1}\right)}{\left(C P^{2}+D P^{2}\right)}-\frac{B^{2}(A P)\left(2 R^{2}-1\right)}{R^{2}\left(A P^{2}+B P^{2}\right)}\right] q,
\end{aligned}
$$


50

$$
\begin{aligned}
\tau_{A, \theta} & =\left[-\frac{2 B^{2} C\left(E P \sin \theta_{1}-F P \cos \theta_{1}\right)\left(R^{2}-1\right)}{R\left(E P^{2}+F P^{2}\right)}\right. \\
& \left.-\frac{B^{2}\left(C P \sin 2 \theta_{1}-D P \cos 2 \theta_{1}\right)}{\left(C P^{2}+D P^{2}\right)}-\frac{B^{2}(B P)}{R^{2}\left(A P^{2}+B P^{2}\right)}\right] \&,
\end{aligned}
$$

where in terms of the computer program notations,

$$
\begin{aligned}
A P & =c^{2} R^{2} \cos ^{2} \theta_{1}+1-c^{2} R^{2} \sin ^{2} \theta_{1}-2 c R \cos \theta_{1}, \\
B P= & 2 c^{2} R^{2} \cos \theta_{1} \sin \theta_{1}-2 c R \sin \theta_{1}, \\
C P= & R^{2} \cos ^{2} \theta_{1}+c^{2}-R^{2} \sin ^{2} \theta_{1}-2 c R \cos \theta_{1}, \\
D P= & 2 R^{2} \sin \theta_{1} \cos \theta_{1}-2 c R \sin \theta_{1}, \\
E P= & c^{3} R^{3} \cos ^{3} \theta_{1}-1+3 c R \cos \theta_{1}-3 c^{2} R^{2} \cos ^{2} \theta_{1}, \\
& \quad+3 c^{3} R^{5} \sin ^{2} \theta_{1} \cos \theta_{1}+3 c^{2} R^{2} \sin ^{2} \theta_{1},
\end{aligned}
$$

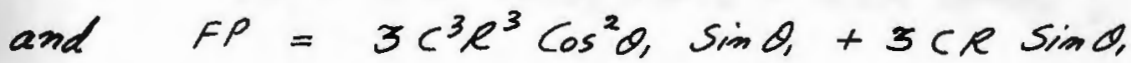

$$
-\sigma c^{2} e^{2} \sin \theta_{1} \cos \theta_{1}-c^{3} e^{3} \sin ^{3} \theta_{1} .
$$

Similarly from the other two stress functions the results with respect to the origin $\mathrm{O}_{2}$ can be obtained as,

$$
\begin{aligned}
b_{\theta_{2}} & =\left[\frac{1}{R^{2}}\right] q-\left[-\frac{2 A^{2} C\left(R^{2}-1\right)\left(w P \cos \theta_{2}+x P \sin \theta_{2}\right)}{R\left(w P^{2}+x P^{2}\right)}\right. \\
& \left.-\frac{A^{2}\left(v P \cos 2 \theta_{2}+V P \sin 2 \theta_{2}\right)}{\left(U P^{2}+V P^{2}\right)}-\frac{A^{2}(s P)\left(2 R^{2}+1\right)}{R^{2}\left(S P^{2}+T P^{2}\right)}\right] p,(71)
\end{aligned}
$$


51

$$
\begin{aligned}
\sigma_{R_{2}}= & {\left[-\frac{1}{R^{2}}\right] q-\left[\frac{2 A^{2} C\left(R^{2}-1\right)\left(w P \cos \theta_{2}+x P \sin \theta_{2}\right)}{R\left(w P^{2}+x P^{2}\right)}\right.} \\
& \left.-\frac{A^{2}\left(V P \cos 2 \theta_{2}+V P \sin 2 \theta_{2}\right)}{\left(U P^{2}+V P^{2}\right)}-\frac{A^{2}(S P)\left(2 R^{2}-1\right)}{R^{2}\left(S P^{2}+T P^{2}\right)}\right] p,(72) \\
\tau_{R_{2} \theta_{2}}= & {\left[-\frac{2 A^{2} C\left(R^{2}-1\right)\left(W P \sin \theta_{2}-x P \cos \theta_{2}\right)}{R\left(W P^{2}+x P^{2}\right)}\right] p, \quad \text { (73) } } \\
& \left.-\frac{A^{2}\left(V P \sin 2 \theta_{2}-V P \cos 2 \theta_{2}\right)}{\left(V P^{2}+V P^{2}\right)}-\frac{A^{2}(T P)}{R^{2}\left(S P^{2}+T P^{2}\right)}\right] p
\end{aligned}
$$

where in terms of the computer program notations,

$$
\begin{aligned}
& S P=c^{2} R^{2} \cos ^{2} \theta_{2}+1-c^{2} R^{2} \sin ^{2} \theta_{2}+2 c R \cos \theta_{2}, \\
& T P=2 c R \sin \theta_{2}+2 c^{2} R^{2} \sin \theta_{2} \cos \theta_{2}, \\
& U P=R^{2} \cos ^{2} \theta_{2}+c^{2}-R^{2} \sin ^{2} \theta_{2}+2 c R \cos \theta_{2}, \\
& V P=2 R^{2} \cos \theta_{2} \sin \theta_{2}+2 c R \sin \theta_{2}, \\
& W P=c^{3} R^{3} \cos ^{3} \theta_{2}+1+3 c R \cos \theta_{2}+3 c^{2} R^{2} \cos ^{2} \theta_{2} \\
& \quad-3 c^{3} R^{3} \sin \theta_{2}^{2} \cos \theta_{2}-3 c^{2} R^{2} \sin ^{2} \theta_{2}, \\
& X P=3 c^{3} R^{3} \cos ^{2} \theta_{2} \sin _{2}+3 c R \sin _{2} \theta_{2}, \\
& \quad+\sigma^{2} R^{2} \sin \theta_{2} \cos \theta_{2}-c^{3} R^{3} \sin ^{3} \theta_{2} .
\end{aligned}
$$

Equations (68) through (73) are programmed to give the stresses at different points when the distance $c$ is varied for the case of $b=2 a, i . e ., B=2.0$ or $A=0.5$. The variation of stress distribution along radial direction are plotted. A sample of the computer program is given in Appendix $C$. 


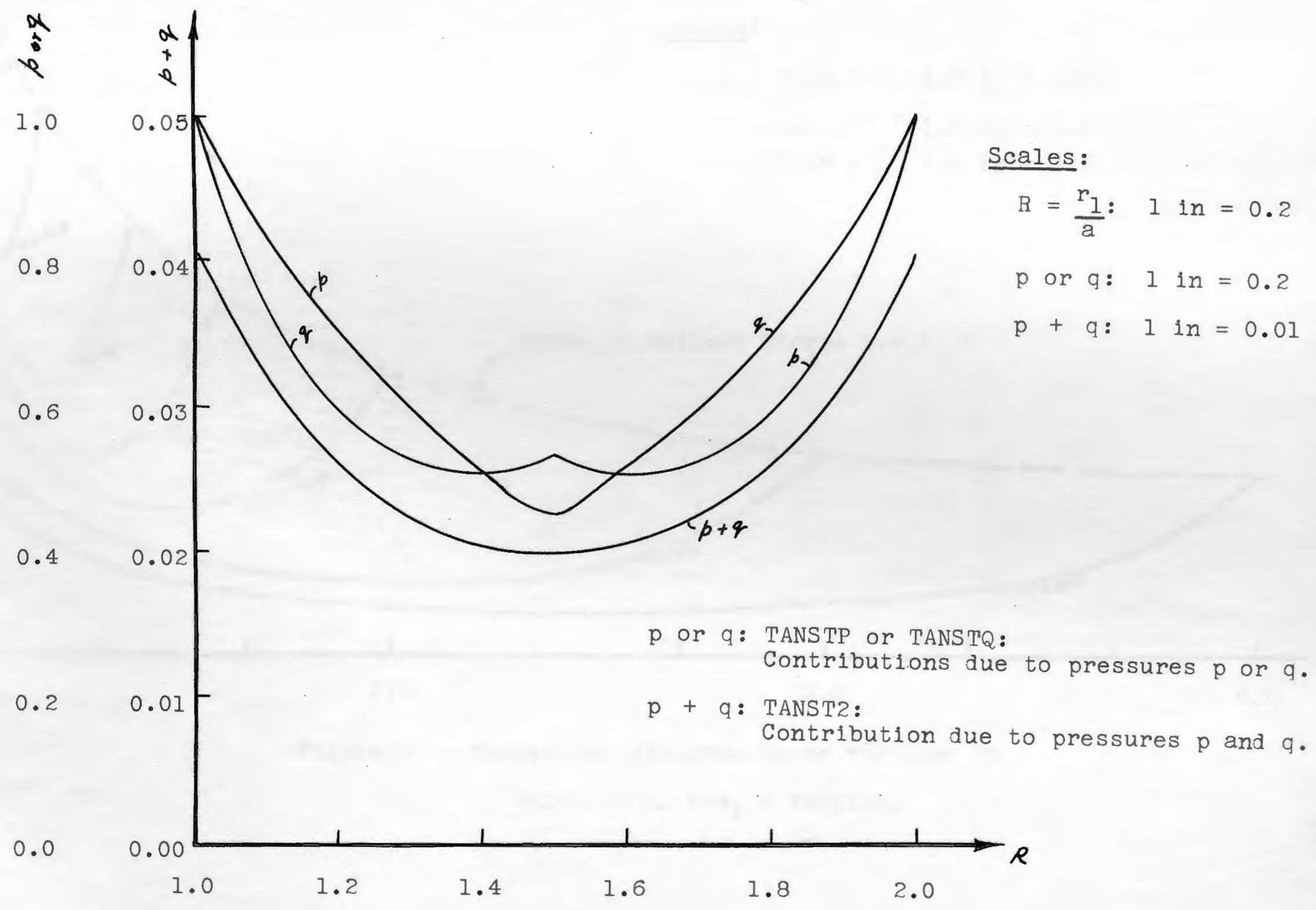

Figure 11 - Tangential Stresses Along the Line $F G$. $A N G=0$ or $\pi, b=a, c=3 a$. 


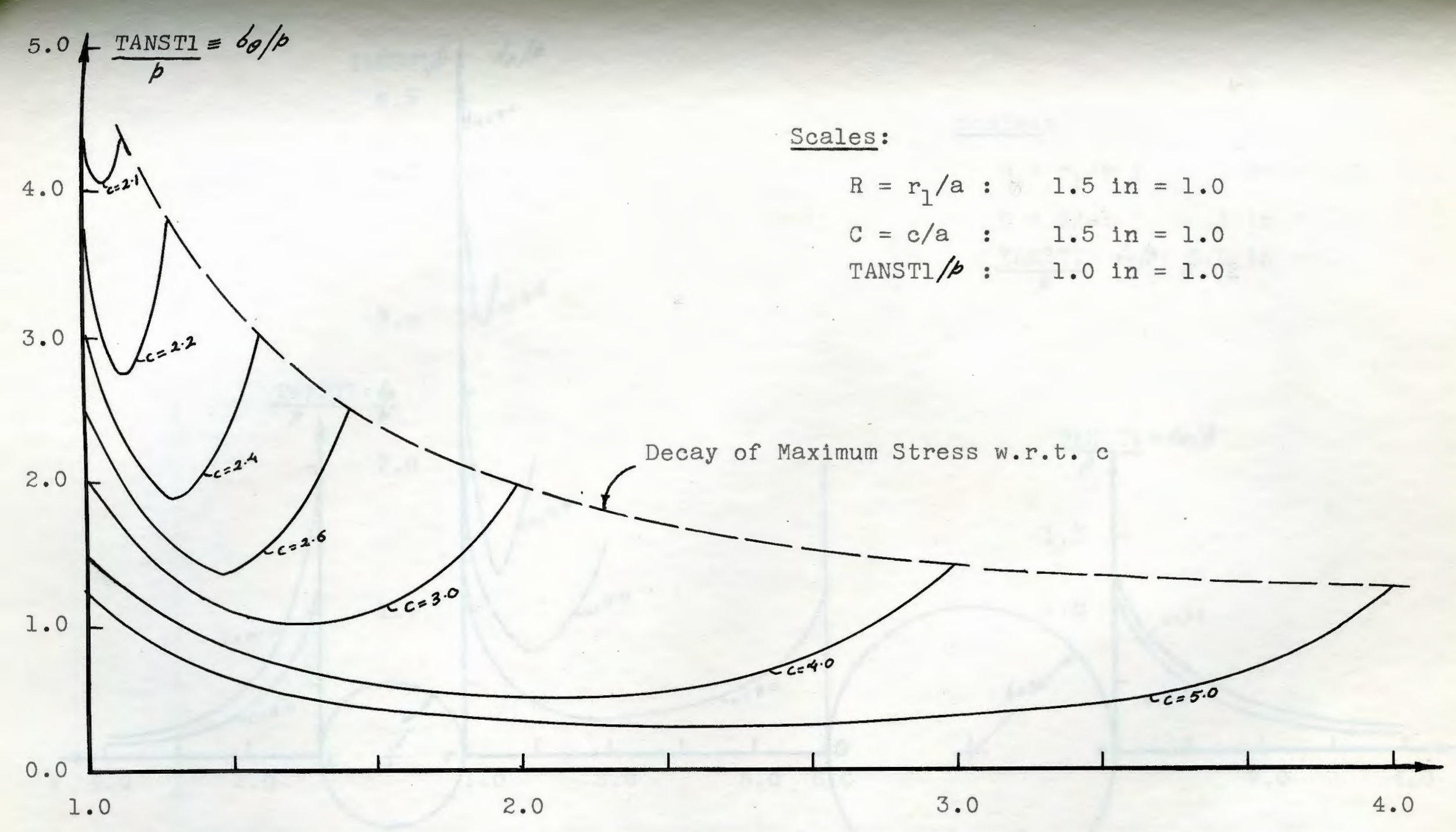

Figure 12 - Tangential Stresses Along the Line FG $A N G=0$ or $\pi, b=a, c$ varying. 


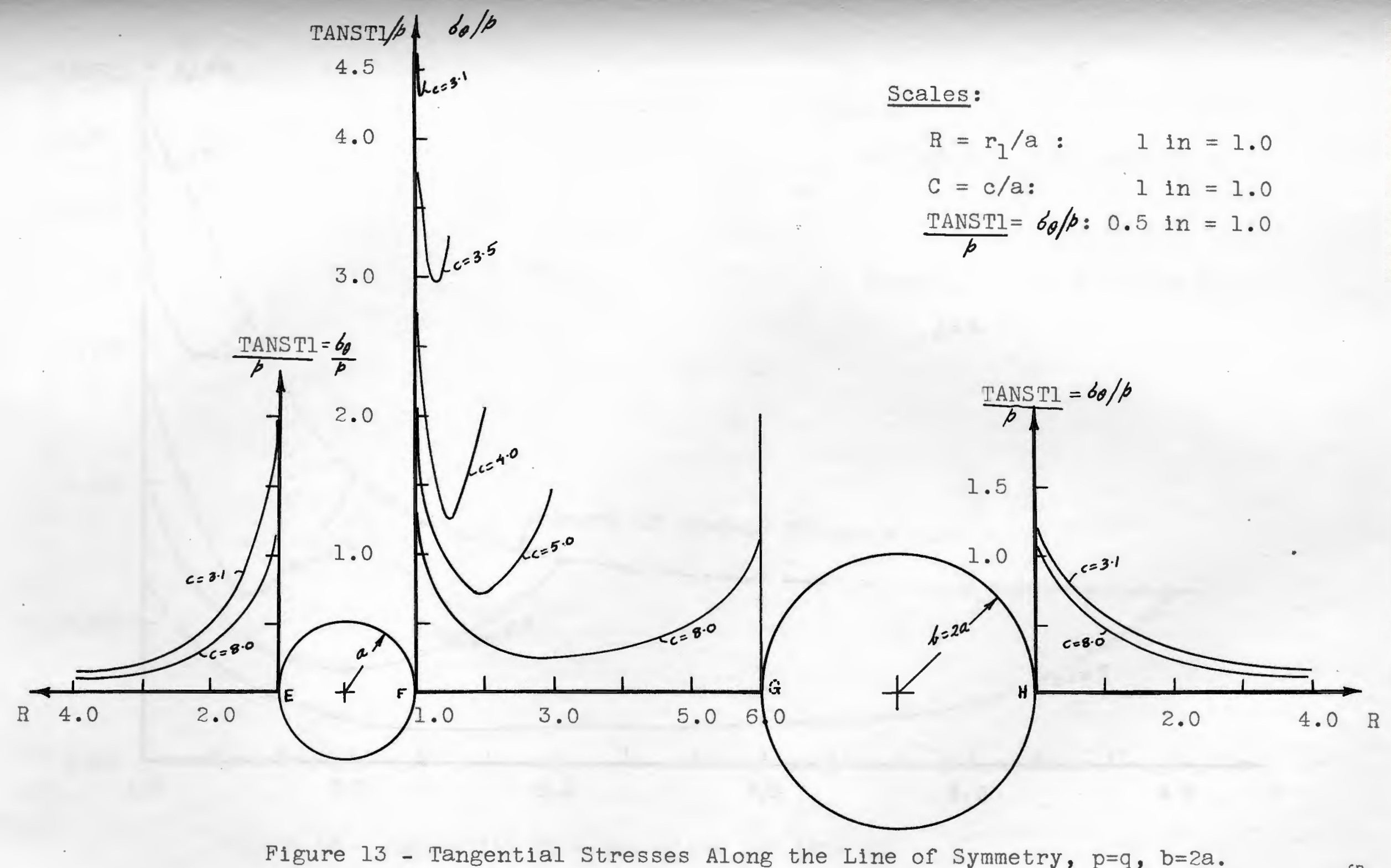

Figure 13 - Tangential Stresses Along the Line of Symmetry, $p=q, b=2 a$. 


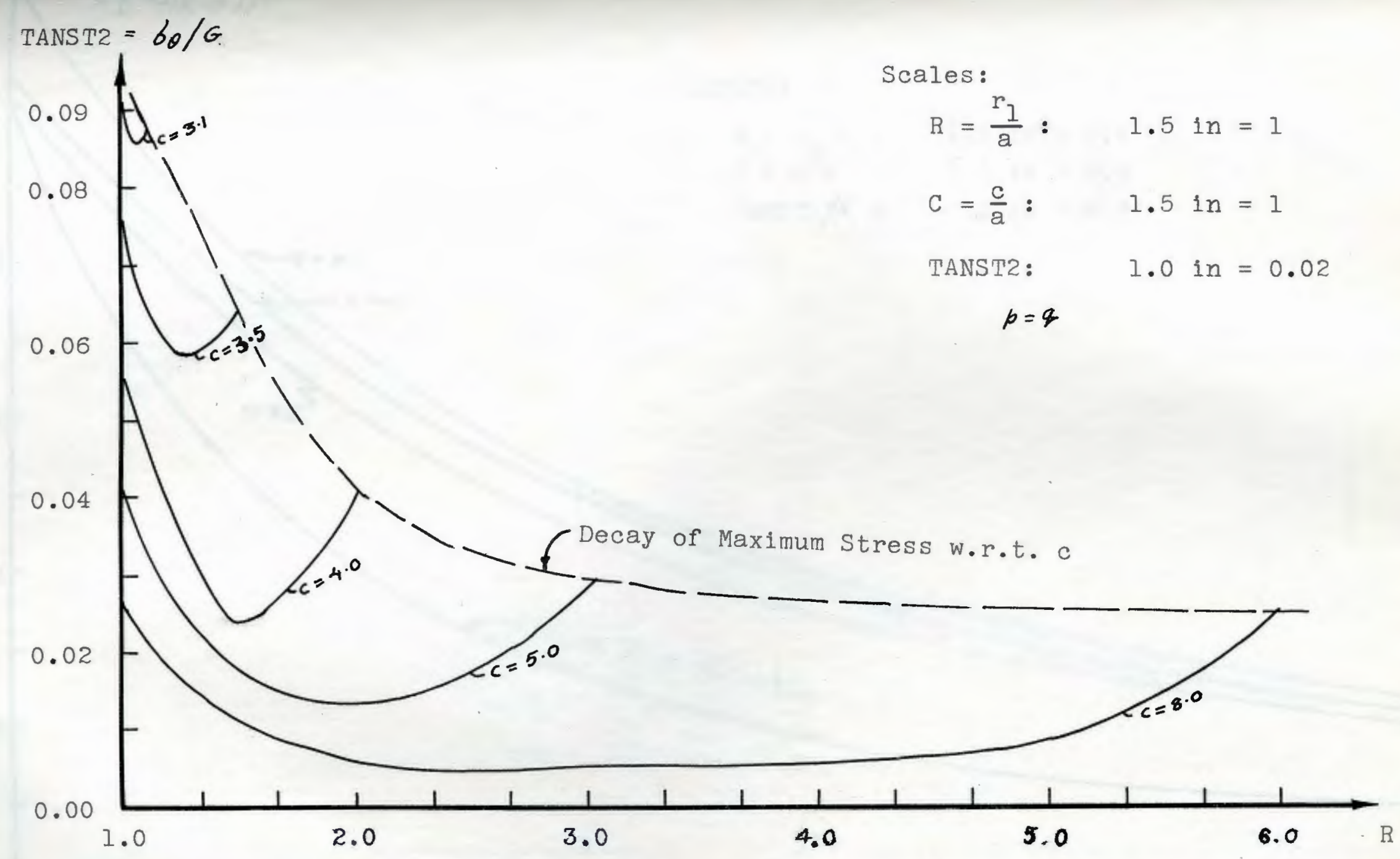

Figure 14 - Tangential Stresses Along the Line FG Ang $=0$ or $\pi, b=2 a, c$ varying. 


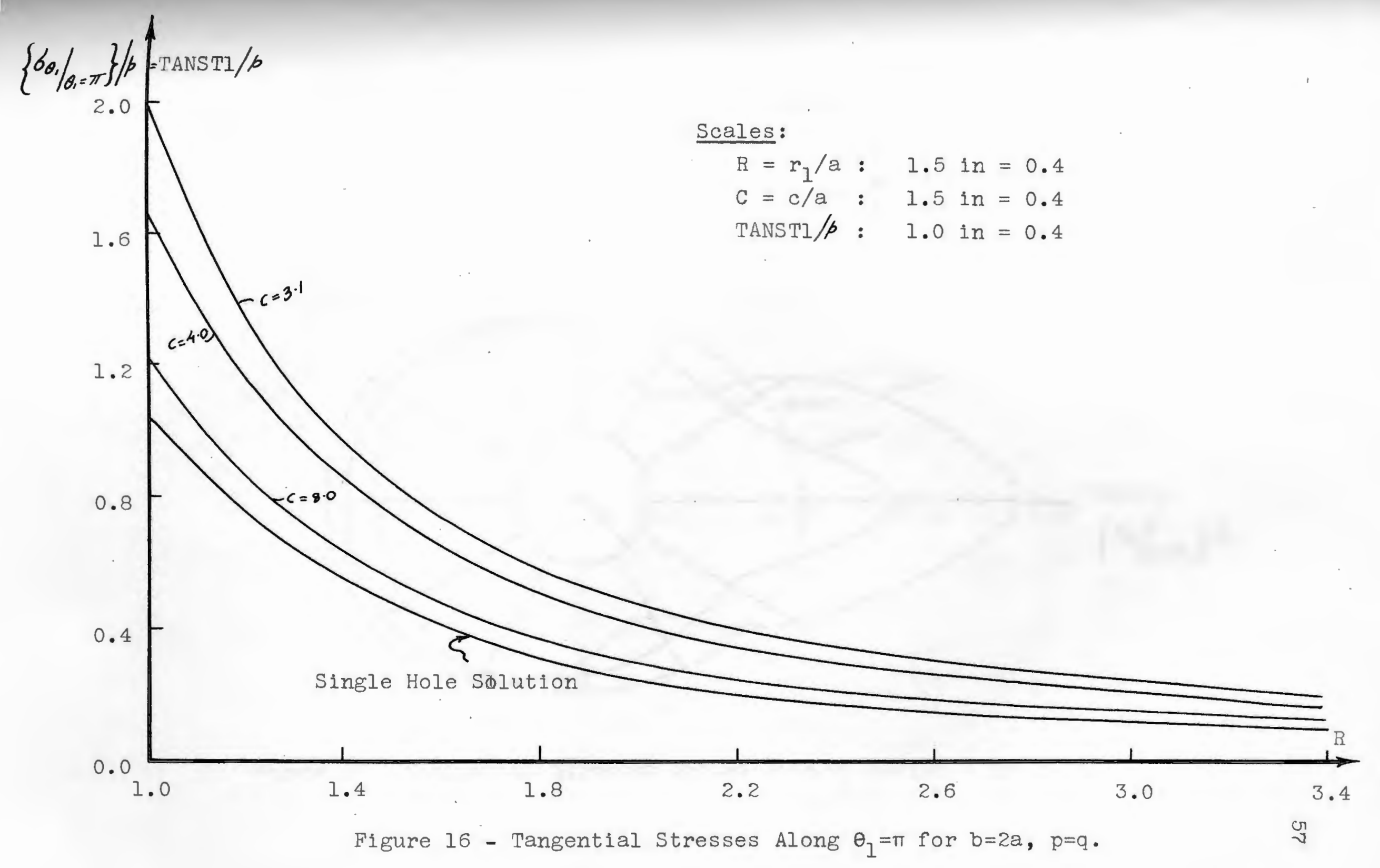




\section{Scales:}

$$
\begin{gathered}
\text { TANST2 }: 1 \text { in }=0.02 \\
c=c / a \\
b=2 a .
\end{gathered}
$$

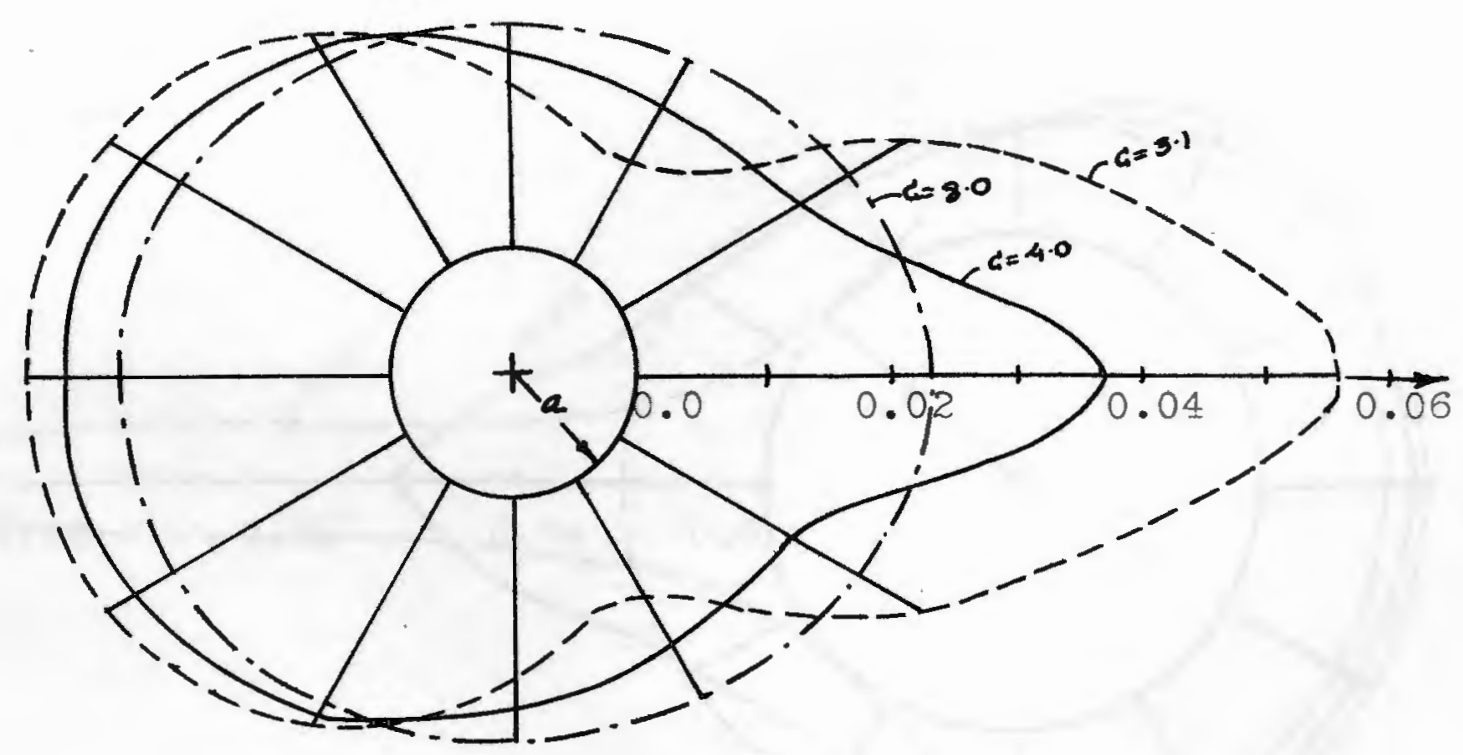

TANST2

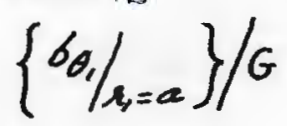

Figure 17 - Tangential Stresses Around Hole of Radius a for $p=2 q$. 
Figure 18 - Tangential Stresses Around Hole of Radius b for $p=2 q$.

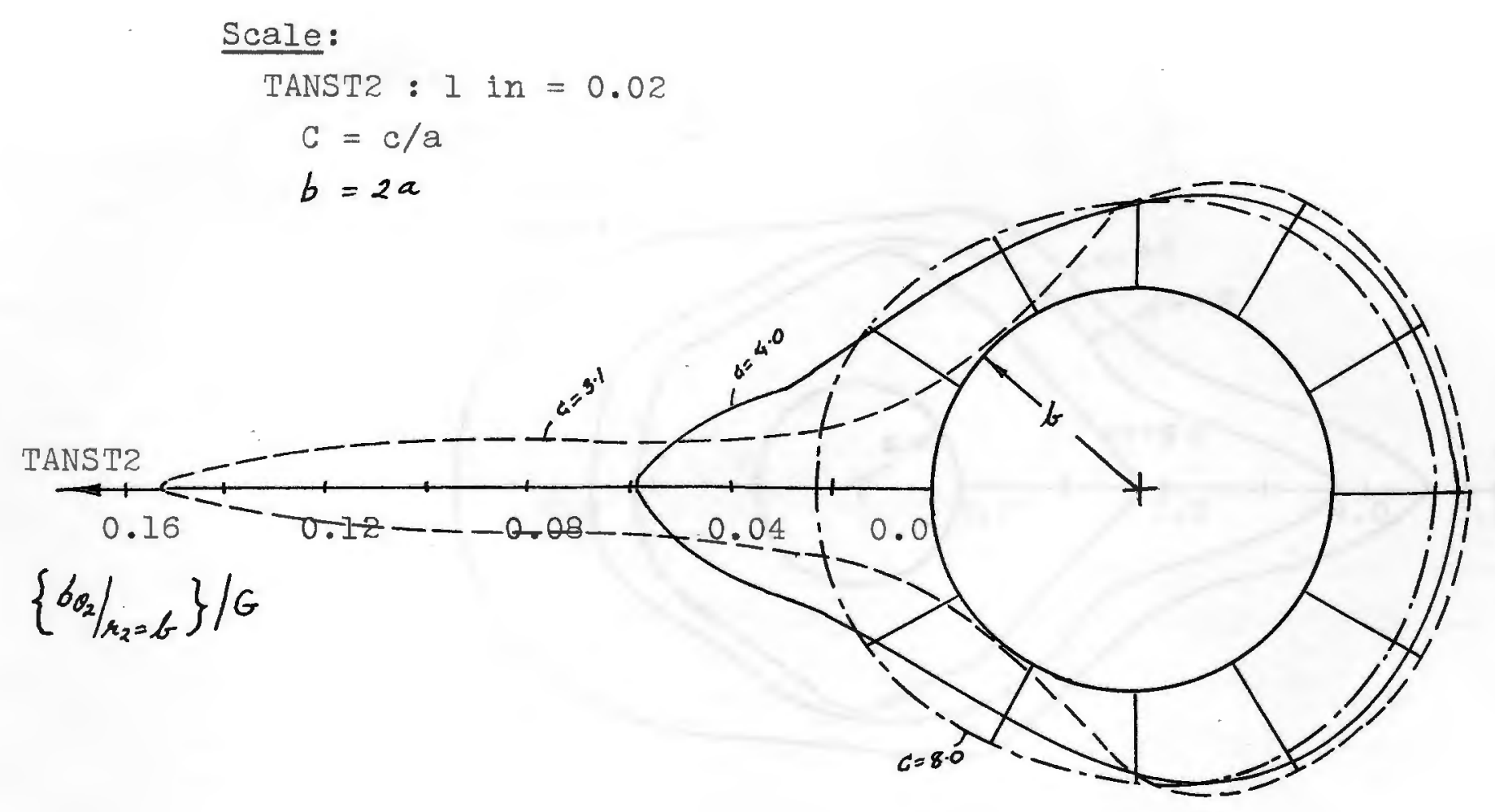


Figure 19 - Tangential Stresses Around Hole of Radius a for $p=q$.

\section{Scale:}

TANST1 : 1 in $=2.0$

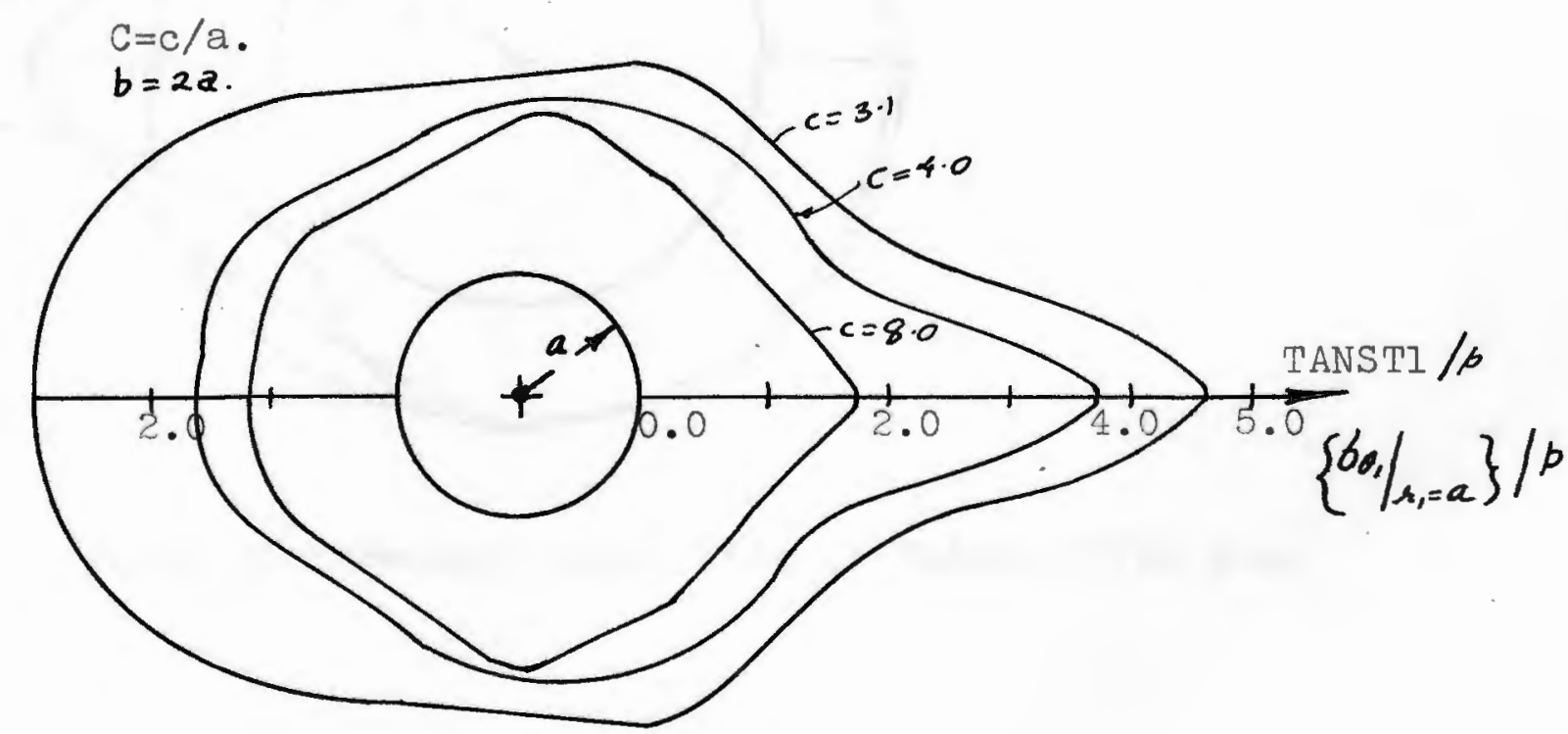




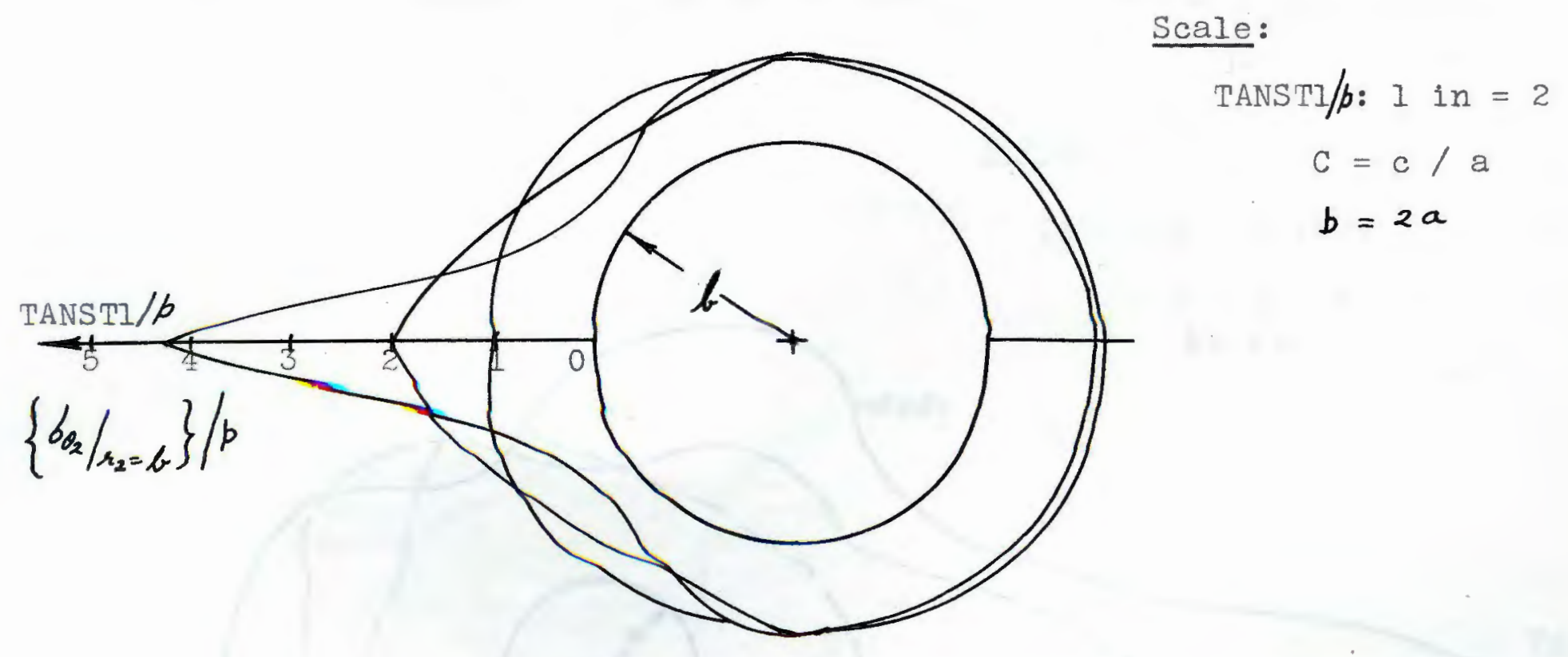

Figure 20 - Tangential Stresses Around Hole of Radius b for $p=q$. 
Figure 21 - Tangential Stresses Around Hole of Radius a for $p=0.5 q$.

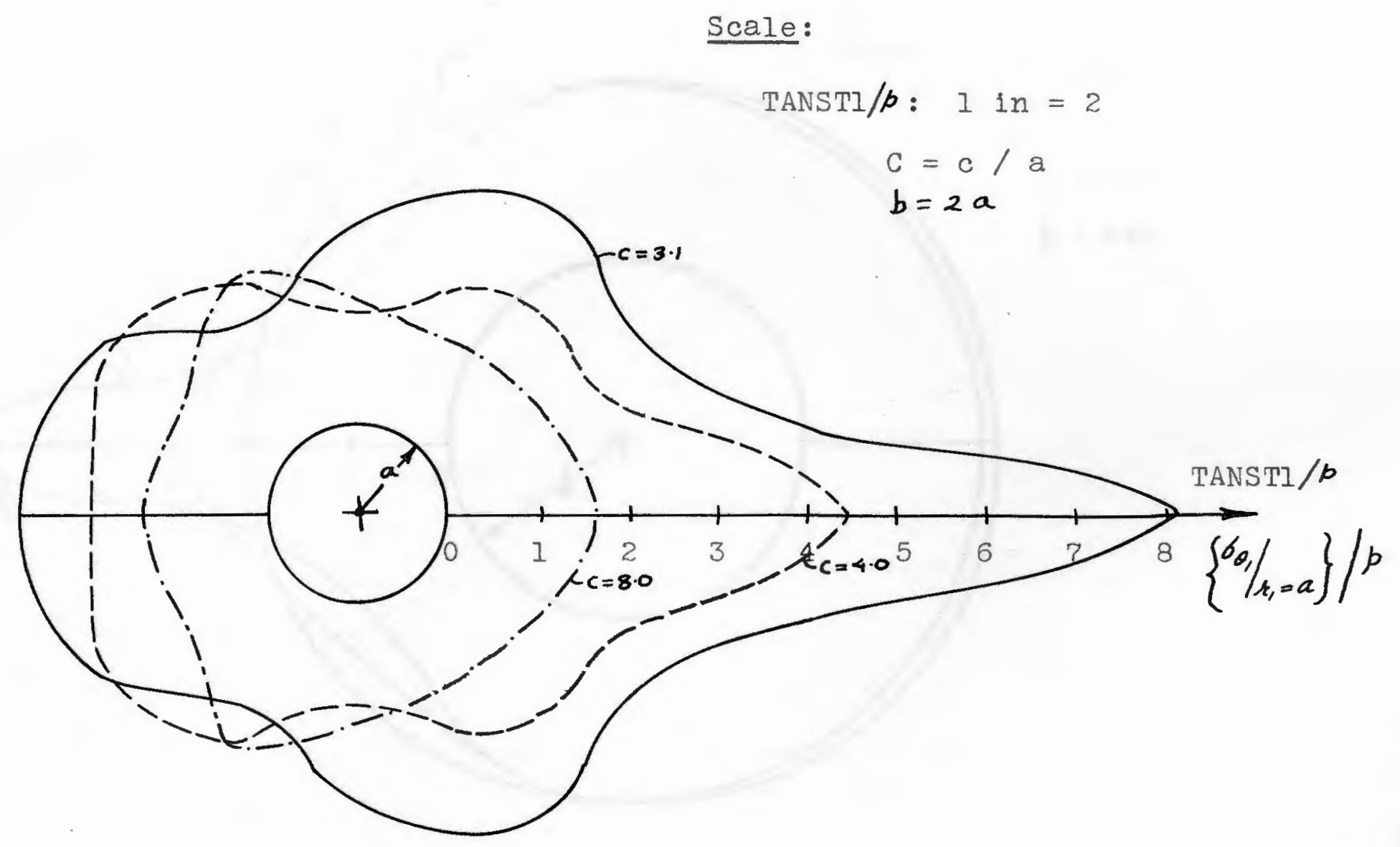


Figure 22 - Tangential Stresses Around Hole of Radius b for $p=0.5 q$.

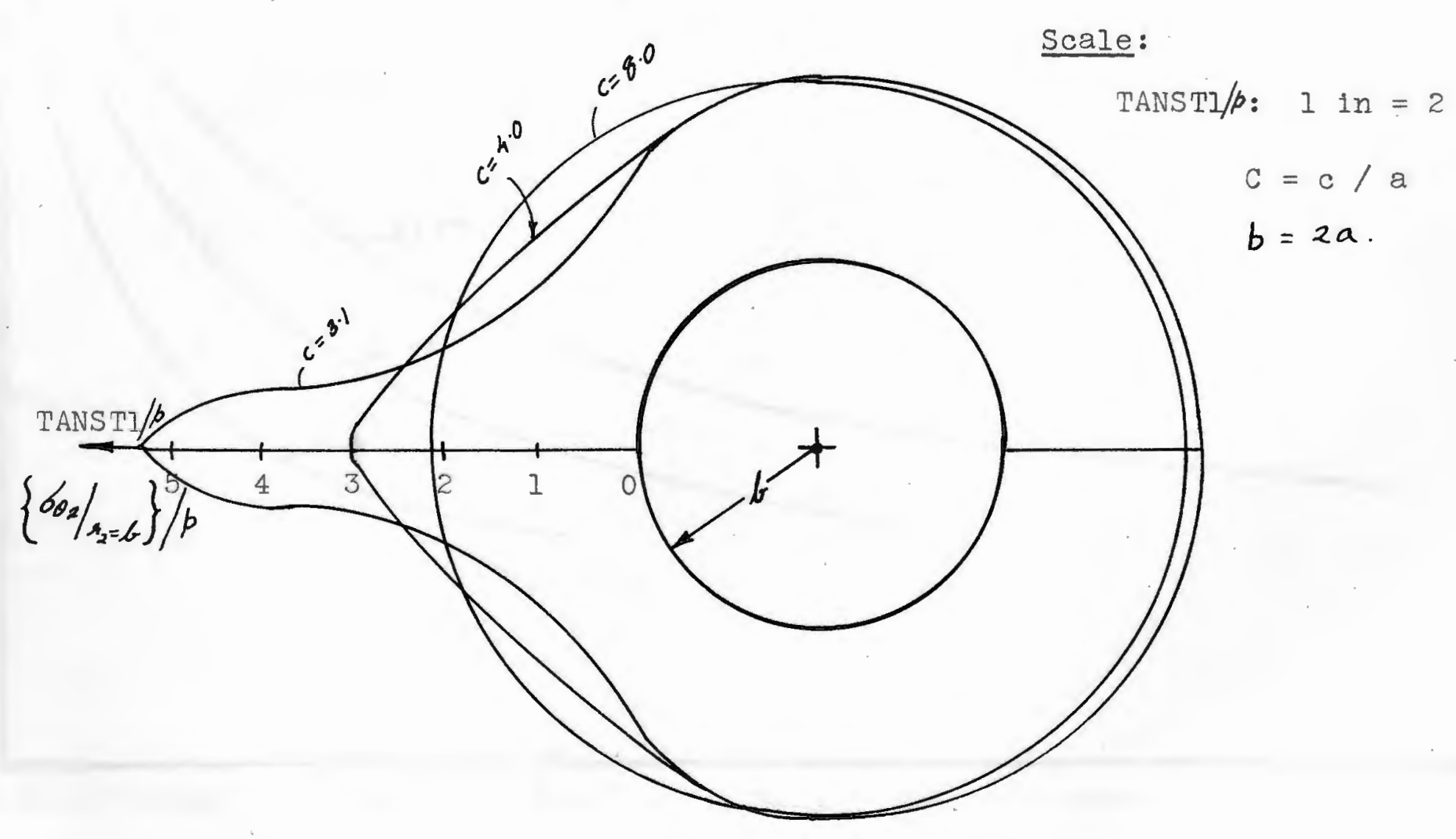




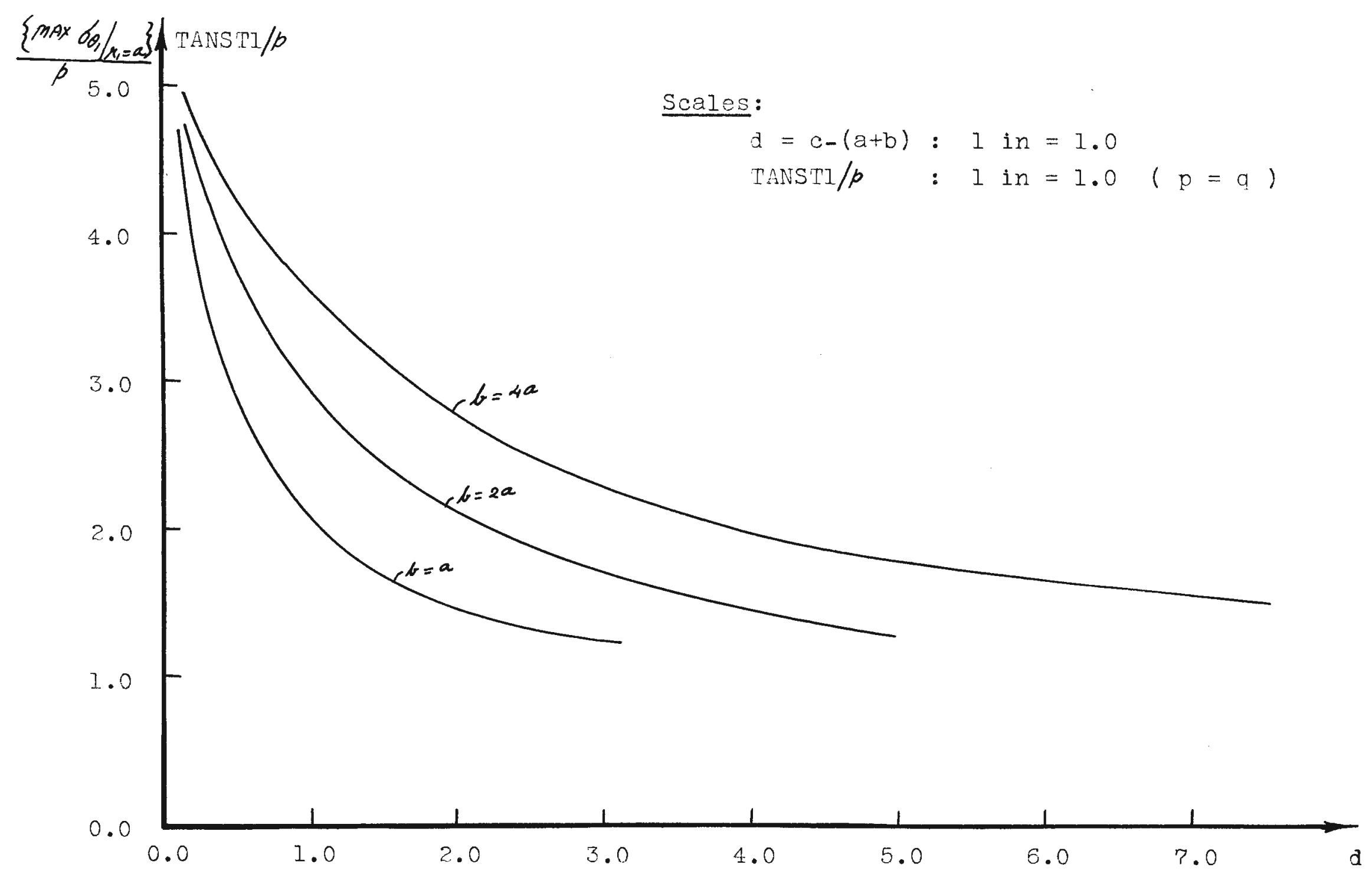

Figure 23 - Maximum Tangential Stress Variation w.r.t.d. 


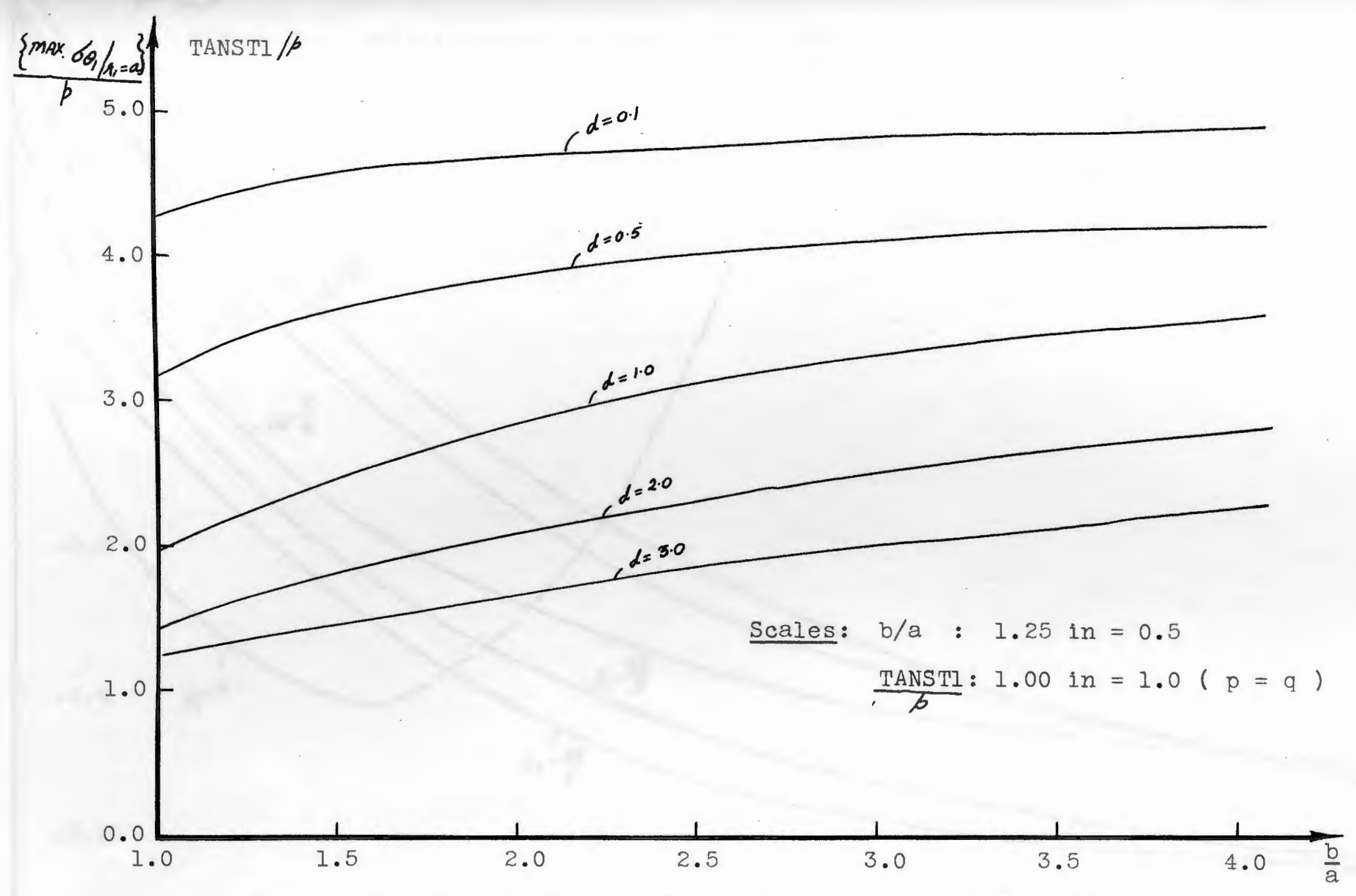

Figure 24 - Maximum Tagential Stress Variation w.r.t. b/a. 


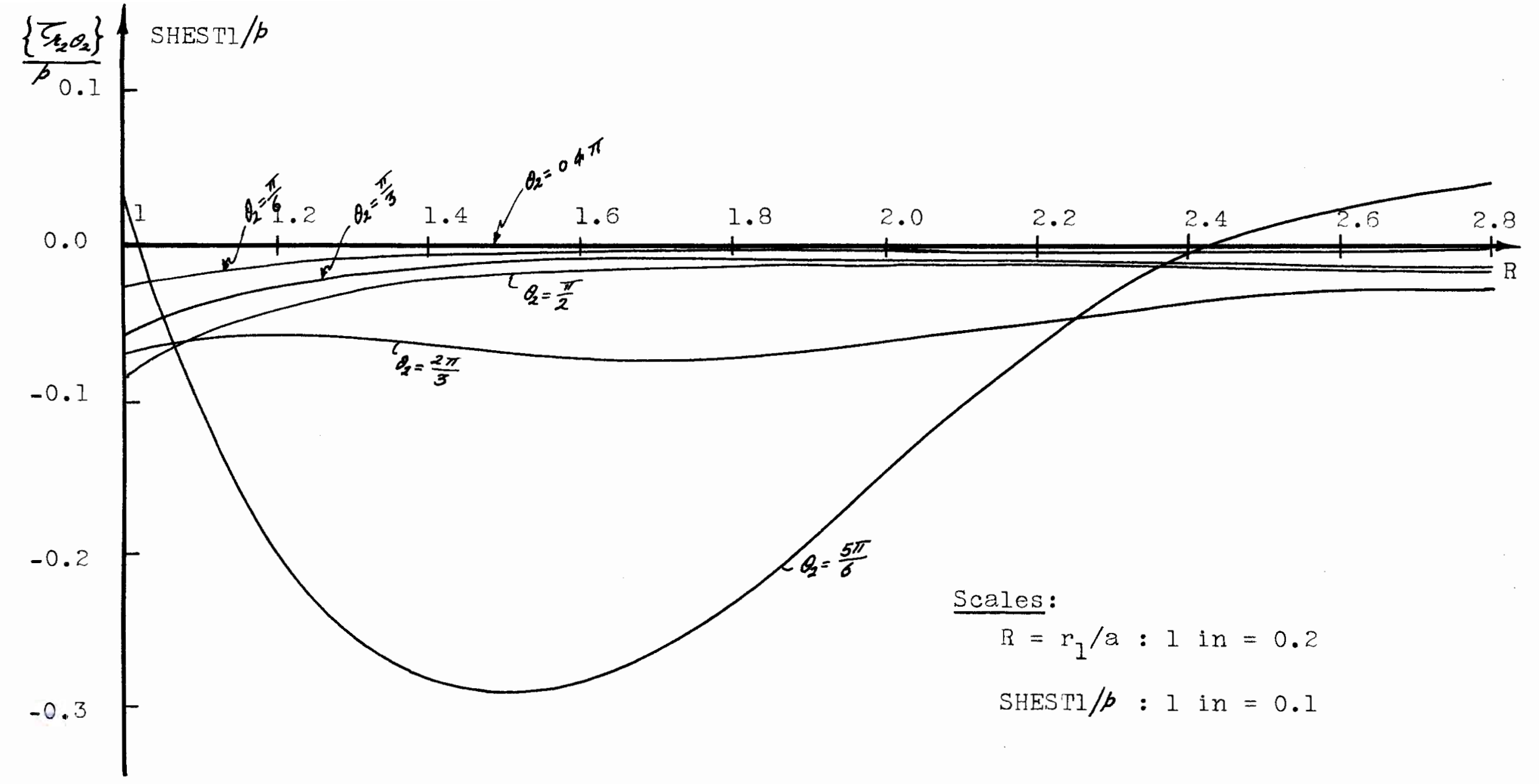

Figure 26 - Shearing Stress for $p=q, b=2 a, c=4 a$. 
Figure 27 - Radial Stress Around the Hole Boundaries.

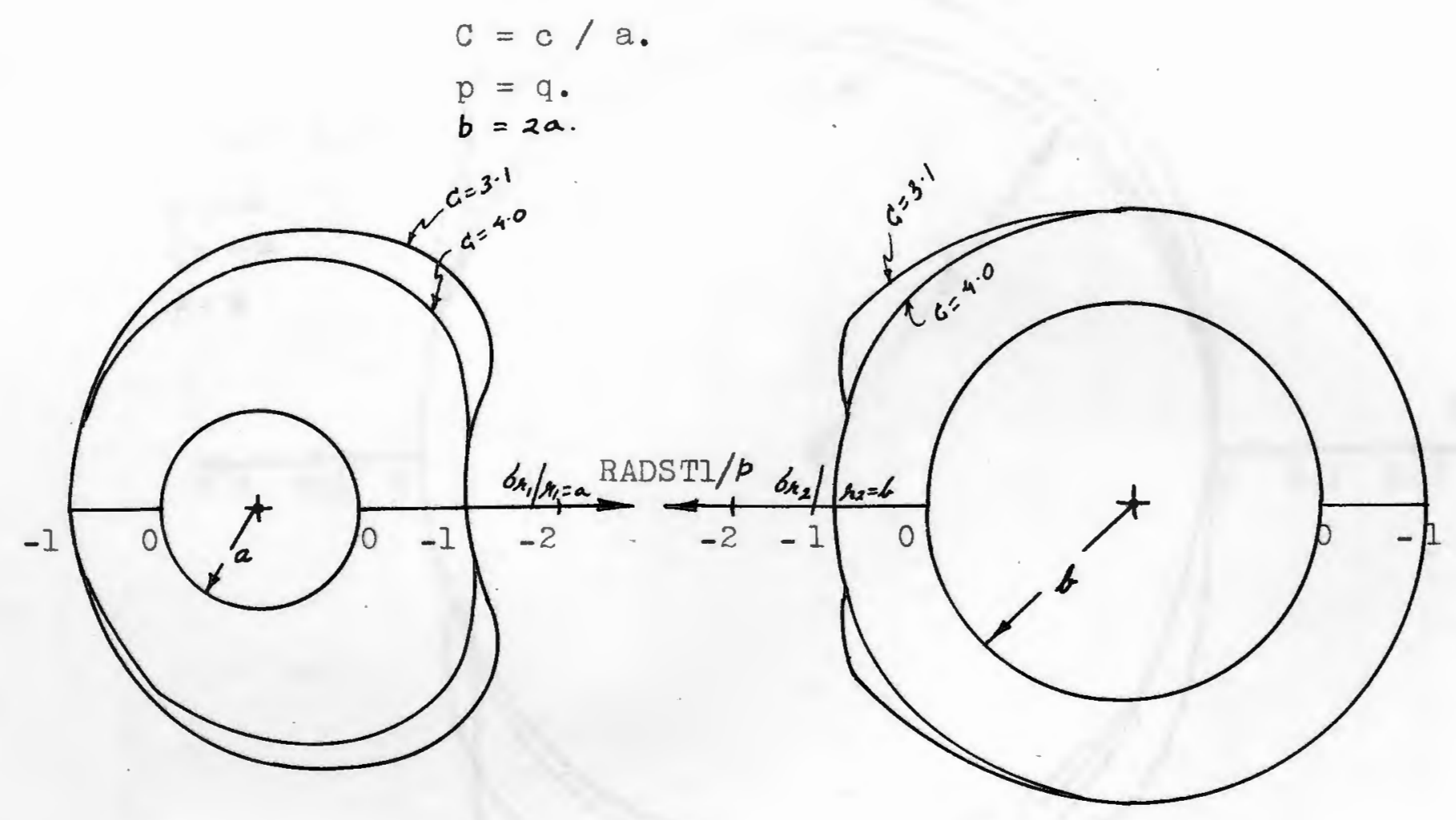

Scales:

$\operatorname{RADST} 1 / \boldsymbol{p}:$ I in $=-2.0$ 


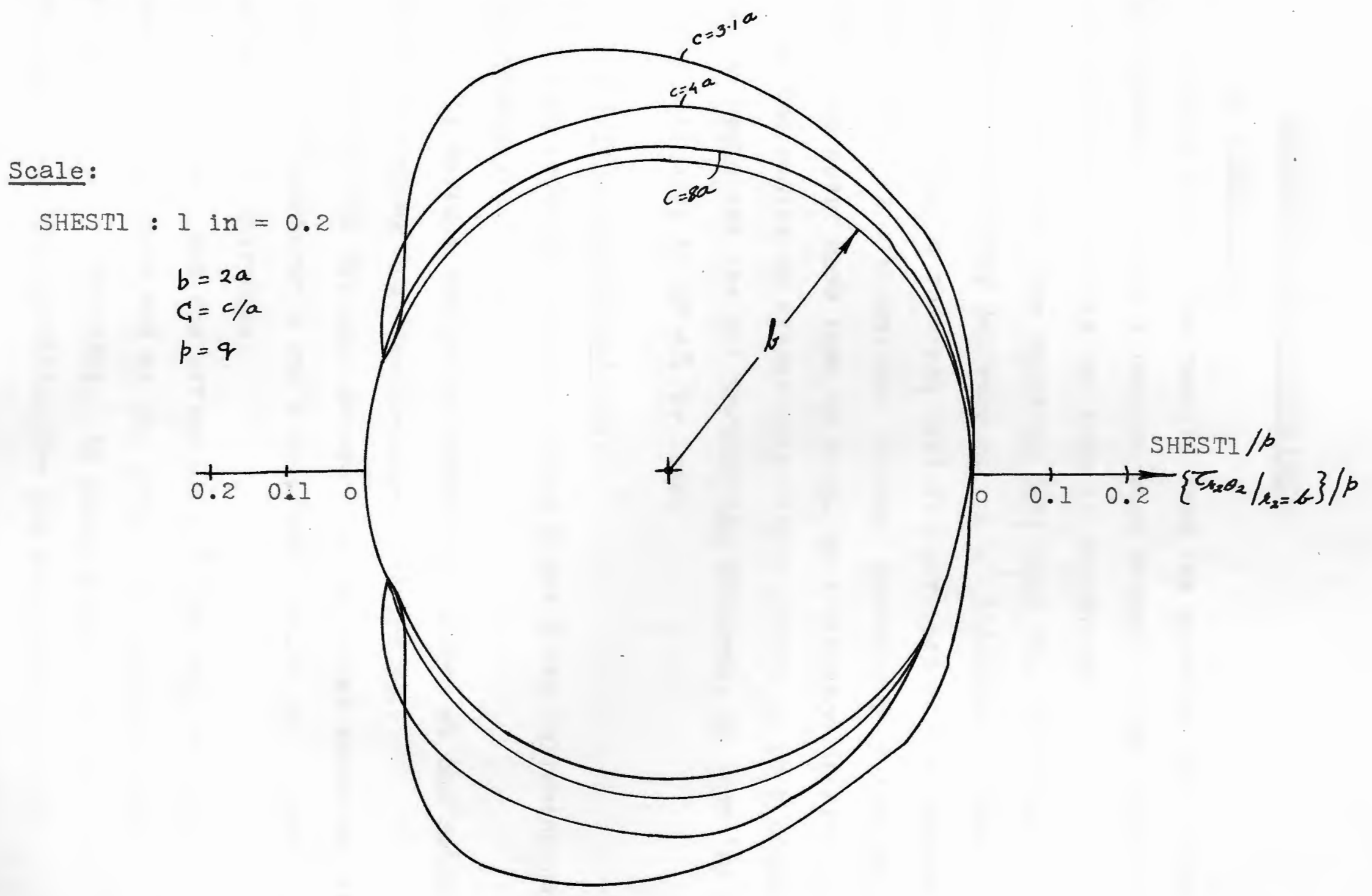

Figure 28 - Shearing Stress Around Hole of Radius b. 


\section{IV-5. DISCUSSION AND CONCLUSIONS:}

\section{(a) Single Hole:}

Table 1 shows the results from the equation (48) which are symmetric in any direction with respect to the center of the hole, because only one hole is considered.

It is clear from equation (48) that the radial and tangential stresses decrease as $\mathrm{r}_{1} / \mathrm{a}$ increases. From table 1 it can be observed that for the case of two unequal circular holes with uniform internal pressures, if the two. holes are apart more than or equal to a distance of five times the radius of bigger hole, their effect on each other can be neglected for all Engineering problems, as then the error will only be of $4 \%$ or less.

\section{(b) First Approximation:}

From equation (51) and tables 2 and 3 the following results are observed:

i) Maximum stress concentration occures at the points F or G depending upon the pressures (Figure 9).

ii) As the distance between the two holes increases the effects of pressures $p$ and $q$ on other edge, 1. e., $G$ and $F$ respectively, decreases.

iii) When $b>a$ the effect of $q$ on the edge $F$ is more than that of $p$ on $G$ and as the ratio $b / a$ increases the effect of $q$ on $F$ increases. In other words, if $b>a$ the maximum stress concentration for $p=q$ will occure at the 
inner edge of the smaller hole, 1.e., at F.

\section{(c) Second Approximation:}

In the following discussion the effects of the pressures $p$ and $q$ are either treated separately or when they are combined then $p=q$ is assumed. Otherwise the stresses depend upon the values of $p$ and $q$, which in tern depend upon the hole radil $a$ and $b$ and the differences in radil of inclusions and holes, i.e., $\varepsilon_{1}$ and $\varepsilon_{2}$.

From equations (55), (56), (58) and (59) and the tables 4,5 and 6 following observations are made:

i) As the two holes come closer the maximum stress concentration of the tangential stresses at the inner edge of the smaller hole increases.

ii) As the two holes come closer stresses along the line FG increase rapidly whereas the effect is not significant beyond the points $E\left(\right.$ along $\left.\theta_{1}=\pi\right)$ and $H\left(\right.$ along $\left.\theta_{2}=0\right)$.

iii) As $b$ is greater than a the effect of $q$ on the edge $F$ is more than that of $p$ on $G$. Hence the tangential stress concentration is at the point $\mathrm{F}$.

iv) As the ratio $\mathrm{b} / \mathrm{a}$ increases the maximum stress concentration for the tangential stresses also increases.

v) For the case of $b=a$ the results with respect to the two origins $\mathrm{O}_{1}$ and $\mathrm{O}_{2}$ are found to be symmetric. vi) Figures 17, 18, 19, 20, 21 and 22 show the stress distribution of the tangential stresses around the two holes. 
They also show the change in stress distribution with respect to the change in the pressure ratio $p / q$ or the radii of inclusions.

vii) The shear stress along the line of symmetry, passing through the points $E, F, G$ and $H$, is zero.

vi1i) Figures 27 and 28 show the stress distribution of the radial and shear stresses around the edge of the two holes. These stresses should be of the magnitude $p$ or $q$ and zero respectively, but they do not satisfy these conditions exactly. However, these figures clearly show that the second approximation is falrly close to the exact solution.

\section{Recommendations:}

1. The third approximation may give closer solution to the exact form[27].

2. With the similar approach of successive approximation to the complex stress functions by the Schwarz's Alternating method, following problems may be tackled:

i) Infinite plate with three or multi holes.

11) Inclusions with uniaxial or biaxial stresses at the infinity.

1i1) Inclusions of elliptic shape, square shape or any arbitrary shape. 


\section{BIBLIOGRAPHY}

[1] S. Timoshenko and J. N. Goodier. Theory of Elasticity. New York, Toronto, London: McGraw-Hill Book Company, Second Edition, 1951.

[2] G. V. Kolossoff. 'On One Application of the Theory of Functions of a Complex Variable to a Plane Problem in the Mathematical Theory of Elasticity.' Z. M. P., v. 62 (1914), 384-409.

[3] N. I. Muskhelishvil1. Some Basic Problems of the Mathematical Theory of Elasticity. Groningen-Holland:

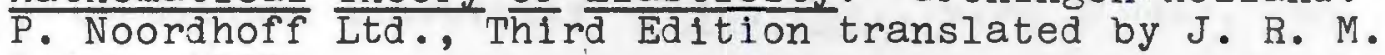
Radok, 1953.

[4] B. Kirsch. Z. Ver. Dtsch. Ing., v. 42 (1898), 797.

[5] E. Sternberg and M. A. Sadowsky. 'Three-Dimensional Solutions for the Stress Concentration Around a C1rcular hole in a Plate of Arbritary Thickness'. Trans. ASME, v. 71 (1949), Applied Mech. Section, 27.

[6] A. J. Durell1 and W. M. Murray. 'Stress Distribution Around an Elliptical Discontinuity in Any Two-Dimensional Uniform and Axial System of Combined Stress'. Proc. SESA, v. 1, No. 1 (1943), 19.

[7] R. C. J. Howland. 'On the Stresses in the Ne1ghbourhood of a Circular Hole in a Strip Under Tension'. Ph11. Trans. Boy. Soc. (London) A, v. $229(1929-30), 27$.

[8] G. B. Jeffery. 'Circular Hole Near Boundary of a Semiinfinite Plate in Tension Parallel to Boundary.' Phil. Trans. Roy. Soc. (London) A, v. 221 (1920), 265.

[9] R. D. Mindlin. 'Stress Distribution Around a Hole Near the Edge of a Plate in Tension.' Proc. Exp. Stress Anal., v. 5, No. $2(1948), 56$. 
[10] C. K. Wang. 'Infinite Plate with Stresses Applied to Boundary of Hole.' J. of Applied Mechanics, v. 13(1946),?7.

[11] S. Sjostrom. 'On the Stresses at the Edge of an Eccentrically Loaded Circular Hole in a Strip Under Tension.' Report No. 36, Aeronaut. Research Inst. of Sweden (1950).

[12] C. E. Inglis. 'Stresses in a Plate due to the Pressure of Cracks and Sharp Corners.' Trans. Instn. Naval Archit., London, v. 15 (1931) pt. 1, 219.

[13] T. L. Posch1. 'Uber eine Patikulare Losung des Biharmonischer Problems fur den Aussenraum der Elitpse.' Math $\underline{Z} \cdot(1921), 89$.

[14] E. G. Coker. 'The Effect of Holes and Semicircular notches on distribution of Stress in Tension Members.' Proc. Phys. Soc. 1912, 95.

[15] L. H. Donell. 'Stress Concentration Due to Elliptical Discontinuities in a Plate Under Edge Force.' Theodore von Karman Aniv. 1941.

[16」A. C. Stevenson. 'Stress Boundary Problems of TwoDimensional Elasticity' Phil. Mag., v.34 (1943), 766.

[17] G. N. Savin. 'Stress Concentration Around Holes.' Rep. Aero. Res. Comm., London, No. 18460 (1951).

[18] B. Sen. 'Direct Determination of Stresses from the Stress Equation in Some Two-Dimensional Problems of Elasticity.' Phil. Mag., v. 39 (1948), 229.

[19] H. L. Cox. 'Four Studies in the Theory of Stress Concentration.' Rep. Mencor. Aero. Res. Comm., London,

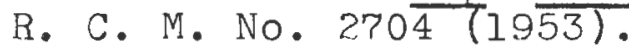

[20] S. R. Heller, Jr., J.S. Brock and R. Bart. 'The Stresses Around a Rectangular Opening with Round Corners in a Uniformly Loaded Plate.' Proc. 3 rd $\underline{U}$. S. Nat. Congr. Appl. Math. (1958), 357 .

[21] M. Greenspan. 'Effect of a Small Hole on the Stresses in a Uniformly Loaded Plate.' Quart. Appl. Math., v. $2(1944), 60$.

[22] Chih Bing Ling. 'On the Stresses in a Plate Containing Two Equal Circular Holes.' Journal of Applied Physics, v. $19(1948)$, ?7-82.

[23] Yu. A. Ustinov. Izv. Akad. Nauk. SSSR (1965), 145. 
[24] Ya. S. Podstrigach. 'Stresses in a Plate Weackened by Two Unequal Circular Holes.' Dopovidi Akademi Nauk Ukrain'skoi RSR (1953), 456-450.

[25] G. A. O. Davies and J. R. Hoddinott. 'Stresses in a Plate Pierced by Two Unequal Circular Holes.' Journal of Royal

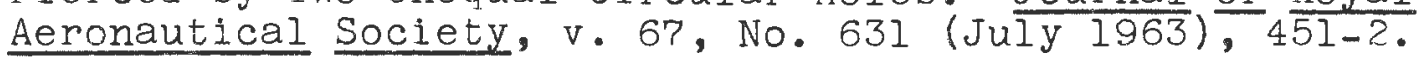

[26] R. A. W. Hodden. 'Stresses in an Infinite Plate Containing Two Unequal Circular Holes.' Quarterly Journal of Mechanics and Applied Mathematics, v.20, (August 19 $\overline{67}$ )

[27] Salerno and Mahoney. 'Stress Solution for an Infinite Plate Containing Two Arbitrary Circular Holes Under Equal Biaxial Stresses.' Journal of Engineering for Industry, v.90, No. 4 (Nov. $1 \overline{968), 656-65 . ~}$

[28] D. I. Sherman. Trudy Seismological Institute, Academy of Science of the USSR, No.S 82 and 83 (1938).

[29] I. S. Sokolnikoff. Mathematical Theory of Elasticity. New York, London: McGraw-Hill Book Company, Second Edition, 1956.

[30] H. A. Schwarz. Gesammelte Mathematische Abhandlungen, v. $2,133-43$.

[31] S. G. Mikhlin. Trudy Seismological Institute, Academy of Science of the USSR, v. 39(1934), 1-14.

[32] C. Neumann. Leipziger Berichte, v. 22, (1870), 264-321.

[33] L. V. Kantorovich and V. I. Krylov. Approximate Methods of Higher Analysis. 4th Edition (1952), 637-95.

L34] S. Soboleff. 'L'algorithme de Schwarz dans la theorie de I'elasticite.' Compie Rendus (Doklady) de L'Academie des Sciences de 1 - URSS, v. IV (XIII), No. 6 (1936), $\overline{243}-\overline{46}$. 
Appendix A

THE GROUPS OF STRESS FUNCTIONS

GROUP (I): From equations (17), (20), (21), (24) and (25), the results starting from smaller hole of radius a are put together in this group, as given below:

$$
\begin{aligned}
& \underline{\phi_{1}\left(z_{1}\right)}=0 . \quad \underline{\phi_{12}\left(z_{2}\right)}=0 .
\end{aligned}
$$

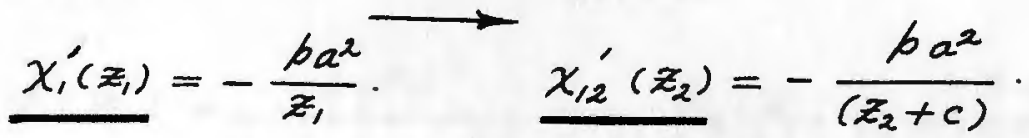

$$
\begin{aligned}
& \phi_{22}\left(z_{2}\right)=-\frac{b a^{2} b^{2}}{c\left(c z_{2}+b^{2}\right)} \text {. } \\
& \underline{x_{22}^{\prime}\left(z_{2}\right)}=\frac{p a^{2}}{c}-\frac{q b^{2}}{z_{2}}-\frac{p a^{2} b^{4}}{z_{2}\left(c z_{2}+b^{2}\right)^{2}} \text {. }
\end{aligned}
$$

GBOUP (II): From equations (29), (30), (33) and (34), the results starting from bigger hole of radius $b$ are put together in this group, as given below:

$$
\begin{array}{ll}
\underline{\phi_{21}\left(z_{1}\right)}=0 . & \underline{\phi_{2}\left(z_{2}\right)}=0 . \\
\underline{\chi_{21}^{\prime}\left(z_{1}\right)}=-\frac{q b^{2}}{\left(z_{1}-c\right)} . & \underline{x_{2}^{\prime}\left(z_{2}\right)}=-\frac{q b^{2}}{z_{2}} . \\
\underline{\phi_{11}\left(z_{1}\right)}=-\frac{q a^{2} b^{2}}{c\left(c z_{1}-a^{2}\right)} . & \\
\underline{x_{11}^{\prime}\left(z_{1}\right)}=-\frac{p a^{2}}{z_{1}}-\frac{q b^{2}}{c}-\frac{q a^{4} b^{2}}{z_{1}\left(c z_{1}-a^{2}\right)^{2}} .
\end{array}
$$


GROUP (III): The First Approximation:

From Groups (I) and (II) the first approximation to the stress functions can be written as

$$
\begin{array}{ll}
\underline{\phi_{1}\left(z_{1}\right)}=0 . & \underline{\phi_{2}\left(z_{2}\right)}=0 . \\
\underline{\chi_{1}^{\prime}\left(z_{1}\right)}=-\frac{p a^{2}}{z_{1}} . & \underline{\chi_{2}^{\prime}\left(z_{2}\right)}=-\frac{q b^{2}}{z_{2}} .
\end{array}
$$

GROUP (IV): The Second Approximation:

From Groups (I) and (II) the second approximation to the stress functions can be written as

$$
\begin{aligned}
& \underline{\phi_{1}\left(Z_{1}\right)}=-\frac{q a^{2} b^{2}}{c\left(c Z_{1}-a^{2}\right)} \cdot \quad \underline{\phi_{2}\left(Z_{2}\right)}=-\frac{p a^{2} b^{2}}{c\left(c Z_{2}+b^{2}\right)} . \\
& \underline{x_{1}^{\prime}\left(z_{1}\right)}=-\frac{q b^{2}}{z_{1}-c}-\frac{q b^{2}}{c} \quad \underline{x_{2}^{\prime}\left(z_{2}\right)}=-\frac{p a^{2}}{z_{2}+c}+\frac{p a^{2}}{c} \\
& -\frac{p a^{2}}{z_{1}}-\frac{q a^{4} b^{2}}{z_{1}\left(c z_{1}-a^{2}\right)^{2}} \\
& -\frac{q b^{2}}{z_{2}}-\frac{b a^{2} b^{4}}{z_{2}\left(c z_{2}+b^{2}\right)^{2}}
\end{aligned}
$$

GROUP (V): The Third Approximation:

From equations (33), (34), (37), (38), (41) and (42) the results starting from smaller hole of radius $a$, as the third approximation to the solution of the stress functions are put together in this group, as given below: 
78

$$
\begin{aligned}
\phi_{11}\left(z_{1}\right) & =-\frac{q a^{2} b^{2}}{c\left(c z_{1}-a^{2}\right)} \cdot \underline{\phi_{12}\left(z_{2}\right)}=-\frac{q a^{2} b^{2}}{c\left(c z_{2}+c^{2}-a^{2}\right)} . \\
\underline{\chi_{11}^{\prime}\left(z_{1}\right)} & =-\frac{p a^{2}}{z_{1}}-\frac{q b^{2}}{c} \quad \underline{\chi_{112}^{\prime}\left(z_{2}\right)}=-\frac{p a^{2}}{z_{2}+c}-\frac{q b^{2}}{c} \\
& -\frac{q a^{4} b^{2}}{z_{1}\left(c z_{1}-a^{2}\right)^{2}} . \\
& +\frac{q a^{2} b^{2}}{\left(z_{2}+c\right)\left(c z_{2}+c^{2}-a^{2}\right)} .
\end{aligned}
$$

$$
\begin{aligned}
& \underline{\phi_{222}\left(z_{2}\right)}=-\frac{b a^{2} b^{2}}{c\left(c z_{2}+b^{2}\right)}-\frac{q b^{4}}{c\left(b^{2}+c z_{2}\right)} \\
& +\frac{q b^{4} c^{2}\left\{\left(c^{2}-a^{2}\right)^{2}-3 a^{2} b^{2}\right\}}{\left(c^{2}-a^{2}\right)^{3}\left\{c b^{2}+Z_{2}\left(c^{2}-a^{2}\right)\right\}}+\frac{q a^{2} b^{8} c^{3}}{\left(c^{2}-a^{2}\right)^{3}\left\{c b^{2}+Z_{2}\left(c^{2}-a^{2}\right)\right\}^{2}} . \\
& \underline{x_{222}^{\prime}\left(z_{2}\right)}=-\frac{q a^{2} b^{4}}{\left(c^{2}-a^{2}\right)\left\{c b^{2}+\left(c^{2}-a^{2}\right) z_{2}\right\}} \\
& -\frac{q b^{2}}{z_{2}}-\frac{q a^{2} b^{4}}{\left(c^{2}-a^{2}\right)^{2} z_{2}}+\frac{b a^{2}}{c}+\frac{q b^{2}}{c}+\frac{2 q a^{2} b^{4} c^{2}}{c\left(c^{2}-a^{2}\right)^{3}} \\
& -\frac{b a^{2} b^{4}}{Z_{2}\left(b^{2}+c Z_{2}\right)^{2}}-\frac{q b^{6}}{Z_{2}\left(b^{2}+c Z_{2}\right)^{2}}+\frac{q b^{6} c^{2}\left\{\left(c^{2}-a^{2}\right)^{2}-3 a^{2} b^{2}\right\}}{\left(c^{2}-a^{2}\right)^{2}\left\{c b^{2}+\left(c^{2}-a^{2}\right) Z_{2}\right\}^{2} Z_{2}} \\
& +\frac{2 q a^{2} b^{10} c^{3}}{\left(c^{2}-a^{2}\right)^{2}\left\{c b^{2}+\left(c^{2}-a^{2}\right) Z_{2}\right\}^{3} Z_{2}} .
\end{aligned}
$$


Appendix $B$

EVALUATION OF THE COMPLEX INTEGRALS

1) $I_{1}=\frac{b}{2 \pi i} \int \frac{t_{1} d t_{1}}{t_{1}-Z_{1}}=0$ as $t_{1}$ is a function analytic everywhere. Using Eq. (8).

2) $I_{2}=\frac{p a^{2}}{2 \pi i} \int \frac{d t_{1}}{t_{1}\left(t_{1}-z_{1}\right)}$

$$
=\frac{b a^{2}}{2 \pi i} \int \frac{d t_{1}}{z_{1} t_{1}}\left[1+\left(\frac{t_{1}}{z_{1}}\right)+\left(\frac{t_{1}}{z_{1}}\right)^{2}+\left(\frac{t_{1}}{z_{1}}\right)^{3}+\cdots\right]
$$

The expansion is posible because $\left(t_{1} / z_{1}\right)<1$. Putting $t_{1}=a e^{i \theta,} \quad$ it can be determined that only the first term of the series leads to a certain value and the remaining terms are zero. This follows

$$
I_{2}=\frac{p a^{2}}{2 \pi z_{1}} \int_{0}^{2 \pi} d \theta_{1}=\frac{p a^{2}}{z_{1}} \text {. }
$$

3) $I_{3}=-\frac{p a^{2}}{2 \pi i} \int \frac{d t_{1}}{t_{1}^{2}}=-\frac{p a}{2 \pi} \int_{0}^{2 \pi} e^{-s \theta_{1}} d \theta_{1}=0$.

4) $I_{4}=0$. Similar to $I_{1}$.

5) $I_{5}=-\frac{1}{2 \pi i} \int \frac{b a^{2} t_{2}}{\left(c t_{2}-b^{2}\right)} \frac{d t_{2}}{\left(t_{2}-z_{2}\right)}$ 


$$
I_{5}=-\frac{b a^{2}}{2 \pi i c} \int \frac{1}{\left(t_{2}-z_{2}\right)}\left[1-\left(\frac{b^{2}}{c t_{2}}\right)+\left(\frac{b^{2}}{c t_{2}}\right)^{2}-\left(\frac{b^{2}}{c t_{2}}\right)^{3}+\cdots\right] d t_{2}
$$

The expansion is posible because $z_{2}>t_{2}$ and $\underset{c t_{2}}{b^{2}}<1 \quad(\because c>b)$.

$$
f\left(z_{2}\right)=\left[1-\left(\frac{b^{2}}{c z_{2}}\right)+\left(\frac{b^{2}}{c z_{2}}\right)^{2}-\left(\frac{b^{2}}{c z_{2}}\right)^{3}+\cdots\right]
$$

and

$$
f(\infty)=1 \text {. }
$$

$f\left(\boldsymbol{z}_{2}\right)$ is analytic in $\mathrm{S}^{-}$. Hence from equation (9) one can write

$$
\begin{aligned}
I_{5} & =-\frac{b a^{2}}{c}\left[-1+\left(\frac{b^{2}}{c z_{2}}\right)-\left(\frac{b^{2}}{c z_{2}}\right)^{2}+\cdots+1\right] \\
& =-\frac{p a^{2} b^{2}}{c\left(c z_{2}+b^{2}\right)} .
\end{aligned}
$$

6) $I_{6}=\frac{q b^{2}}{Z_{2}}$. Similar to $I_{2}$.

7) $\quad I_{7}=-\frac{p a^{2}}{2 \pi i} \int \frac{d t_{2}}{\left(c+t_{2}\right)\left(t_{2}-z_{2}\right)}$

$$
=-\frac{b a^{2}}{2 \pi i c} \int \frac{d t_{2}}{\left(t_{2}-z_{2}\right)}\left[1-\frac{t_{2}}{c}+\left(\frac{t_{2}}{c}\right)^{2}-\cdots\right]
$$

$1, t_{2}, t_{2}^{2}, t_{2}^{3}$, etc. are analytic in $\mathrm{S}^{+}$. Hence from Eq. (8) one can write

$$
I_{p}=0 \text {. }
$$

8) $I_{8}=\frac{q b^{2}}{2 \pi i} \int \frac{d t_{2}}{t_{2}^{2}}=0$. Similar to $I_{3}$.

9]

$$
\begin{aligned}
I_{9} & =\frac{p a^{2}}{2 \pi i} \int \frac{d t_{2}}{t_{2}\left(c+t_{2}\right)} \\
& =\frac{p a^{2}}{2 \pi i c} \int\left[\frac{1}{t_{2}}-\frac{1}{c}+\frac{t_{2}}{c^{x}}-\frac{t_{2}^{2}}{c^{3}}+\cdots\right] d t_{2}
\end{aligned}
$$

Second, third and all other higher order terms in $t_{2}$ are 
analytic in $\mathrm{S}^{+}$and hence from equation (8) they will not have any contribution towards the integration. Hence substituting $t_{2}=b e^{i \theta_{2}}$, it can be shown that

$$
I_{9}=\frac{p a^{2}}{2 \pi i c} \int \frac{d t_{2}}{t_{2}}=\frac{p a^{2}}{c} \text {. }
$$

10) $I_{10}=0$. Same as $I_{1}$.

11) $I_{11}=-\frac{q b^{2}}{2 \pi i c} \int \frac{d t_{1}}{\left(\frac{a^{2}}{c t_{1}}-1\right)\left(t_{1}-z_{1}\right)}$

$$
\begin{aligned}
& =\frac{q b^{2}}{2 \pi i c} \int\left[1-\frac{a^{2}}{c t_{1}}-\left(\frac{a^{2}}{c t_{1}}\right)^{2}-\left(\frac{a^{2}}{c t_{1}}\right)^{3}-\cdots\right] \frac{d t_{1}}{\left.c t_{1}-z_{1}\right)} \\
& =\frac{q b^{2}}{c}\left[-\frac{1}{\left(1-\frac{a^{2}}{c z_{1}}\right)}-1\right] \quad[\text { from equation }(9) . \\
& =-\frac{q a^{2} b^{2}}{c\left(c z_{1}-a^{2}\right)} .
\end{aligned}
$$

12) $I_{12}=\frac{\not b a^{2}}{z_{1}} \cdot$ Same as $I_{2}$.

13) $I_{13}=-\frac{q b^{2}}{2 \pi i} \int \frac{d t_{1}}{\left(t_{1}-c\right)\left(t_{1}-Z_{1}\right)}=0$. similar to $I_{r}$.

14) $I_{14}=0$. Same as $I_{8}$.

15) $I_{15}=\frac{q b^{2}}{2 \pi i} \int \frac{d t_{1}}{t_{1}\left(t_{1}-c\right)}=\frac{q b^{2}}{c}$. Similar to $I_{9}$.

16) $I_{16}=-\frac{p a^{2}}{2 \pi i} \int \frac{d t_{2}}{\left(\frac{b^{2}}{t_{1}}+c\right)\left(t_{2}-z_{2}\right)}$.

$$
=-\frac{p a^{2} b^{2}}{c\left(c z_{2}+b^{2}\right)} \text {. Similar to } I_{11} \text {. }
$$

17) $I_{17}=0$. Same as $I_{4}$. 
82

$$
\begin{aligned}
& K_{1}=-\frac{\left(c^{2}-a^{2}\right)^{2} b^{2}}{a^{2}\left(b^{2}+c Z_{2}\right)} \\
& K_{2}=\lim _{t_{2} \rightarrow-\frac{c b^{2}}{c^{2}-a^{2}}} \frac{d}{d t_{2}}\left[\frac{\left\{\left(b^{2}+c^{2}-a^{2}\right) t_{2}^{3}+c t_{2}^{4}+c b^{2} t_{2}^{2}\right\}}{\left(\frac{b^{2}}{c}+t_{2}\right)\left(t_{2}-z_{2}\right)}\right] \\
& =\frac{c b^{2}\left\{\left(c^{2}-a^{2}\right)^{2}-3 a^{2} b^{2}\right\}}{a^{2}\left(c^{2}-a^{2}\right)\left\{c b^{2}+\left(c^{2}-a^{2}\right) z_{2}\right\}} \\
& +\frac{c^{4} b^{6}}{\left(c^{2}-a^{2}\right)\left\{c b^{2}+\left(c^{2}-a^{2}\right) z_{2}\right\}^{2}} \\
& I_{19}=-\frac{q b^{4}}{c\left(c z_{2}+b^{2}\right)}+\frac{q c^{2} b^{4}\left\{\left(c^{2}-a^{2}\right)^{2}-3 a^{2} b^{2}\right\}}{\left(c^{2}-a^{2}\right)^{3}\left\{c b^{2}+\left(c^{2}-a^{2}\right) z_{2}\right\}} \\
& +\frac{q a^{2} c^{3} b^{8}}{\left.\left(c^{2}-a^{2}\right)^{3}\left\{c b^{2}+c c^{2}-a^{2}\right) z_{2}\right\}^{2}} .
\end{aligned}
$$

$203 \mathrm{I}_{20}=0$. Same as $\mathrm{I}_{4}$.

21\} $I_{21}=0$. Same as $I_{r 7}$.

223 $I_{22}=0$. Same as $I_{1}$.

$233 \quad I_{23}=-\frac{q a^{2} b^{2}}{2 \pi i c\left(c^{2}-a^{2}\right)} \int \frac{t_{2} d t_{2}}{\left(t_{x}+\frac{c b^{2}}{c^{2}-a^{2}}\right)\left(t_{2}-z_{2}\right)}$

Here $f\left(t_{2}\right)$ has a pole inside $S^{+}$at $t_{1}=-\frac{c b^{2}}{c^{2}-a^{2}}$. Hence,

$$
\begin{aligned}
I_{23} & =-\frac{q a^{2} b^{2}}{2 \pi i\left(c^{2}-a^{2}\right)} \lim _{t_{2} \rightarrow-\frac{c b^{2}}{c^{2}-a^{2}}}\left[\frac{t_{2}}{t_{2}-z_{2}}\right] \\
& =-\frac{q a^{2} b^{4}}{\left(c^{2}-a^{2}\right)\left\{c b^{2}+\left(c^{2}-a^{2}\right) z_{2}\right\}}
\end{aligned}
$$

243 $I_{24}=-\frac{q b^{2}}{z_{2}} \cdot$ Similar to $I_{2}$. 
183 $I_{18}=-\frac{q a^{2} b^{2}}{2 \pi i c} \int \frac{d t_{2}}{\left(c t_{2}+c^{2}-a^{2}\right)\left(t_{2}-Z_{2}\right)}$

$$
=-\frac{q a^{2} b^{2}}{2 \pi i c\left(c^{2}-a^{2}\right)} \int\left[1-\frac{c t_{2}}{c^{2}-a^{2}}+\left(\frac{c t_{2}}{c^{2}-a^{2}}\right)^{2}-\cdots\right] \frac{d t_{2}}{\left(t_{2}-z_{2}\right)}
$$

The expansion is posible because $\frac{c t_{2}}{c^{2}-a^{2}}<1$, since $\frac{c t_{2}}{c^{2}-a^{2}}=\frac{c t_{2}}{(c+a)(c-a)}$ and $(c+a)>c$ and $(c-a)>\left|t_{2}\right|$.

I, $t_{x}, t_{2}^{2}, t_{2}^{3}$ etc. are all analytic in $S^{+}$. Hence from the equation (8) one can write

$$
I_{18}=0 \text {. }
$$

$$
I_{19}=\frac{q a^{2} b^{2}}{2 \pi i} \int \frac{\left(b^{2}+c t_{2}+\frac{c b^{2}}{t_{2}}+c^{2}-a^{2}\right) d t_{2}}{\left(\frac{b^{2}}{t_{2}}+c\right)\left(c \frac{b^{2}}{t_{2}}+c^{2}-a^{2}\right)^{2}\left(t_{2}-z_{2}\right)}
$$

Here $f\left(t_{2}\right)$ has three poles.

1) at $t_{2} \rightarrow \infty$ which is in $S^{-}$.

11) at $t_{2}=-\frac{b^{2}}{c}$ which is in $S^{+}$; because $c>b, \frac{b^{2}}{c}<b$.

11i) at $t_{2}=-\frac{c b^{2}}{c^{2}-a^{2}}$ which is of second order and in $S^{+}$; because $(c+a)>c$ and $(c-a)>b, \quad c c^{2}-a^{2}<b$. Integrating inside the region $\mathrm{S}^{+}$one can write

$$
I_{19}=\frac{q a^{2} b^{2}}{c\left(c^{2}-a^{2}\right)^{2}}\left[K_{1}+K_{2}\right]
$$

where $K_{1}$ and $K_{2}$ are the residues at the Second and Third poles as stated above.

$$
\mathrm{K}_{1}=\lim _{t_{2} \rightarrow-\frac{b^{2}}{c}} \frac{\left\{\left(b^{2}+c^{2}-a^{2}\right) t_{2}^{3}+c t_{2}^{4}+c b^{2} t_{2}^{2}\right\}}{\left(\frac{c b^{2}}{c^{2}-a^{2}}+t_{2}\right)^{2}\left(t_{2}-z_{2}\right)}
$$


25\} $I_{25}=\frac{q a^{2} b^{2}}{2 \pi i c^{2}} \int \frac{\left\{c t_{2}+\left(b^{2}+c^{2}-a^{2}\right) t_{2}+c b^{2}\right\} d t_{2}}{t_{2}\left(t_{2}+c\right)\left(t_{2}+\frac{c^{2}-a^{2}}{c}\right)^{2}\left(t_{2}-z_{2}\right)}$

Here $f\left(t_{2}\right)$ has four poles, of which only one is inside $S^{+}$, at $t_{2}=0$ and other three are in $S^{-}$region. Hence integrating inside $\mathrm{S}^{+}$, one can write from equation (10)

$$
\begin{aligned}
I_{25} & =\frac{q a^{2} b^{2}}{c^{2}} \lim _{t_{2} \rightarrow 0}\left[\frac{\left\{c t_{2}^{2}+\left(b^{2}+c^{2}-a^{2}\right) t_{2}+c b^{2}\right\}}{\left(t_{2}+c\right)\left(t_{2}+\frac{c^{2}-a^{2}}{c}\right)^{2}\left(t_{2}-z_{2}\right)}\right] \\
& =-\frac{q a^{2} b^{4}}{\left(c^{2}-a^{2}\right)^{2} z_{2}} .
\end{aligned}
$$

26) $I_{26}=\frac{p a^{2}}{c}$. Same as $I_{9}$.

27) $I_{27}=\frac{q b^{2}}{2 \pi i c} \int \frac{d t_{2}}{t_{2}}=\frac{q b^{2}}{2 \pi i c} \int_{0}^{2 \pi} \frac{i b e^{i \theta_{2}}}{b e^{i \theta_{2}}} d \theta_{2}$

$$
=\frac{q b^{2}}{6} \text {. }
$$

$28\}$

$$
\begin{aligned}
I_{28} & =\frac{q a^{2} b^{2}}{2 \pi i c} \int \frac{d t_{2}}{t_{2}\left(c \frac{b^{2}}{t_{2}}+c^{2}-a^{2}\right)} \\
& =\frac{q a^{2} b^{2}}{2 \pi i c\left(c^{2}-a^{2}\right)} \int \frac{d t_{2}}{t_{2}}\left[1-\frac{c b^{2}}{t_{2}\left(c^{2}-a^{2}\right)}+\left\{\frac{c b^{2}}{t_{2}\left(c^{2}-a^{2}\right)}\right\}^{2}+\cdots\right]
\end{aligned}
$$

The expansion is posible because $\frac{c b^{2}}{t_{2}\left(c^{2}-a^{2}\right)}<1 \quad$ and $(c-a)>b$. Hence $(c+a)>a|d| t_{2} \mid=b$. Only the first term in the expansion will have the contribution towards the integration. Now putting $t_{2}=b e^{i b}$ one can obtain, 


$$
\begin{aligned}
I_{28} & =\frac{q a^{2} b^{2}}{2 \pi i c\left(c^{2}-a^{2}\right)} \int_{0}^{2 \pi} \frac{i b e^{i \theta_{2}}}{b e^{i \theta_{2}}} d \theta_{2} \\
& =\frac{q a^{2} b^{2}}{c\left(c^{2}-a^{2}\right)} .
\end{aligned}
$$

29\} $I_{29}=0$. Same as $I_{8}$.

$30\} \quad I_{30}=-\frac{q a^{2} b^{2}}{2 \pi i c^{2}} \int \frac{\left\{c t_{2}^{2}+\left(b^{2}+c^{2}-a^{2}\right) t_{2}+c b^{2}\right\} d t_{2}}{t_{2}^{2}\left(t_{2}+c\right)\left(t_{2}+\frac{c^{2}-a^{2}}{c}\right)^{2}}$

Here $f\left(t_{2}\right)$ has four poles, of which only one lies inside $S^{+}$, at $t_{2}=0$ and $1 t$ is of second order. The other three are in $\mathrm{S}^{-}$region. Hence integrating inside $\mathrm{S}^{+}$region one can write from equation (10), as follows

$$
\begin{aligned}
I_{30} & =-\frac{q a^{2} b^{2}}{c^{2}} \lim _{t_{2} \rightarrow 0} \frac{d}{d t_{2}}\left[\frac{\left\{c t_{2}^{2}+\left(b^{2}+c^{2}-a^{2}\right) t_{2}+c b^{2}\right\}}{\left.c t_{2}+c\right)\left(t_{2}+\frac{c^{2}-a^{2}}{c}\right)^{2}}\right] \\
& =-\frac{q a^{2} b^{2}}{c\left(c^{2}-a^{2}\right)}+\frac{2 q a^{2} b^{4} c^{2}}{c\left(c^{2}-a^{2}\right)^{3}} .
\end{aligned}
$$

All the above integrals are checked by two different methods, ones integrating outside the region $\mathrm{S}^{+}$and next integrating inside. They are found to be same by both the methods. 
Appendix $C$ COMPUTER FORTRAN PROGRAM FOR TANGENTIAL STRESSES

/ID 24500525 VIJAY UKADGAONKER SECOND APPROXIMATION $/ J O B$ GO, MAP, TIME $=02$

/FTC LIST, REF

C THIS PROGRAM IS FOR THE SECOND APPROXIMATION TO THE

C SOLUTION OF THE TANGENTIAL STRESSES WITH RESPECT TO

C THE SMALLER HOLE OF RADIUS A.

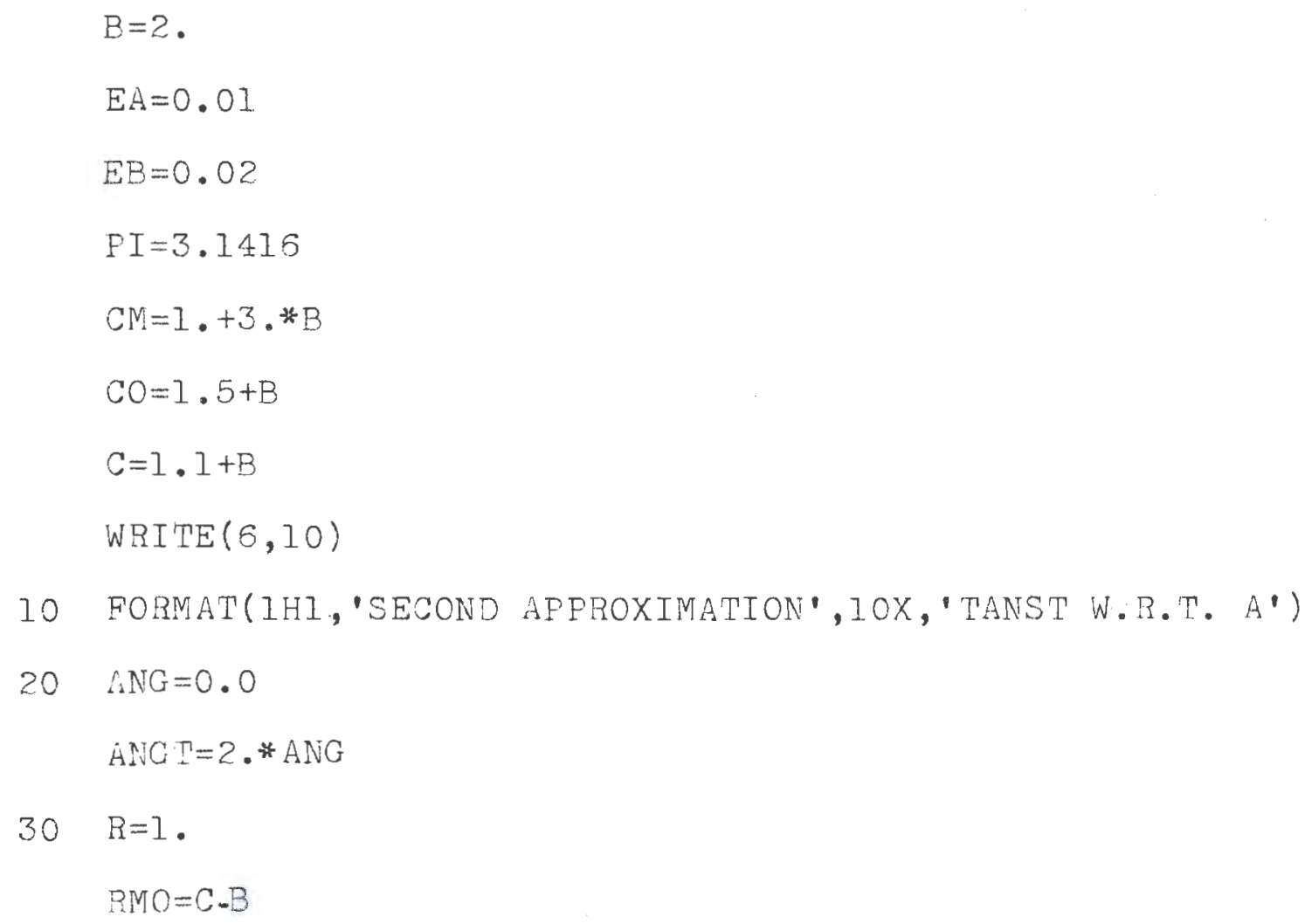


40 1

$$
\begin{aligned}
& B P=2 *(C * C) *(R * R) * \operatorname{COS}(A N G) * \operatorname{SIN}(\text { ANG })-2 * C^{*} * P^{*} \operatorname{SIN}(\text { ANG }) \\
& C P=(R * R) *((\operatorname{COS}(A N G)) * 2)+(C * C)-(R * R) *((\operatorname{SIN}(\text { ANG })) * 2) \\
& 1 \\
& D P=2 *(R * R) * \operatorname{SIN}(A N G) * \operatorname{COS}(A N G)-2 . \operatorname{C} * R * \operatorname{SIN}(\text { ANG }) \\
& \mathrm{EP}=(\mathrm{C} * 3) *(\mathrm{R} * 3) *((\cos (\text { ANG })) * 3)-1 \cdot+3 \cdot \mathrm{C} * \mathrm{R} * \cos (\mathrm{ANG}) \\
& 1 \\
& 1 \\
& 1 \\
& -3 *(C * C) *(R * R) *((\operatorname{COS}(\text { ANC })) * 2)+3 .(C * 3) *(R * 3) \\
& *((\operatorname{SIN}(A N G)) * 2) * \operatorname{COS}(A N G)+3 *(C * C) *(R * R) \\
& \mathrm{FF}=3 .(\mathrm{C} * 3) *(\mathrm{R} * 3) *((\operatorname{COS}(\mathrm{ANG})) * 2) * \operatorname{SIN}(\mathrm{ANG})+3 * \mathrm{C} * \mathrm{R} \\
& 1 \\
& 1 \\
& \text { *((STN }(A N G)) * 2) \\
& 1 * \operatorname{SIN}(\text { ANG })-6 *(C * C) *(R * R) * \operatorname{SIN}(\text { ANG }) * \operatorname{COS}(\text { ANG }) \\
& 1-(C * 3) *(R * 3) *((\operatorname{SIN}(A N G)) * * 3)
\end{aligned}
$$

TANSTP $=1 . /(13 * R)$

$U=(2 *(B * B) * C *(B * R-1) *.(E P * \operatorname{COS}(A N G)+F P * \operatorname{SIN}($ ANG $)))$

$$
/(R(E P * E P+F P * F P))
$$

$V=((B * B) *(C P * \operatorname{COS}(A N G T)+D F * \operatorname{SIN}(A N G T)) /(C P * C P+D F * D P)$ $W=((B * B) *(A P)(2 *(R * R)+1)) /.((R * R) *(A P * A P+B P * B P))$ $\operatorname{TANST} 2=(-U+V+W)$

$\operatorname{TANST} 2=(2 *$ EA* TANSTP $)+((2 *$ EB*TANSTQ $) / B)$

WRITE $(6,50)$ TANS TP, TANS TQ, TANST2, C, ANG , R

50 FORMAT('TANSTI=',F8.4,' X P +',F8.4,' X Q',

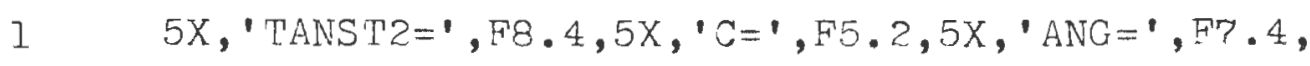
$\left.15 \mathrm{X}, \cdot \mathrm{R}={ }^{\prime}, \mathrm{F} 5.2, /\right)$

$\operatorname{IF}(A N G-0.0) 11,11,12$

$11 \operatorname{IF}(\mathrm{R}-\mathrm{RM}) \geq 1,22,22$ 
$21 \operatorname{IF}(\mathrm{R}-\mathrm{RMO}) 31,32,33$

$31 \mathrm{R}=\mathrm{R}+0.1$

GO TO 40

$32 \mathrm{R}=\mathrm{R}+2 \cdot * \mathrm{~B}$

GO TO 40

$33 R=R+0.5$

GO TO 40

12 $I F(R-R M) 41,22,22$

$41 \quad R=R+0.1$

GO TO 40

$22 \quad I F(A N G-P I) 51,52,52$

51. $A N G=A N G+(P I / 6$.

GO TO 30

$52 \operatorname{IF}(\mathrm{C}-\mathrm{CO}) 61,62,62$

6]. $\mathrm{C}=\mathrm{C}+0.9$

GO TO 20

$62 \operatorname{IF}(\mathrm{C}-\mathrm{CM}) 71,72,72$

$71 \mathrm{C}=\mathrm{C}+1.0$

GO TO 20

72 STOP

END

/END 